



\section{CURRÍCULO REGIONAL, DEPARTAMENTO DE CALDAS, COLOMBIA}

Luis Hernando Amador Pineda 



\section{CURRÍCULO REGIONAL, DEPARTAMENTO DE CALDAS, COLOMBIA}

Luis Hernando Amador Pineda

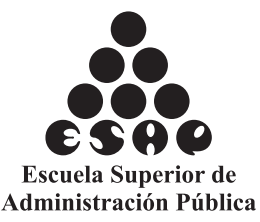




\section{CURRÍCULO REGIONAL,}

DEPARTAMENTO DE CALDAS,

COLOMBIA

Luis Hernando Amador Pineda

Primera edición 2017

\section{ISBN 978-958-652-432-2}

Catalogación en la publicación - Biblioteca Luis Oswaldo Beltrán Jara - ESAP

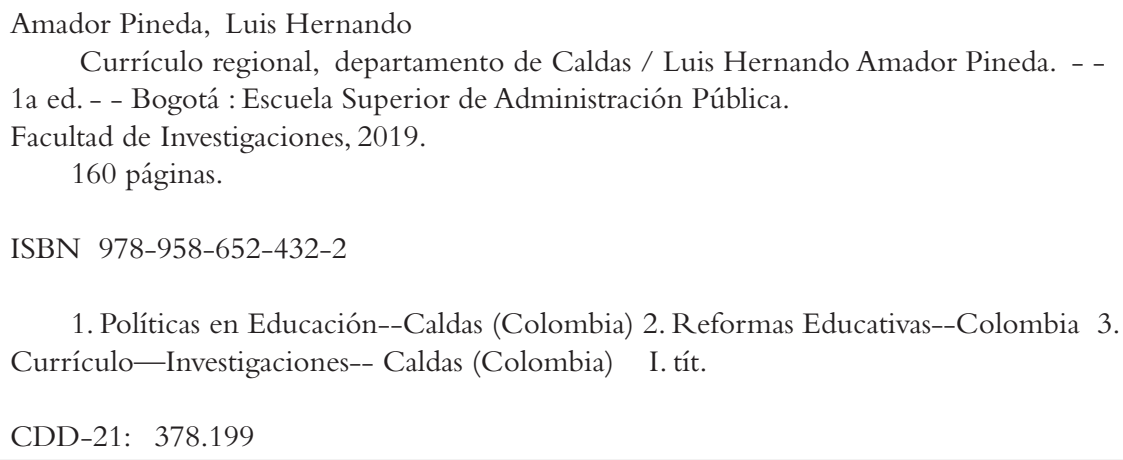

Currículo regional, departamento de Caldas / Luis Hernando Amador Pineda. - 1a ed. - - Bogotá : Escuela Superior de Administración Pública.

Facultad de Investigaciones, 2019.

160 páginas.

ISBN 978-958-652-432-2

1. Políticas en Educación--Caldas (Colombia) 2. Reformas Educativas--Colombia 3. Currículo-Investigaciones-- Caldas (Colombia) I. tít.

CDD-21: 378.199

ESCUELA SUPERIOR DE ADMINISTRACIÓN PÚBLICA

Claudia Marcela Franco Domínguez, Directora Nacional (E)

Claudia Inés Ramírez Méndez, Subdirectora Académica

Alexander Cruz Martínez, Subdirector de Proyección Institucional

Oswaldo Bernal Sánchez, Subdirector (E) de Alto Gobierno

Claudia Marisol Moreno Ojeda, Decana (E) Facultad de Investigaciones

Luz Stella Parrado, Decana Facultad de Pregrado

Maryyuri Rocío Galeano Jiménez, Secretaria General (E)

Coordinación editorial, Facultad de Investigaciones y Grupo de Publicaciones

Fotografía de cubierta: www.istock.com/filograph

Diseño de cubierta: José Luis Carrasco Borrero

Diseño contenido: Carlos Müller

Bogotá D.C., diciembre de 2017

Todos los derechos reservados. Esta obra no puede ser reproducida sin el permiso escrito de la Escuela Superior de Administración Pública. La responsabilidad de las opiniones expresadas en este documento compete exclusivamente a sus autores y no compromete de modo alguno, el pensamiento oficial de la Escuela Superior de Administración Pública, salvo en aquellos casos en que expresamente así se indique. 


\section{DEDICATORIA}

las directivas de la Universidad de Salamanca España, quienes con
su programa de posgrado, Doctorado en Educación "Fundamentos
de Política Educativa ante el Revelo Milenar" me han permitido cualificar el desempeño profesional. A un número significativo de educadores de Manizales y Colombia, por cualificarnos en nuestra profesión, alcanzar una meta más en la misión de formadores y haber posibilitado los medios necesarios para efectuar este programa educativo que contribuye a la calidad de la educación colombiana.

A mis padres, Luis Moisés Amador Ortegón, que en paz descanse, y Alicia Pineda Leiva, que con esmero y amor contribuyen para construir mi proyecto de vida.

A María Eucaris, Claribel, Héctor, José Iván, Gilberto, hermanos, a todos mis sobrinos: Nelson Andrés, Ana Milena, Iván Daniel, Leidy Johana, Laura María, Andrés Felipe, David Alejandro, Natalia, Luis José, Juan Martín, Ana María, Tomás y mis sobrinos nietos: Isabela, María Camila y Samuel, quienes son la elongación de la familia Amador Pineda, a ellos gratitud perenne.

A Marleny Murillo, Lina Marcela Morales, Alejandra Toro, Álvaro Quiroz Hernández, Rafael Augusto Cubillos, Marcela, Damaris Torres, Yisel González, Mauricio Pacheco y Alejandro Zambrano compañeros y amigos quienes cada día despliegan la condición humana y la urgencia por una apuesta en mi Doctorado. 



\section{AGRADECIMIENTOS}

n el trajinar por el mundo del saber y el conocimiento doy gracias a Dios
y a la Universidad de Salamanca España por la posibilidad y el desarrollo
exitoso de este programa de Doctorado en Educación.

A los doctores orientadores de los componentes académicos del programa, quienes con su capacidad intelectual y su gran calidad humana despliegan y hacen emerger nuevas posibilidades en el saber y conocimiento.

Al doctor José María Hernández de la Universidad de Salamanca, quien me indicó el sendero, me enriquece como persona y contribuye a los procesos del desarrollo educativo nacional y latinoamericano.

A los compañeros del doctorado "Fundamentos de Política Educativa ante el Revelo Milenar", quienes con su calidad humana y experiencias en el campo educativo brindan nuevos horizontes y lecciones de prácticas en el quehacer pedagógico.

A la Universidad Católica de Manizales, un proyecto académico que apunta a la excelencia.

A la hermana Judith León Guevara, exrectora de la Universidad Católica de Manizales, quien permitió la puesta en marcha del primer Doctorado en Educación en nuestra región caldense, a la hermana Aracely Gutiérrez (q.e.p.d.) con su insistencia y persistencia desde la vicerrectoría académica para la formación de un alto nivel en la Universidad, a la hermana Gloria del Carmen Bustamante, Rectora del año 2015, por su carisma y apoyo.

A Marleny Murillo, Lina Marcela Morales, Alejandra Toro, Álvaro Quiroz Hernández, Rafael Augusto Cubillos, Marcela, Damaris Torres, Yisel González, Mauricio Pacheco y Alejandro Zambrano compañeros y amigos en el trasegar humano y en el despliegue laboral. 
A los directivos y docentes de las instituciones educativas del departamento de Caldas y al departamento de Caldas, quienes con su labor permanente construyen nuevos horizontes para las infancias y las juventudes.

A mis estudiantes de pregrado y posgrado de la Universidad del Tolima, Universidad de Caldas, Universidad Católica de Manizales, Universidad de Manizales, Universidad Autónoma y Universidad Católica Popular de Risaralda, quienes con su mirada expectante en diálogo de saber fundan nuevas posibilidades del conocimiento y del proyecto de existencia. 


\section{TABLA DE CONTENIDO}

Resumen 13

$\begin{array}{ll}\text { Introducción } & 15\end{array}$

\section{CAPÍTULO 1. REFERENTE CONCEPTUAL}

1.1 Descripción del escenario del estudio 17

1.1.1. Identificación 17

1.1.2. Reseña histórica del departamento de Caldas 17

1.1.3. Características económicas, políticas, socioculturales, educativas y demográficas del departamento de Caldas 20

1.1.4. Inventario de centros e instituciones educativas de educación inicial, básica, media y superior en el departamento de Caldas 22

1.2. Planteamiento y formulación del problema 29

1.2.1. Formulación del problema 29

1.2.2. Descripción del área problemática 29

1.2.3. Descripción de hechos portadores de futuro en la región 29

1.2.4. Pregunta problema 30

1.2.5. Afirmaciones problemáticas 30

1.2.6. Formulaciones orientadoras del estudio 33

1.3. Antecedentes investigativos 34

1.4. Justificación 36

1.5. Objetivos 39

1.5.1. Objetivo general 39

1.5.2. Objetivos específicos 39

1.6. Supuestos del estudio 40

\section{CAPÍTULO 2. FUENTES TEÓRICAS}

2.1. Planeación educativa en Colombia 41

2.1.1. Políticas educativas 41

2.1.2. Ejes temáticos de política educativa 42

2.1.3. Planes de desarrollo 43

2.2. Las reformas educativas en Colombia 81

2.2.1. La reforma educativa del año $1980 \quad 82$

2.2.2. La contrarreforma educativa del año 1990 
2.2.3. Reforma educativa del 2000

2.3. Tendencias actuales en el currículum 85

2.3.1. Calidad educativa 86

2.4. La concepción de educación 90

2.4.1. Conceptos de educación 90

2.4.2. A manera de colofón educativo curricular 94

2.5. La concepción curricular 98

2.5.1. La conceptualización del currículo 104

2.5.2. Fundamentación teórica del currículo 111

2.5.3. Plan de estudios 114

2.5.4. Área de conocimiento, disciplinas y áreas de formación $\quad 115$

2.5.5. Marcos generales del currículo 119

2.6. El código educativo colombiano 128

CAPÍTULO 3. REFERENTE METODOLÓGICO

3.1. Enfoque investigativo 131

3.1.1. Características metodológicas $\quad 132$

3.2. Procedimiento 132

3.3. Técnicas e instrumentos 133

3.4. Unidad de trabajo 133

3.5. Unidad de análisis 134

CAPÍTULO 4. ANÁLISIS DE PROBLEMÁTICAS

CURRICULARES EN EL DEPARTAMENTO DE CALDAS

4.1. Factores inhibidores 139

4.2. Factores potenciadores 141

\section{CAPÍTULO 5. ALCANCES DEL CONOCIMIENTO}

5.1. Propuesta emergente curricular para el departamento de Caldas $\quad 144$

5.2. Hallazgos y conclusiones 147

5.3. Recomendaciones del estudio 151

Referencias bibliográficas $\quad 153$

Anexos $\quad 157$ 


\section{RESUMEN}

\footnotetext{
( e asume un ir y venir, un desplazarse en interlinealidad, un viaje por renovados vientos del pensar, transitar por la conjetura, las apuestas y textos en torno al currículo en dinámicas de vida, en miradas estéticas y en pensamiento complejo.
}

Se asume el currículo como un caminar, una andadura, una apuesta en avanzada conceptual en posibilidad de educación, en enseñabilidad y educabilidad (en contexto y recurrencia), en procura de coherencias semánticas y en pragmáticas sociales y con la intención de descubrir una asunto fundante de la hermeneusis curricular.

La ignición de la investigación se despliega en la posibilidad de lograr comprensiones conceptuales, a través de la episteme y la lógica curricular, para interpretar la educación en los currículos regionales.

El escrito investigativo se mueve en ámbitos que convocan la interpretación del contexto, su problemática y la apuesta por un currículo regional en trama conceptual de condiciones epistemológicas y pedagógicas que estén en reforma permanente de construcción y deconstrucción.

Se acompaña al texto en una visión humana de lo curricular y en una hermenéutica que posibilita la conversión de condiciones a posibles.

Se convocan autores a partir del interés particular y se muestran sus condiciones de posibilidad en el despliegue teórico, conceptual y metodológico, reformando y recreando en subjetividad (creadora-poiesis).

El cierre ubica rupturas y tensiones poliintersistémicas en el pensamiento y conocimiento de lo curricular para abrir un espacio tiempo-curricular en el paisaje y acontecimiento en tiempos posibles, en tiempo presente continuo, en condiciones en el mundo de la vida, en potencias del ser, en un ontos 
de sentido, en civilidad, intersubjetividad, en autonomía, en soberanía, en mirada estética, en una estética de la existencia y en una apuesta de sí mismo y autoposición. 


\section{INTRODUCCIÓN}

1 asunto curricular deviene humanidad. Por ello, el interés fundamental
cursa en el interrogante de investigación que se expresa en caracterizar
las interacciones del currículo en la región del departamento de Caldas, Colombia, con la aspiración de interpretar sus recorridos y orientar la hermenéutica hacia un currículo pertinente, contextualizado y problémico que ofrezca luces para el hallazgo de las condiciones posibles de la formación.

la palabra hermenéutica es antigua; pero también la cosa por ella designada, llámese hoy interpretación, es muy anterior a la idea de una ciencia metódica como la construida en la época moderna, (...) la hermenéutica es, pues, algo más que un método de las ciencias o el distintivo de un determinado grupo de ellas, designa sobre todo una capacidad natural del ser humano. (Gadamer, 1998).

Condiciones posibles para desarrollar las capacidades de los humanos en la humanidad, en panoramas de colores y aconteceres de compresión de la multiplicidad de opciones y en donde el mundo se ha pensado en una visión de lo inacabado, de lo relativo y en permanente emergencia.

La condición del ser para Heidegger es una ontología en donde lo esencial es el ser. La interpretación cruza miradas al mundo para entenderlo en sus polidimensiones, captura las claves y las señales de los sentidos en posibilidad ontológica de extensión para configurar racionalidades y nuevos sentidos. Lo anterior, como una acción eminentemente humana que en sus formas diversas admita la historicidad imbricadas del pensamiento, conocimiento, sentimiento y acción. Por ello, el recorrido curricular y su interpretación evoca lógicas de sentido, formas de relación del sujeto con el objeto de conocimiento y relieva la fuerza ontológica desde la subjetividad; se atrae constantemente la situación de hechos, épocas y tiempos, cuyas rememoraciones son pertinentes en la construcción del significado de los currículos. 
El panorama hermenéutico del currículo en la región del departamento de Caldas es una condición de compresión, ubica lo humano y categoriza la acción de la escolaridad en la educación. Saca a flote las significaciones en una visión de mundo y de época con instantaneidad en los eventos cotidianos para fluir en la compresión de las movilidades de nuevos hechos de ciencia, tecnología e innovación que se acogen en la pragmática social. Es una travesía hermenéutica en vínculos ontológicos, en formas perceptuales y en sentir y expresar de humanidad. 


\section{CAPÍTULO 1 \\ REFERENTE CONCEPTUAL}

\subsection{Descripción del escenario del estudio}

\subsubsection{Identificación}

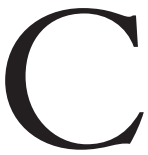

aldas es un departamento del país Colombia. Cuenta con una superficie de 7888 km cuadrados y una población de 984115 habitantes (según proyección a 2015). El departamento de Caldas forma parte del Eje Cafetero y de la región paisa. El Eje Cafetero, hoy paisaje cultural cafetero, fue denominado patrimonio cultural de la humanidad.

El departamento de Caldas fue creado en 1905, como consecuencia de una reforma en la división político-administrativa propuesta por el general Rafael Reyes Prieto, quien asumió la presidencia en 1904.

Hasta el año 1966 estaba conformado por los hoy departamentos de Risaralda, Quindío y Caldas. Estos se denominan popularmente como el Viejo Caldas, El gran Caldas o la Mariposa verde.

En el departamento de Caldas se encuentran los diferentes pisos térmicos, desde los más cálidos, en el valle del río Magdalena y el río Cauca, hasta los más fríos, inclusive de nieves perpetuas en el volcán Nevado del Ruiz.

\subsubsection{Reseña histórica del departamento de Caldas}

Antes de la colonización española, las principales tribus que habitaban la región fueron los Armas, Paucaras, Pijaos, Ansermas, Quinchías, Chimúes y los Quimbayas. Los primeros exploradores fueron Sebastián de Belalcázar, quien fundó la ciudad actual de Anserma en 1539 por la cuenca del río La Vega, y el oidor Juan Badillo, que en 1538 se adentró en la provincia de Ríosucio. Durante la colonia se introdujo la esclavitud negra en áreas mineras en Marmita, Supía, Arma yVictoria. Los yacimientos eran explotados en los siglos XV y XVI por los españoles, con 
mano de obra indígena y negra, lo que dio origen a estas poblaciones. En el siglo XIX comenzaron las explotaciones colonizadoras provenientes de Antioquia, Tolima y Cauca. El 11 de abril de 1905, con municipios segregados de los tres departamentos, fue fundado por Rafael Reyes el departamento de Caldas, que está ubicado entre Antioquia y Cauca, cuyo territorio está delimitado así:

el río Arma desde su nacimiento hasta el río Cauca; este aguas arriba hasta la quebrada de Arquía, que es el límite de la provincia de Marmato por los límites legales que hoy tienen, como también la provincia del sur del departamento de Antioquia. La capital de este departamento será la ciudad de Manizales (Ley 17 de 1905, art. 3).

El departamento nació con clases políticas y empresariales fuertes que se hacían escuchar en Bogotá. Personajes como Justiniano Londoño — padre de Fernando Londoño-, Daniel Gutiérrez Arango, Carlos Eduardo Pinzón Posada, Liborio Gutiérrez Echeverri y Francisco Jaramillo Ochoa eran dirigentes caracterizados por tener una visión a largo plazo.

Ellos se preocuparon por integrar a Caldas en el contexto nacional y conquistar los mercados de Europa. Eran empresarios y políticos a los que les cabía el país en la cabeza. Construyeron caminos de herradura y sacaron adelante la navegación a vapor por los ríos Magdalena y Cauca. (Albeiro Valencia Llano, historiador de Manizales)

La década de los 20 trajo el progreso de la mano del ferrocarril y otros megaproyectos de la época como el cable aéreo, que unía a Manizales con la población de Mariquita. "El quinquenio entre 1920 y 1925 fue una etapa de oro para Caldas. Se manejaron divisas y quien quería comprar libras esterlinas, marcos o dólares tenía que venir a Manizales", recuerda Valencia. Se fundaron dos bancos: el de Caldas y el del Ruiz, donde se emitió papel moneda que era más fuerte que el papel que emitía el Estado. Sobre esa base se desarrolló la industria en Manizales. Se construyeron las cinco fosforeras más importantes del país, apareció la cervecería Póker, surgieron trilladores y tostadoras, hubo una gran producción de café, panela, minería y ganadería, surgió la fábrica de chocolates Luker, creció el 
auge del periódico La Patria y de la producción de libros. Pero el empuje definitivo para consolidar el desarrollo de Caldas se lo dieron las llamas, o al menos eso fue lo que ocurrió en la década de los 30 cuando se presentaron tres graves incendios que acabaron con la catedral, 25 manzanas y la zona comercial de Manizales.

La reconstrucción fue una labor titánica que sacó a relucir lo mejor de la sociedad manizalita. Como había dinero, fruto de las primeras exportaciones de café, la clase dirigente impuso los estilos arquitectónicos de las casas que ellos veían durante sus viajes por Roma, París, Londres y Madrid. Esto fue definitivo para que en su momento Manizales fuera considerada la ciudad más moderna de Colombia.

En la década de los 60, el ferrocarril dejó de funcionar, incluso se levantaron sus rieles, y empezó a gestarse la separación del Quindío y Risaralda, golpe dificil de asimilar para Caldas. Aunque siempre se ha dicho que la división ocurrió porque la clase dirigente de Manizales fue muy arrogante y miraba con desdén a la gente de Pereira, este es un mito que el tiempo se encargó de desmentir. La realidad es que los políticos dividieron el Gran Caldas para asegurarse un feudo político y burocrático a través de la Cámara y el Senado a donde llegaban con los votos de esos nuevos departamentos.

Aunque Caldas conservó la presidencia de la Federación Nacional de Cafeteros, que en su momento fue más influyente que la Presidencia de la República, al desintegrarse perdió poder e incluso el primer lugar en la producción de café ante departamentos que pujaban desde atrás como Antioquia y Cauca. Caldas se aisló del país. La economía se vino a menos por diversos motivos, entre esos, porque Risaralda y Quindío quedaron mejor ubicados geográficamente y se convirtieron en paso obligado para el comercio, mientras Manizales quedó convertida en una población alejada.

Hasta 1960 la dirigencia de Manizales siempre se preocupó por hacer de esta ciudad un paso obligado, pero la nueva clase política se tragó el cuento de que Manizales había quedado fuera del camino. Se durmió y no hubo una generación de relevo, dijo Valencia. 
En los años 70 sobrevino el ocaso de Caldas, se cerraron decenas de empresas, otras se trasladaron a Bogotá y con la ruptura del Pacto Internacional del Café la región se vio sumida en la más profunda de sus crisis y perdió su lugar preponderante en el contexto nacional. (Semana, 2005)

\subsubsection{Características económicas, políticas, socioculturales, educativas y demográficas del departamento de Caldas}

En la actividad económica del departamento de Caldas prevalece la agricultura y en su mayoría el cultivo del café . La ganadería se concentra en el Magdalena caldense y se desarrolla la minería en prácticas artesanales y de manera ilegal. Se destaca en la industria textil, de confecciones, químicos, licores, madera, cemento y metalmecánica. Ante todo prevalece el sector primario y secundario de la economía. En el sector tres de servicios destaca el turismo con atractivos de orden mundial, como lo son el paisaje cultural cafetero, las nieves perpetuas del volcán Nevado del Ruiz (Parque Natural de los Nevados) y las aguas termales.

En el sector tres de servicios es de resaltar las movilidades turísticas de diferentes partes del mundo a vivenciar las actividades deportivas, el disfrute de los paisajes arquitectónicos e históricos y el deleite de las festividades en carnavales y ferias. Es representativa la Feria Internacional de Manizales y el Carnaval de Riosucio.

A nivel gastronómico se brinda identidad desde el legado paisa y antioqueño, en platos como los fríjoles caldenses, los plátanos maduros y el sancocho con hogao, ensalada de repollo y el encurtido casero.

El departamento de Caldas lo conforman 27 municipios (ver tabla 1).

El departamento de Caldas tiene como capital la ciudad de Manizales, capital cafetera de Colombia, ubicada en el centro occidente de Colombia, sobre la cordillera central de los Andes.

Manizales celebra la Feria de Manizales, una de las mejores de América, el Festival Internacional de Teatro y el Festival Manizales Grita Rock. La capital caldense es denominada la "Ciudad de las puertas abiertas" por la cordialidad de sus gentes, 
Tabla 1. Listado de municipios de Caldas

\begin{tabular}{|c|c|}
\hline MUNICIPIO & POBLACIÓN \\
\hline Manizales & 396102 \\
\hline Aguadas & 22081 \\
\hline Anserma & 33792 \\
\hline Aranzazu & 11422 \\
\hline Belalcázar & 10863 \\
\hline Chinchiná & 51492 \\
\hline Filadelfia & 11034 \\
\hline La Dorada & 76963 \\
\hline La Merced & 5508 \\
\hline Manzanares & 23274 \\
\hline Marmato & 9096 \\
\hline Marquetalia & 14992 \\
\hline Marulanda & 3406 \\
\hline Neira & 30513 \\
\hline Norcasia & 6374 \\
\hline Pácora & 11952 \\
\hline Palestina & 17760 \\
\hline Pensilvania & 26361 \\
\hline Riosucio & 61535 \\
\hline Risaralda & 9583 \\
\hline Salamina & 16635 \\
\hline Samaná & 25777 \\
\hline San José & 7588 \\
\hline Supía & 26728 \\
\hline Victoria & 8415 \\
\hline Villamaría & 56288 \\
\hline Viterbo & 12469 \\
\hline
\end{tabular}

Fuente: DANE, 2015. 
se le conoce como "Manizales del alma" por el pasodoble taurino que lleva su nombre, la "Perla del Ruiz", la "Capital del afecto", la "Capital mundial del café", la "Colina iluminada", la "Ciudad educadora" y la "Ciudad universitaria", entre otras. Lo que permite que la ciudad y el departamento en su conjunto sea, en decir de sus habitantes y extranjeros, una región culta. Esa denominación de "ciudad educadora" connota también un departamento educado en tanto:

- Es el espacio participativo de construcción de saberes, conocimientos, afectos y herramientas para la acción, que permite a los integrantes de la comunidad ir cualificando la calidad de vida y el desarrollo integral a nivel individual, colectivo y del entorno.

- Es aquella donde las personas tienen suficientes oportunidades de formarse en la educación superior con marcadas diferencias en relación a las demás ciudades.

- Es un campo de saberes de conocimientos para todos los ciudadanos de campos de distracción a todo nivel como por ejemplo: deportivo, cultural, social. Una ciudad y un departamento culto desde todo su entorno cultural, social y político.

- Es una ciudad y un departamento con sentido de pertenencia, en donde cada una de las instituciones establecen comunicación permanente con su talento humano, en donde se dan a conocer los proyectos o programas que cada uno está liderando, en donde se pueden unificar contenidos, donde el presupuesto no siempre es el obstáculo para el desarrollo de los mismos.

- Es una ciudad y un departamento donde se ofrece a toda persona con diferente cultura, la posibilidad de educación de acuerdo con sus intereses personales, económicos y sociales. (Gobernación de Caldas, 2005).

\subsubsection{Inventario de centros e instituciones educativas de educación inicial, básica, media y superior en el departamento de Caldas}

El departamento de Caldas cuenta con 169 instituciones educativas y 1066 sedes. Para comprender la distribución de las instituciones educativas y las sedes, se 
presenta la distribución geográfica del departamento por subregiones y allí los municipios que la conforman.

El departamento de Caldas está conformado por 26 municipios no certificados (dependen del departamento) y uno certificado (con autonomía administrativa y financiera), que es el municipio de Manizales. Todos estos, a su vez, se han agrupado en subregiones por afinidad económica, cultivos o utilización de la tierra, cercanía geográfica, entre otros. Dicha distribución se puede visualizar así:

Figura 1. Mapa del departamento de Caldas.

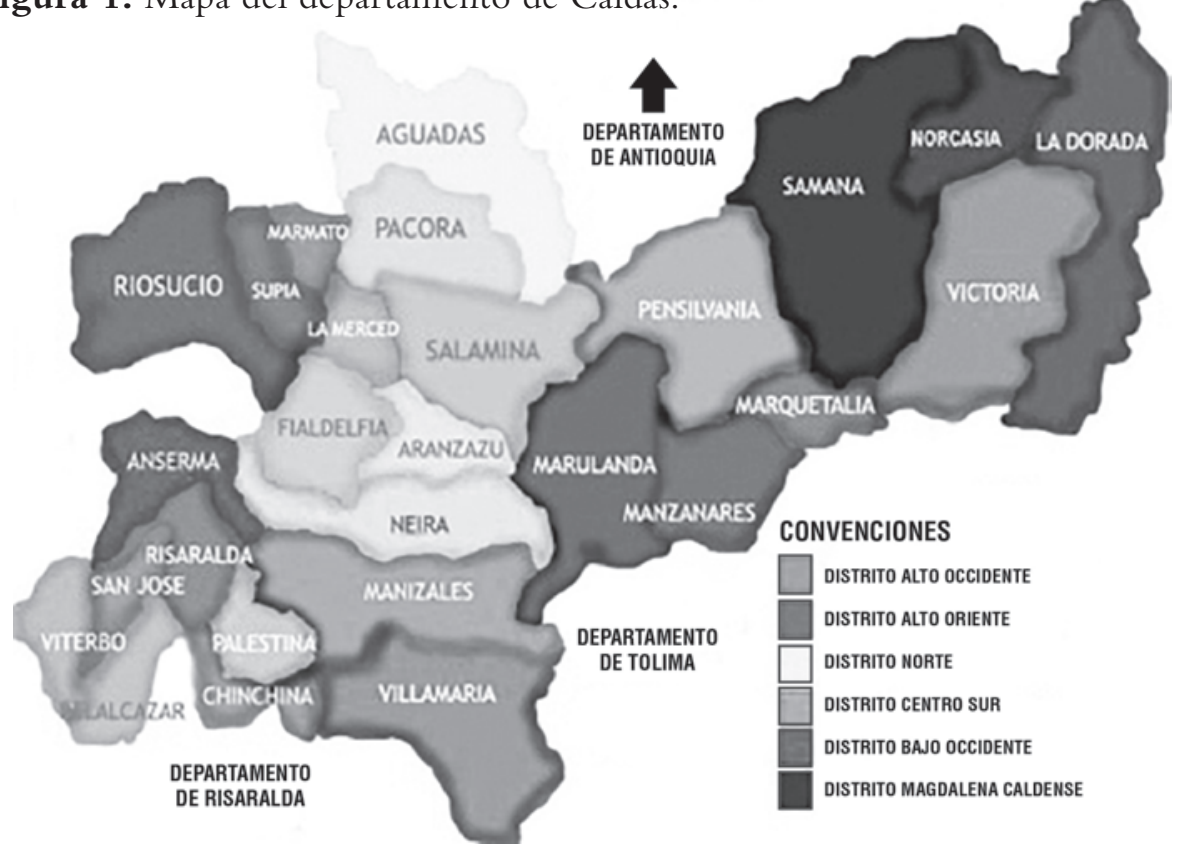

Fuente: Secretaría de Educación, s.f.

El departamento de Caldas está dividido en 27 municipios, 22 corregimientos, 142 inspecciones de policía, así como en numerosos caseríos y sitios poblados. Los municipios están agrupados en 24 círculos notariales, con un total de 29 notarías; un círculo de registro con sede en Manizales y nueve oficinas seccionales con sede en Anserma, Aguadas, La Dorada, Manzanares, Pácora, Pensilvania, Riosucio y Salamina; un distrito judicial, Manizales, con 10 circuitos judiciales en Manizales, Aguadas, Anserma, Chinchiná, La Dorada, Manzanares, Pácora, Pensilvania, Riosucio y Salamina. El departamento conforma la circunscripción electoral de Caldas. 
Conformacion de subregiones del departamento de Caldas (tabla 2)

El departamento de Caldas está compuesto por 27 municipios y conformado por 6 subregiones así:

Tabla 2. Conformación de subregiones del departamento de Caldas

\begin{tabular}{|l|l|}
\hline \multicolumn{1}{|c|}{ SUBREGIÓN } & \multicolumn{1}{c|}{ MUNICIPIOS } \\
\hline Norte & Aguadas, Aranzazu, Pácora y Salamina \\
\hline Centro sur & Manizales, Chinchiná, Neira, Palestina y Villamaría \\
\hline Occidente próspero & Anserma, Belalcázar, Risaralda, San José y Viterbo \\
\hline Occidente alto & Filadelfia, La Merced, Marmato, Riosucio y Supía \\
\hline Oriente cercano & Manzanares, Marquetalia, Marulanda y Pensilvania \\
\hline Magdalena caldense & La Dorada, Norcasia, Samaná y Victoria \\
\hline
\end{tabular}

Fuente: elaboración propia.

\section{Establecimientos educativos}

Para el 2012, el departamento de Caldas registró un total de 169 establecimientos educativos y 1066 sedes educativas distribuidas tanto en la zona rural como urbana del territorio caldense. Así mismo, se tiene registro de 45 establecimientos educativos no oficiales.

Los municipios que presentan mayor proporción con relación al total de sus establecimientos educativos y sedes educativas en el área rural son los siguientes:

- Samaná registra el $91 \%$ de sus instituciones educativas en la zona rural dado que presenta el mayor número de veredas.

- Riosucio, Palestina, Marmato y Pensilvania registraron entre el $82 \%$ y $80 \%$ de las instituciones educativas. Para el caso de Riosucio y Pensilvania se da por ser los municipios con el mayor número de habitantes de cada una de sus regiones, según el censo del 2005. 
- Neira, Belalcázar, Risaralda, Filadelfia, La Merced, Manzanares, Marquetalia y Anserma registraron entre un 75\% y 70\%, esta última por tener la mayor población del occidente bajo según el censo de 2005.

- Dentro del $67 \%$ y $60 \%$ se encontraron los municipios de Aranzazu,Victoria y Aguadas, este último presenta la mayor extensión y número de habitantes de la región norte, según el Censo de 2005.

- En Pácora, Salamina, Villamaría, San José, Supía, Marulanda y Norcasia se encontraron entre el 57\% y 50\% de los establecimientos en el área rural; los municipios de San José, Marulanda y Norcasia, dado que son los municipios de menor extensión territorial, cuentan con pocos establecimientos educativos en esta zona rural.

- La Dorada y Chinchiná registran el $44 \%$ y el $43 \%$ respectivamente. Viterbo el 33\% por no tener gran extensión de zona rural.

\section{Sedes educativas en la zona rural}

La subregión occidente alto presentó el mayor número de sedes educativas localizadas en la zona rural con 181. El municipio de Anserma es el que más sedes registró con 56. Los municipios de Samaná, San José, Pensilvania, La Merced, Filadelfia, Salamina, Neira y Pácora tuvieron entre el $97 \%$ y el $90 \%$ de sus sedes educativas localizadas en la zona rural.

Con un $89 \%$ y $82 \%$ de sus sedes educativas situadas en la zona rural se encuentran los municipios de Risaralda, Palestina, Riosucio, Marmato,Victoria, Belalcázar, Aguadas, Marquetalia, Manzanares, Supía, Anserma, Aranzazu, Marulanda y Norcasia.

Con el menor porcentaje de sus sedes educativas en esta zona se encontraron los municipios de Villamaría con el 78\%, Chinchiná con el 62\%,Viterbo con el 56\% y La Dorada con el $40 \%$.

Dada su topografía, el departamento de Caldas presenta el relieve más montañoso del país, no es ajeno que sus instituciones educativas presenten una 
Tabla 3. Establecimientos educativos del departamento de Caldas

\begin{tabular}{|c|c|c|c|c|c|c|c|}
\hline \multicolumn{7}{|c|}{ NÚMERO DE ESTABLECIMIENTOS EDUCATIVOS } \\
\hline \multirow{2}{*}{ Años } & \multicolumn{3}{|c|}{ Sector oficial } & \multicolumn{3}{c|}{ Sector no oficial } & $\begin{array}{c}\text { Total } \\
\text { (Oficial - } \\
\text { no oficial) }\end{array}$ \\
\cline { 2 - 8 } & Rural & Urbano & Total & Rural & Urbano & Total & $\mathbf{2 2 5}$ \\
\hline 2009 & 116 & 57 & $\mathbf{1 7 3}$ & 4 & 48 & $\mathbf{5 2}$ & $\mathbf{2 2 5}$ \\
\hline 2010 & 116 & 57 & $\mathbf{1 7 3}$ & 3 & 49 & $\mathbf{5 2}$ & $\mathbf{2 1 7}$ \\
\hline 2011 & 114 & 56 & $\mathbf{1 7 0}$ & 2 & 45 & $\mathbf{4 7}$ & $\mathbf{2 1 6}$ \\
\hline 2012 & 114 & 55 & $\mathbf{1 6 9}$ & 2 & 45 & $\mathbf{4 7}$ & \\
\hline
\end{tabular}

Fuente: Secretaría de Educación, s.f.

gran dispersión. Para el año 2012 se localizaron 539 sedes caracterizadas como de dificil acceso, equivalentes al 50.6\% del total de sedes.

\section{Establecimientos educativos}

En Caldas, para el año 2012 se reconocieron 216 establecimientos educativos, de los cuales, 169 hicieron parte del sector oficial y 47 del no oficial. Lo que representó una decadencia de 9 establecimientos en los últimos cuatro años.

En el sector no oficial, la mayor proporción de establecimientos educativos se encontraron en zona urbana. Se registraron 45 establecimientos y solo 2 en el área rural. Mientras que en el sector oficial se observa lo contrario, pues reportó el mayor número de establecimientos educativos en el área rural con 114 que corresponden al 67\%, y 55 en el área urbana equivalentes al 33\%.

Para este mismo año, el departamento contó con 1 111) sedes educativas distribuidas en los 26 municipios no certificados, de las cuales 45 pertenecían al sector no oficial, y 1066 al oficial. De las últimas, la mayor proporción se concentró en la zona rural con el 86\%, equivalente a 915 sedes.

La topografía del departamento, la dispersión de la población en la zona rural y las condiciones climáticas, ha llevado a que para el año 2012 se categoricen 539 
Tabla 4. Sedes educativas del departamento de Caldas.

\section{NÚMERO DE SEDES EDUCATIVAS}

\begin{tabular}{|c|c|c|c|c|c|c|c|}
\hline \multirow{2}{*}{ Años } & \multicolumn{3}{|c|}{ Sector oficial } & \multicolumn{3}{c|}{ Sector no oficial } & Total \\
\cline { 2 - 7 } & Rural & Urbano & Total & Rural & Urbano & Total & $\begin{array}{c}\text { Ofial - } \\
\text { no oficial) }\end{array}$ \\
\hline 2009 & 922 & 154 & $\mathbf{1} \mathbf{0 7 6}$ & 4 & 48 & $\mathbf{5 2}$ & $\mathbf{1} \mathbf{1 2 8}$ \\
\hline 2010 & 906 & 179 & $\mathbf{1} \mathbf{0 8 5}$ & 3 & 49 & $\mathbf{5 2}$ & $\mathbf{1} \mathbf{1 3 7}$ \\
\hline 2011 & 924 & 153 & $\mathbf{1} \mathbf{0 7 7}$ & 2 & 45 & $\mathbf{4 7}$ & $\mathbf{1} \mathbf{1 2 4}$ \\
\hline 2012 & 915 & 151 & $\mathbf{1} \mathbf{0 6 6}$ & 3 & 42 & $\mathbf{4 5}$ & $\mathbf{1} \mathbf{1 1 1}$ \\
\hline
\end{tabular}

Fuente: Secretaría de Educación, s.f.

sedes rurales como de difícil acceso, lo que hace necesario para llegar a ellas la utilización habitual de dos o más medios de transporte para un desplazamiento hasta el perímetro urbano. No se tienen vías de comunicación que permitan el tránsito motorizado durante la mayor parte del año lectivo, o la prestación del servicio público de transporte terrestre, fluvial o marítimo tiene una sola frecuencia, ida o vuelta diaria.Aunado a lo anterior, durante el 2012 se contó con 312 sedes que reportaron una matrícula inferior a quince estudiantes, que aunque incumple la relación técnica establecida en el Decreto 3020 del Ministerio de Educación Nacional, la Secretaría de Educación logró un permiso especial, a fin de garantizar el acceso al sistema educativo de la población rural, a quienes el desplazamiento a otras sedes se les dificulta ya sea por las vías de acceso o el tiempo excesivo del traslado.

El departamento de Caldas presentó 45 establecimientos educativos no oficiales en 8 de sus 26 municipios no certificados. La mayor proporción de estos establecimientos se concentró en la zona urbana, mientras en la zona rural del municipio de Villamaría fueron registrados 3 establecimientos educativos.

Los municipios de Chinchiná, La Dorada y Villamaría registraron el mayor número de establecimientos educativos no oficiales, por tener la mayor población en Caldas. Lo anterior, de acuerdo a la matrícula no oficial registrada en el Sistema Integrado de Matrícula (SIMAT) (Secretaría de Educación, 2013). 
Tabla 5. Establecimientos educativos no oficiales

\begin{tabular}{|c|c|c|c|}
\hline \multirow{4}{*}{\begin{tabular}{c} 
ESTABLECIMIENTOS EDUCATIVOS NO OFICIALES \\
\cline { 2 - 4 } MUNICIPIO
\end{tabular}} & TOTAL & RURAL & URBANA \\
\hline Anserma & $\mathbf{2}$ & 0 & 2 \\
\hline Chinchiná & $\mathbf{1 0}$ & 0 & 10 \\
\hline La Dorada & $\mathbf{1 5}$ & 0 & 15 \\
\hline Manzanares & $\mathbf{1}$ & 0 & 1 \\
\hline Palestina & $\mathbf{1}$ & 0 & 1 \\
\hline Supía & $\mathbf{1}$ & 0 & 1 \\
\hline Villamaría & $\mathbf{1 4}$ & 3 & 11 \\
\hline Viterbo & $\mathbf{1}$ & 0 & 42 \\
\hline Total & $\mathbf{4 5}$ & 3 & 1 \\
\hline
\end{tabular}

Fuente: Secretaría de Educación, s.f.

Figura 2. Establecimientos educativos no oficiales.

\section{ESTABLECIMIENTOS EDUCATIVOS NO OFICIALES}

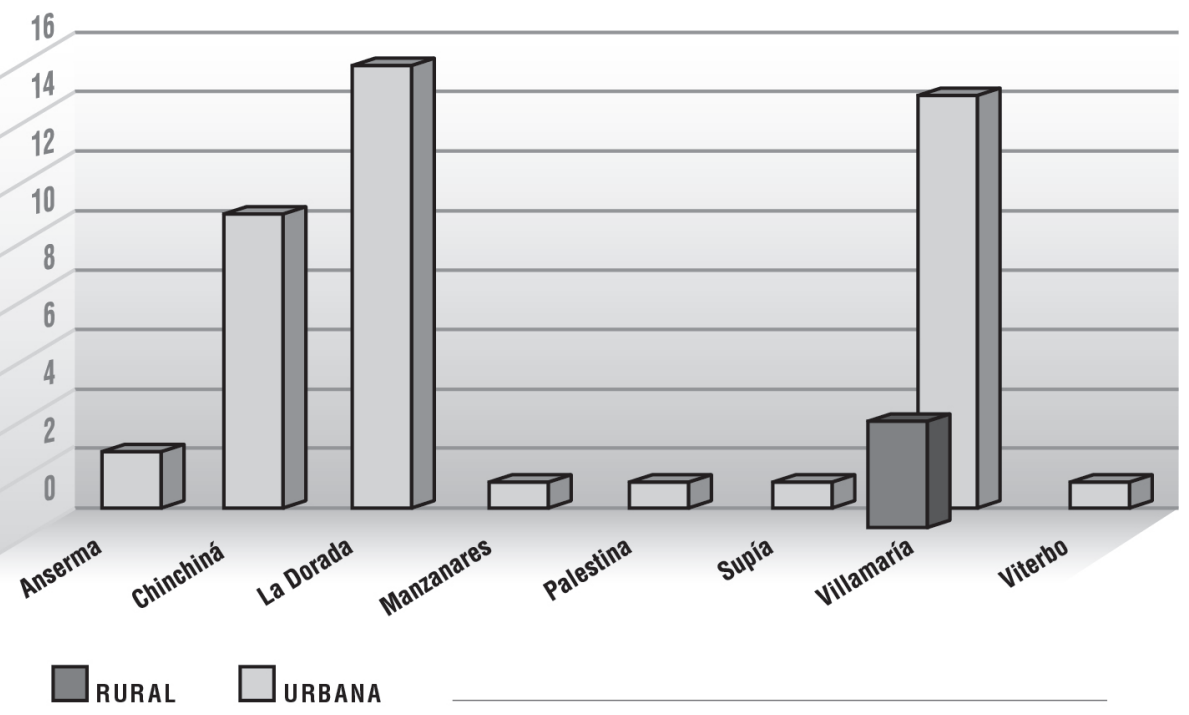

Fuente: elaboración propia. 


\subsection{Planteamiento y formulación del problema}

\subsubsection{Formulación del problema}

Cuáles son las interacciones existentes entre el currículum y la productividad en la región (departamento de Caldas, Colombia)

\subsubsection{Descripción del área problemática}

La educación es una práctica eminentemente social, debe por lo tanto generar igualdad de oportunidades para las comunidades. Ello requiere permanentemente de situaciones que eleven su calidad y mejoren sus procesos.

La educación y su calidad es un problema multifacético que se ha definido más en términos cuantitativos que cualitativos para dar explicación a su gestión. Por ello, es necesario considerar aspectos fundamentales como el aprendizaje y las relaciones con los procesos y estrategias cognoscitivas implícitas en el procesamiento de la información y la transferencia de los aprendizajes de la vida cotidiana. Esas interacciones determinan prácticas pedagógicas que inciden en los perfiles de formación de los sujetos que interactúan en contextos específicos.

Las prácticas pedagógicas evidencian las concepciones de currículum que las iluminan y determinan sus lógicas en la organización de las relaciones que intervienen en las propuestas educativas de la región (departamento de Caldaspaís Colombia). La situación de la región del occidente colombiano ostenta preocupantes indicadores educativos, muchos por debajo del promedio nacional y algunos, inclusive, con tendencia a la baja. Simultáneamente tiene fortalezas importantes en sus universidades y sus gentes. Además se crea conciencia clara de que esta es una prioridad indiscutible.

\subsubsection{Descripción de hechos portadores de futuro en la región}

La región-departamento de Caldas tiene un balance hacia el futuro que se puede indicar en los siguientes aspectos: 
- La región cuenta con centros de investigación y desarrollo en las áreas agropecuaria, biotecnológica, industrial y de productividad.

- Una tercera parte de las universidades con potencial en investigación funcionan en la región del occidente del país.

\subsubsection{Pregunta problema}

El estudio plantea: ¿Cómo organizar teórica y prácticamente las demandas productivas de una comunidad en un currículo articulado al desarrollo regional?

\subsubsection{Afirmaciones problemáticas}

El estudio parte de afirmaciones problemáticas:

- Las prácticas pedagógicas presentan fragmentación del conocimiento, enmarcadas en la transmisión de información.

Tabla 6. Centros de investigación en Caldas

\section{Centros de investigacion en caldas}

Centro de Investigación, Innovación y Tecnología del Sector Panelero del Departamento de Caldas, conocido como el "Centro Bekdau". Municipio de Supía, departamento de Caldas.

El Centro de Estudios Avanzados en Niñez, Juventud, Educación y Desarrollo —alianza de la Universidad de Manizales y el Cinde - gestiona el doctorado en Ciencias Sociales, Niñez y Juventud y la maestría en Educación y Desarrollo Humano. Universidad de Manizales, municipio de Manizales, departamento de Caldas.

Directora: Sara Victoria Alvarado Salgado.

Correo electrónico: doctoradocinde@umanizales.edu.co 
El Centro de Investigaciones en Medio Ambiente y Desarrollo (Cimad) gestiona la maestría en Desarrollo Sostenible y Medio Ambiente. Universidad de Manizales, municipio de Manizales, departamento de Caldas.

Directora: Irma Soto V.

Correo electrónico:irma@umanizales.edu.co

El Centro de Estudios en Conocimiento y Cultura de América Latina -(Ceccal), vinculado con el Instituto IPECAL de México. Universidad de Manizales, municipio de Manizales, departamento de Caldas.

Director: Germán Guarín Jurado

Correo electrónico: gerguaju@umanizales.edu.co, cis@umanizales.edu.co

El Centro de Investigaciones Socio-Jurídicas, vinculado con la maestría en Derecho y el pregrado en esa misma disciplina. Universidad de Manizales, municipio de Manizales, departamento de Caldas.

Directora: Claudia Munévar Quintero

Correo electrónico: cmunevar@umanizales.edu.co

Centro de Investigaciones del Café (Cenicafé). Municipio de Chinchiná, Departamento de Caldas.

Centro de Investigacion Socio-jurídica. Universidad de caldas, municipio de Manizales, departamento de Caldas.

http://www.ucaldas.edu.co/portal/tag/centro-de-investigacion-sociojuridica/

Fuente: elaboración propia. 
Tabla 7. Universidades del Eje Cafetero

\section{UNIVERSIDADES DEL EJE CAFETERO}

Universidad Tecnológica de Pereira, departamento de Risaralda

Universidad Libre de Pereira, departamento de Risaralda

Universidad Católica Popular de Pereira, departamento de Risaralda

Universidad del Área Andina (Pereira), departamento de Risaralda

Universidad de los Andes (sede Pereira), departamento de Risaralda

Colegio Mayor de Nuestra Señora del Rosario (sede Pereira), departamento de Risaralda

Universidad de la Sabana (sede Pereira), departamento de Risaralda

Universidad Eafit (Sede Pereira), departamento de Risaralda

Universidad de Caldas, departamento de Caldas

Universidad Autónoma de Manizales, departamento de Caldas

Universidad Católica de Manizales, departamento de Caldas

Universidad de Manizales, departamento de Caldas

Universidad Antonio Nariño, departamento de Caldas

Universidad del Quindío, departamento del Quindío

Universidad Gran Colombia, sede departamento del Quindío

Universidad Cooperativa de Colombia,

sede departamento del Quindío y departamento de Caldas

Fundación Universitaria Autónoma de Las Américas,

departamentos de Caldas, Quindío y Risaralda

Universidad Remington - Departamento de Caldas, Quindío, Risaralda

Escuela Superior de Administración Pública,

departamento de Caldas, Quindío, Risaralda

Fuente: elaboración propia. 
Las normativas del Ministerio de Educación Nacional:

Tabla 8. Normativas del Ministerio de Educación Nacional de Colombia

\section{NORMATIVAS}

Constitución Política de Colombia de 1991

- La ley 30 de 1992 (Ley de Educación Superior) favorece la expansión física, administrativa y académica de la Universidad

- Ley 115 de febrero 8 de 1994 (Ley General de Educación) obliga a los municipios a aportar el $15 \%$ de sus recursos para educación.

- El decreto 1860 de 1994 expedido por el Ministerio de educación oficializa la construcción de un proyecto educativo y la formación integral.

- Los Planes Decenales de Educación permiten la promoción de proyectos educativos relacionados con la conservación del medio ambiente y en pertinencia con las problemáticas sociales en contexto.

Fuente: elaboración propia.

- La relación maestro-alumno es determinada por el poder y el autoritarismo.

- La calidad de la formación del maestro se mide en títulos, no se tiene en cuenta el cómo se apropia del conocimiento, qué estrategias cognoscitivas utiliza en sus prácticas pedagógicas.

- Se ignoran los niveles de comprensión y de explicación sobre el aprendizaje alcanzado por los docentes en la región, a la vez que la apropiación se tiene sobre el desarrollo humano.

- Es difícil comprender la realidad interactiva del currículum y la productividad.

\subsubsection{Formulaciones orientadoras del estudio}

Algunas formulaciones del estudio:

a) Cuáles son los intereses teóricos y la motivación epistémica que orienta las prácticas pedagógicas y curriculares en la región (departamento de Caldas, Colombia). 
b) Cuáles son las dimensiones fundamentales del currículum en la región visto como proceso formativo de la persona, producto del conocimiento y de la productividad.

c) Cómo trascender teórica y prácticamente la concepción currículumproductividad.

\subsection{Antecedentes investigativos}

Se presentan a continuación elementos que giran en torno a reformas curriculares en el siglo XX, contexto de las políticas educativas en Latinoamérica.

Las reformas curriculares del siglo XX en Latinoamérica se caracterizan por presentar vacíos y problemáticas que aún no han podido ser resueltos, y los cuales pueden seguir profundizándose si las políticas y lineamientos que se establecen no se trasforman y se brinda una organización adecuada para cada situación o contexto educativo.

Estos vacíos y problemáticas se revelan desde aquella descentralización a la cual se ha sometido la educación en todos sus niveles, pero que a la hora de la verdad se continúa con un centralismo en el que se toman las decisiones, se administra y se invierten los recursos desde el centro de cada país. Las condiciones laborales para el docente, las escuelas rurales en manos de multinacionales, o diferentes entes que nada tienen que ver con lo educativo, la distribución económica insuficiente para las administraciones municipales y las escuelas, contenidos de aprendizaje escolar descontextualizados que se perciben desvinculados de las necesidades sociales y del mundo del trabajo moderno, e incluso una marcada inequidad para el acceso a la educación, tal como lo expresan Gajardo (1999), Winkler (2000) y Ravela (2001).

Acuerdos y declaraciones mundiales sobre educación para todos y marcos de acción para satisfacer las necesidades básicas de aprendizaje, como la Conferencia Mundial de Jomtien, son encuentros que le permiten avanzar a Latinoamérica frente a los procesos lentos y sostenidos de democratización política educativa, en los que se sitúan los vacíos y problemáticas. 
Al igual que con la Comisión Económica para América Latina y el Caribe (Cepal), la Oficina Regional para América Latina y el Caribe (Unesco y Orealc), los encuentros del Comité Regional Intergubernamental del Proyecto Principal de Educación en América Latina y el Caribe (Promedlac), así como el Banco Interamericano de Desarrollo (BID), se establecen alianzas y propuestas para dar atención a las necesidades prioritarias de la agenda educativa latinoamericana, que determina a la equidad y la calidad educativa como los vacíos y problemáticas más urgentes y determinantes.

Se hace necesario mirar con detenimiento qué alcances puede tener estos acuerdos y sugerencias que desde estas organizaciones internacionales se tiene en el desarrollo educativo de cada país, al intuir que estas decisiones pueden verse condicionadas a estrategias de un contexto globalizado que no atienda las realidades de contexto.

Para América Latina los procesos de desarrollo curricular han sido definidos como un modelo de especificación, dada su naturaleza global que requiere ser interpretado y adecuado a las necesidades y demandas de aprendizaje en los niveles regional, local y escolar (Terigi, 1999; Braslavsky, 1999; Sacristán, 1995).

Es evidente que este proceso de políticas educativas para América Latina permite desarrollar un concepto de cohesión social, donde se suscriben agendas para el diseño y el desarrollo curricular desde el proyecto principal de educación para América Latina y el Caribe. Es importante destacar como ejes de investigación curricular:

- El financiamiento educacional en América Latina.

- Los procesos de evaluación.

- La gestión de los sistemas escolares.

- La profesión docente.

- la reconstrucción de lo común y los currículos sobre su historia y su significado en la cohesión y participación social de las comunidades.

Aparecen otros ejes de investigación enmarcados en las políticas públicas, en la micropolítica escolar y en las nuevas emergencias curriculares. 


\section{Currículum en Colombia}

Las exigencias y desafíos del mundo contemporáneo plantean nuevas concepciones curriculares y pedagógicas acordes a las necesidades locales y globales. Por ello, se requiere ampliar estas concepciones hacia la interpretación de los procesos metodológicos y didácticos como procesos de reflexión en construcción, reconstrucción y potenciación colectiva de los saberes, en contraposición al concepto y discurso habitual.

En Colombia, los antecedentes de investigación en lo curricular se sitúan en la desconcentración y descentralización educativa. Es evidente que el Estado colombiano y varios países en Latinoamérica desde su visión plantean procesos de descentralización, pero la relación e inversión reversan el proceso a la centralización.

Los ejes de investigación curricular giran en torno a:

- Autonomías escolares, donde se centra el proyecto educativo institucional.

- La investigación y desarrollo comunitario, donde se lideran procesos de implicación de las comunidades en la toma de decisiones.

- La generación de experiencias significativas.

Estos tres elementos requieren sinergias que articulen y generen cohesión social, aumentando la pertinencia educativa.

\subsection{Justificación}

El papel de la educación en Colombia se perpetúa a través de la historia por su condición de necesaria en el país.

En la actualidad se le otorga gran responsabilidad a los procesos de transformación y cambio de la sociedad. Es necesario asumir el panorama desde las concepciones del currículum como realidad interactiva de la cultura y que encierra un sistema simbólico de representaciones mentales y de concepción del mundo. 
Es necesario considerar la educación, no solo como el cambio para propiciar habilidades y destrezas, sino además, para establecer relaciones con los saberes y los conocimientos a partir de la comprensión de la realidad posible, mediante el procesamiento de transformación de conocimientos.

Preparar a las nuevas generaciones en el seno de sociedades democráticas y solidarias obliga a concebir la planificación y el desarrollo de propuestas curriculares que contribuyan a la concepción de hombre, educación y sociedad. Es necesario visionar el currículo regional en una perspectiva productiva para el territorio. En este caso, los departamentos y nuestro país Colombia.

El estudio construye un concepto emergente del currículo en contexto regional, desde el punto de vista de su etimología y sus posibles interpretaciones en el proceso histórico. Ubica la temática y problemática del currículo en trayectos de indagación, autores y tendencias para visualizar su trascendencia en la educación y su posibilidad de método, metodología, camino, apuesta. Por ello, es procedente el inicio por el mito, el rito, el saber, la práctica y el conocimiento de su concepto, y abordar los teóricos clásicos, especialmente a Grundy, Morin, Lundgren, Kemmis, Kant, Alicia de Alba.

El ejercicio de indagación transita por una visión metódica desde los griegos, que en su principio de la mayéutica expresa conocimiento, y la dialéctica como la posición de ese conocimiento. La observación fue la fuente de conocimiento que permitió el transitar por documentos, experiencias e historias que implican el concepto curricular emergente y lo sitúa de los centros a las periferias y de la periferia al territorio. "Sean cualquiera el modo y los medios con que un conocimiento se refiere a sus objetos, la referencia inmediata -que todo pensar busca como medio- se llama intuición” (Kant, 2000, p. 41).

Las formas del entendimiento espacio-temporales en la comprensión curricular se adquieren a partir del espacio del conocimiento físico y a partir del tiempo adquiere el conocimiento relacional. Cabe anotar que el currículo se da en diversas representaciones y lógicas.

La novedad del estudio radica en la comprensión curricular en el contexto regional, donde se dan multiplicidad de versiones que expresan una situación 
compleja en cuento a la orientación, diseño, desarrollo y evaluación del currículo. El currículo se encuentra en crisis, lo cual afecta los discursos y las prácticas en diversos aspectos y dimensiones, el currículo cuenta con un acervo de experiencias y de producción discursiva, el currículo experimenta una exigencia conceptual al situarlo al contexto institucional y el currículo se convierte en objeto de discusión y trasformación permanente.

El impacto de este proceso se da en la comprensión de los discursos y prácticas en los contextos de realidad regional, local e institucional para posibilitar desde una perspectiva crítica la opción formativa de los ciudadanos.

El proceso del conocimiento a partir de la comprensión curricular ha sido develado, partiendo de que el currículo se da en la inmediatez del objeto, camino, recorrido, posibilidad. Por lo tanto, conocer el currículo produce un conocimiento verdadero que implica una realidad que aplica para un contexto y significa al sujeto en su construcción de realidad.

El proceso del conocimiento provee ciertas comprensiones que implican que el sujeto las trascienda y emancipe. Hay posibilidad curricular constante en el sujeto que indica y construye sus nuevas realidades en su contexto natural, y determina sus posibilidades aplicables a la vida cotidiana y a la realidad de la naturaleza.

En la práctica educativa profesional, el currículo en gran medida se reduce a procesos de educación direccionados hacia el saber, con un carácter teorético orientado a entender lo educativo desde las teorías y, así mismo, el desarrollo de la individualización. Lo anterior implica entonces trascender el proceso educativo para develarlo y cambiarlo a una propuesta social práctica.

Deben los maestros no solo saber mucho para enseñar bien, sino tener la aptitud y habilidad necesarias; ser de costumbres puras, y su principal cuidado es el de no decir ni hacer cosa que traiga mal ejemplo a los oyentes o los induzca a imitar lo que carezca de justificación (Amador, 2004, p. 65). 
Desde esta perspectiva, la educación incide en la vida de los demás, en su condición en función del que aprende desde procesos educativos y pedagógicos. Fomentar desde el presente y desde una apuesta en la formación de los saberes locales en relación con los globales, desarrolla la idea de que el currículo es una posibilidad constante de conocimiento; donde el educar es una actitud que transita sobre la cultura y admite comprender, entender y determinar la condición de lo humano. Además, desarrolla actitudes de subjetivación que permiten decidir y evidenciar el modo de comprender el momento histórico, la institucionalización y el ideal educativo.

Feyerabend planteaba la propuesta fundamental del todo vale. Tratar de argumentar el currículo con fundamento en este principio es determinar que el currículo es una construcción de novedad que implica el desarrollo de las metódicas en el proceso histórico-social y en el desenvolvimiento educativo abierto. Además vislumbra y emerge como un proceso creativo donde se marcan territorios y se comparten otras formas de pensamiento y de encuentro de estos que inducen a develar, a comprender que el currículo es una forma de no seguir el conocimiento lineal impartido, sino que nos acerca a la unicidad del sujeto con el objeto en la multiplicidad de lo cotidiano, del mundo que nos rodea, del estar ahí, es decir, el mundo para ser develado en una apuesta de la educación.

\subsection{Objetivos}

\subsubsection{Objetivo general}

Caracterizar las interacciones del currículum en la región del departamento de Caldas, Colombia.

\subsubsection{Objetivo específicos}

1. Refundar los planteamientos teóricos del currículum en contexto de productividad.

2. Analizar los aspectos implícitos de la relación currículum y la productividad.

3. Caracterizar la visión curricular de la región del departamento de Caldas, Colombia. 
4. Plantear lineamientos (propuestas) curriculares para la región del departamento de Caldas, Colombia.

\subsection{Supuestos del estudio}

- Currículo regional o contexto

Los desafios del mundo de hoy exigen a los sistemas educativos vincular las regiones desde el desarrollo de los procesos políticos que giran de la centralización a la desconcentración y la descentralización para permitir autonomía a sus localidades. Es así como los currículos giran en las mismas dinámicas.

- Productividad

La productividad de la educación es importante para la realización del potencial individual y el éxito personal, la apropiación del conocimiento y su uso como ciudadanos del mundo y su contribución al desarrollo económico, político y social de las naciones. 


\section{CAPÍTULO 2 FUENTES TEÓRICAS}

L

a teoría curricular establece la conexión entre la teoría pedagógica y la práctica educativa desde una fundamentación filosófica, sociológica, psicológica y antropológica. La conexión se establece por la teoría del currículum que guía la acción educativa y la fundamentación científica desde los problemas de conocimiento en la relación educación-cultura.

La teoría curricular se apoya en los desarrollos del conocimiento en las diferentes disciplinas y se funda en prácticas educativas y pedagógicas.

En el estudio prevalece el desarrollo curricular en múltiples entramados que superan el carácter instrumental del currículum y brinda una naturaleza abierta donde coexisten pensamiento, conocimiento, saber y sentimiento para el accionar humano. Accionar sobre incertidumbres de lo humano en los procesos políticos, culturales e históricos reintroduce el devenir curricular de manera permanente.

En la perspectiva social y cultural del currículum, se transita teóricamente por autores como Jimeno Sacristán, Grundy, Edgar Morin, Lundgren, Kemmis, Kant, Alicia de Alba.

\subsection{Planeación educativa en Colombia}

\subsubsection{Políticas educativas}

Las políticas educativas como acciones del Estado en relación con las prácticas educativas que potencian el desarrollo de las personas en las sociedades, en términos de producción, distribución y apropiación del legado cultural, se construyen y constituyen un asunto estratégico en cuestión de poder, potenciación del talento humano y el fortalecimiento del capital social.

Las políticas educativas en tiempo presente viven una tensión entre el reconocimiento de la educación como derecho y el enfoque del desarrollo 
humano en Colombia, desde la Constitución Política de 1991 se promueve el ejercicio del derecho a la educación y se enfatiza en la definición de planes, programas y proyectos para la satisfacción de las necesidades básicas del aprendizaje.

Las políticas educativas develan fuerzas y tensiones, intereses en conflicto y necesidades de la sociedades. Por ello, es preciso reconocer que las políticas son discursos que incursionan en lo educativo, pero son coherentes con las prácticas. El discurso de los derechos es de orden mundial, pero las políticas son las maneras de visibilizar sus intencionalidades en los escenarios de aplicación: lo educativo-formativo.

Las políticas educativas están en relaciones y tensiones permanentes que, en palabras de Bourdieu, se presentan en un campo representado en lo educativo, lugar donde las reformas educativas y sus planes pretenden transformar los procesos, las prácticas, saberes, conocimientos e incluso creencias, mitos y ritos.

Las políticas educativas se materializan y se configuran en el Estado en intenciones, deseos y propósitos de lo educativo y lo formativo.

En Colombia, por disposición constitucional y legal, el Ministerio de Educación Nacional es el encargado de generar la política y la reglamentación pertinente para la organización de las diferentes modalidades de prestación del servicio público educativo, con el fin de orientar la educación en los niveles de preescolar, básica, media, superior, educación para el trabajo y el desarrollo humano.

\subsubsection{Ejes temáticos de política educativa}

Los ejes de las políticas educativas en Colombia, desde el Plan decenal de educación 2006-2016, son:

1. Fines y calidad de la educación en el siglo XXI (globalización y autonomía).

2. Educación en y para la paz, la convivencia y la ciudadanía.

3. Renovación pedagógica y uso de las TIC en la educación.

4. Ciencia y tecnología integradas a la educación.

5. Más y mejor inversión en educación (gestión).

6. Desarrollo infantil y educación inicial. 
7. Equidad: acceso, permanencia y calidad.

8. Liderazgo, gestión, transparencia y rendición de cuentas en el sistema educativo.

9. Desarrollo profesional, dignificación y formación de docentes y directivos docentes.

10. Otros actores en y más allá del sistema educativo.

\subsubsection{Planes de desarrollo}

Los planes de desarrollo son instrumentos de gestión pública empleados para potenciar el desarrollo social en determinados territorios y son la base de las políticas públicas de los gobernantes. En este sentido, se presentan elementos de los planes de desarrollo en Colombia desde año 1950 a 2015.

\subsubsection{Planes nacionales de desarrollo en Colombia 1950-2015}

El Plan Nacional de Desarrollo (PND) es el instrumento formal y legal por medio del cual el Gobierno nacional traza unos objetivos específicos encaminados hacia unos propósitos puntuales de crecimiento a largo plazo para el país. Estos compromisos son definidos mediante estrategias y orientaciones generales de la política económica, social y ambiental adoptadas por el gobierno. Todo este proceso permite una evaluación subsecuente de su gestión, compuesta por un plan de inversiones públicas de orden nacional.

La Constitución Política de 1991 dispone en su Artículo 339 que habrá un plan nacional de desarrollo que se compone de dos partes:

- La general: que señala los objetivos nacionales de largo plazo y las prioridades estatales de mediano plazo, así como las orientaciones generales de la política económica, social y ambiental.

- El plan de inversiones: que debe contener los presupuestos de los programas y los proyectos de inversión pública, y la especificación de los recursos correspondientes.

El marco legal que rige el Plan Nacional de Desarrollo está consignado en la Ley 152 de 1994, esta incluye, entre otros, los principios generales de planeación, la definición de las autoridades e instancias nacionales de planeación y el 
procedimiento para la elaboración, aprobación, ejecución y evaluación del Plan Nacional de Desarrollo. En la tabla 9 se encuentra el trazo de los planes de desarrollo desde 1950 hasta 2015.

Tabla 9. Planes de desarrollo desde 1950 hasta 2015

\begin{tabular}{|l|l|l|}
\hline Presidente & Periodo & Plan de desarrollo \\
\hline Laureano \\
Gómez & $\mathbf{1 9 5 0 -}$ & $\begin{array}{l}\text { Los planes de este gobierno: plan vial nacional, } \\
\text { construcción de oleoductos, comunicaciones } \\
\text { (ferrocarriles) y puertos marítimos, creación de } \\
\text { Ecopetrol, del Banco Popular y del Ministerio de } \\
\text { Fomento. El país avanzó en el desarrollo del campo. } \\
\text { Los índices económicos señalaron avance y bonanzas } \\
\text { en la economía. }\end{array}$ \\
\hline $\begin{array}{l}\text { Roberto } \\
\text { Urdaneta } \\
\text { Arbeláez }\end{array}$ & $\mathbf{1 9 5 1 -}$ & $\begin{array}{l}\text { Plande Gobierno:adhesión a las políticas mundiales de las } \\
\text { Naciones Unidas, partidario de la planeación, siguió los } \\
\text { programas de la Comisión Económica, ofreció amnistía } \\
\text { para los alzados en armas, atrajo capitales extranjeros. } \\
\text { La Siderúrgica de Paz de Río se impulsó como una de } \\
\text { las grandes empresas del desarrollo de Colombia (Gran } \\
\text { enciclopedia de Colombia, tomo 9, 1993). }\end{array}$ \\
\hline $\begin{array}{l}\text { Gustavo } \\
\text { Rojas } \\
\text { Pinilla }\end{array}$ & $\mathbf{1 9 5 3 -}$ & $\begin{array}{l}\text { Planes de Gobierno: se dio desarrollo económico y } \\
\text { educativo bajo una política de orden, desarrollo de } \\
\text { la infraestructura del país y facilidad en la asistencia } \\
\text { social, la educación y la orientación técnica, introdujo } \\
\text { la televisión, veló por los derechos indígenas y su } \\
\text { integración al Estado, fortaleció la educación popular } \\
\text { práctica y tecnológica y la educación rural con nuevas } \\
\text { tecnologías agrícolas, se creó el SENA (Servicio } \\
\text { Nacional de Aprendizaje). }\end{array}$ \\
\hline
\end{tabular}




\begin{tabular}{|l|l|l|}
\hline $\begin{array}{l}\text { Junta Militar: } \\
\text { Gabriel París } \\
\text { Gordillo, } \\
\text { Deogracias } \\
\text { Fonseca } \\
\text { Espinosa, } \\
\text { Rafael Navas } \\
\text { Pardo, Rubén } \\
\begin{array}{l}\text { Piedrahita } \\
\text { Arango, } \\
\text { Luis Ernesto } \\
\text { Ordóñez } \\
\text { Castillo }\end{array}\end{array}$ & $\mathbf{1 9 5 7 -}$ & $\begin{array}{l}\text { Frente Nacional: mediante plebiscito se formalizó } \\
\text { la alternancia política en los siguientes 16 años. Se } \\
\text { estableció la paridad política en los cargos públicos y se } \\
\text { exigió el voto de las dos terceras partes en el Congreso } \\
\text { para las reformas constitucionales. }\end{array}$ \\
\hline & $\begin{array}{l}\text { Primer Plan Quinquenal: a partir del informe Lebret } \\
\text { se inició en Colombia la formulación de planes de } \\
\text { desarrollo educativo con base institucional en la oficina } \\
\text { sectorial de Planeación Educativa, creada en la segunda } \\
\text { parte de la década de los años 50. }\end{array}$ \\
$\begin{array}{l}\text { El primer ejercicio en este sentido se cumple con el } \\
\text { Plan Quinquenal publicado en 1957. En el mismo, } \\
\text { después de señalar unos principios, objetivos y metas } \\
\text { de la planeación, la administración y la organización } \\
\text { del sistema, se pasa al análisis y programación de cada } \\
\text { uno de los niveles de enseñanza, los cuales son tratados } \\
\text { de manera exhaustiva y con recomendaciones y metas } \\
\text { muy detalladas. } \\
\text { En cuanto a la educación primaria que se estudia } \\
\text { conjuntamente con la formación normalista, el plan } \\
\text { parte de determinar los indicadores cuantitativos de la } \\
\text { misma en relación con el rendimiento, el ausentismo } \\
\text { escolar, los contenidos de la educación, la educación } \\
\text { diferenciada de la escolaridad por zonas urbana y rural, } \\
\text { la organización escolar, los edificios y mobiliario escolar } \\
\text { y la cantidad y calidad de los maestros. }\end{array}$ \\
\hline
\end{tabular}


Con estas bases señala un plan de acción en el cual el elemento principal lo constituye el establecimiento de una escolaridad mínima obligatoria de 6 años para todos los niños colombianos. Para lograrlo propone, además de las construcciones escolares, la formación de un número suficiente de maestros y la dignificación de la profesión docente, introducir reformas sustanciales en la administración educativa e incrementar progresivamente el presupuesto de educación primaria. Sobre las bases anteriores desarrolla métodos y medios de acción para cada una de las áreas y años de duración del plan, llegando a detalles mínimos que no han sido considerados en planes posteriores a este.

El segundo tema tratado es el de la educación industrial fundamentada en la necesidad de preparar operarios calificados para la industria que se halla en plena fase de desarrollo. Propone dos puntos para la enseñanza industrial; el primer ciclo con modalidades de cursos preparatorios con objetivos de orientación profesional, cursos industriales de tres años para formación de personal ejecutivo para la industria, cursos artesanales de 3 años para la formación de trabajadores para este tipo de actividades y cursos de aprendizaje de 3 años para los jóvenes que se encuentran trabajando. El segundo ciclo debe comprender cursos técnicos, cursos para personal de mando y cursos pedagógicos para formar docentes de esta área.

El tercer tema se relaciona con la enseñanza comercial, sobre la cual considera que debe haber un sistema que comprenda tres categorías secuenciales: un ciclo de comercio general, uno de comercio superior y uno de carácter universitario, además de aceptar y 
estimular la enseñanza por correspondencia y resaltar la importancia de la integración de la escuela y la comunidad con la necesidad de tener una enseñanza eminentemente práctica.

Dada la desigualdad que se presenta en la formación de hombres y mujeres en el sistema educativo colombiano, el Plan Quinquenal dedica un capítulo de educación femenina. La política consiste en dirigir y orientar la formación de la mujer en su aspecto estrictamente femenino, como base de la formación que debe adquirir para desempeñar a cabalidad las funciones que le corresponden en la sociedad. Este principio se debe mantener en los distintos niveles educativos para diferenciar la formación femenina de la formación de los hombres.

Un tema al cual se concede especial importancia es el de la educación campesina, estimulada bajo el criterio de que la industrialización debe ser una consecuencia de la tecnificación del campo. Luego de un extenso y detallado análisis de los problemas de la educación campesina, se propone un plan general de acción que parte de la reestructuración de la división de la educación campesina del Ministerio de Educación para poder lograr objetivos concretos en cuanto a la construcción de establecimientos educativos, creación de fincas escolares, formación de personal docente, extensión de la escolaridad, ofrecimiento de cursos para campesinos adultos y mejoramiento de la eficiencia y la calidad de este tipo de educación.

El último tema que trata el Plan Quinquenal se refiere a la educación universitaria. En este caso se le reconoce a la universidad su capacidad para preparar su 
propio plan. Por ello, el plan solo contiene un estudio sobre la evolución y estado actual de la educación superior en Colombia y, como única recomendación, fórmula crear una junta de universidades a la cual se encomienda la tarea de elaborar el plan básico de desarrollo universitario.

\section{Plan General de Desarrollo Económico y Social.}

La idea central del plan es dotar al mayor número de colombianos de conocimientos generales y de la formación profesional mínima necesaria para que pueda beneficiarse del proceso general de desarrollo. Este enfoque implica énfasis significativo en las actividades tecnológicas y científicas características del mundo contemporáneo. Esto, a su vez, significa que nuevas profesiones del nivel intermedio y nuevas carreras universitarias deben ser incorporadas a la ya tradicional lista de profesiones liberales.

En lo específico al plan, propone un amplio plan de construcciones escolares (22000) para solucionar el problema que se halla con base en la baja escolaridad. Ligado a esto se requiere el nombramiento de un número suficiente de maestros y capacitar a carentes de título, así como la formación de superiores y de directores de escuela.

En educación media se propone dotar al país de institutos de este tipo para que cada lugar y cada región llenen las necesidades de la población, según la índole de sus ocupaciones, sus recursos naturales y humanos y el ordenamiento de su desarrollo económico y social. También se refiere al mejoramiento de la calidad de la 


\begin{tabular}{|c|c|c|}
\hline & & $\begin{array}{l}\text { educación media mediante un programa de preparación } \\
\text { del profesorado. En materias de escuelas vocacionales } \\
\text { (agrícolas, comerciales e industriales) su establecimiento } \\
\text { será en función de los nuevos frentes de trabajo y la } \\
\text { enseñanza se adaptará tanto a los requisitos técnicos } \\
\text { de la profesión u oficio como a las peculiaridades de } \\
\text { oferta y demanda de empleados y trabajadores. } \\
\text { En el campo de la educación superior anunció un } \\
\text { programa completo de reestructuración y orientación } \\
\text { de la universidad colombiana con miras a fundamentar } \\
\text { su organización sobre bases más acordes a las exigencias } \\
\text { del país. También se propone un amplio programa de } \\
\text { becas de posgrado para formar el personal técnico } \\
\text { especializado que requiere el desarrollo nacional. } \\
\text { Este plan está complementado por un plan cuatrienal } \\
\text { de inversiones públicas en el cual, además de asegurar la } \\
\text { financiación de los programas anteriormente descritos, } \\
\text { se asignará recursos para construir escuelas anexas a las } \\
\text { normales, internados en regiones periféricas, colonias } \\
\text { de vacaciones, escuelas vocacionales agrícolas, escuelas } \\
\text { industriales, escuelas comerciales, lo mismo que para } \\
\text { adquisición de dotaciones. }\end{array}$ \\
\hline $\begin{array}{l}\text { Alberto } \\
\text { Lleras } \\
\text { Camargo }\end{array}$ & $\begin{array}{l}1958- \\
1962\end{array}$ & $\begin{array}{l}\text { Reconstrucción nacional: este plan es un pacto político } \\
\text { de los partidos tradicionales para resolver la coyuntura } \\
\text { política y consolidar su hegemonía, pero lo que sucede } \\
\text { es que en lugar de canalizar los conflictos sociales } \\
\text { pierde su legitimidad y credibilidad política. A pesar } \\
\text { del proceso de modernización agrícola ocurrido en } \\
\text { las dos décadas anteriores, en los años } 60 \text { se inicia un } \\
\text { retraso en el sector agrícola referente a las demandas } \\
\text { industriales y de alimentos. Nace la Ley de la Reforma }\end{array}$ \\
\hline
\end{tabular}




\begin{tabular}{|c|c|c|}
\hline & & $\begin{array}{l}\text { Social Agraria Ley } 135 \text { de 1961, la cual privilegió las } \\
\text { mejoras en la producción y productividad, mediante el } \\
\text { desarrollo físico y tecnológico, sin tenerse en cuenta los } \\
\text { beneficios sociales del campesino. Esta administración } \\
\text { se enfrenta al problema de la pacificación del país } \\
\text { después del periodo de violencia, con los problemas } \\
\text { económicos de la devaluación de la moneda y el alto } \\
\text { costo de vida. }\end{array}$ \\
\hline \multirow[t]{2}{*}{$\begin{array}{l}\text { Carlos } \\
\text { Lleras } \\
\text { Restrepo }\end{array}$} & $\begin{array}{l}1966- \\
1970\end{array}$ & $\begin{array}{l}\text { Operación Colombia: plantea el desarrollo económico } \\
\text { y social, la tecnificación para el progreso de Colombia, } \\
\text { el saneamiento de la administración pública, la } \\
\text { organización de las finanzas, el estímulo a la inversión } \\
\text { de capital extranjero, el establecimiento de una política } \\
\text { de independencia económica de las grandes potencias. } \\
\text { Estimuló la industrialización en Colombia y la } \\
\text { integración con otros países latinoamericanos. }\end{array}$ \\
\hline & 1974 & $\begin{array}{l}\text { Plan Quinquenal de Desarrollo Educacional: el plan } \\
\text { de desarrollo educacional para los primeros años del } \\
\text { decenio del } 70 \text { continúa y completa una serie de acciones } \\
\text { tomadas recientemente en el sector: reorganización } \\
\text { administrativa orientada a descentralizar las operaciones } \\
\text { educacionales, aplicación de planes de aprovechamiento } \\
\text { más intensivo de la educación primaria, diversificación } \\
\text { y modernización de la enseñanza media a través de los } \\
\text { INEM, creación de institutos descentralizados como el } \\
\text { Icfes, Colcultura, Colciencias, Coldeportes, etc., para el } \\
\text { fomento y desarrollo de las respectivas áreas. } \\
\text { Se trata de un plan global, nacional, con miras } \\
\text { a impulsar la elaboración de planes regionales y } \\
\text { sectoriales homogéneos. Sus bases para la elaboración } \\
\text { del diagnóstico y punto de partida del plan están }\end{array}$ \\
\hline
\end{tabular}


constituidas por las estadísticas del DANE, en particular, por los datos que arroja el censo educativo de 1968.

En su conjunto,incluye tres partes claramente identificadas:

- Diagnóstico en el que se analizan aspectos generales y específicos del sector educación.

- El plan propiamente tal, y

- Algunos programas para el desarrollo de áreas o aspectos particulares que, sin embargo, no se incluyen en este trabajo.

Los aspectos demográficos destacan el rápido crecimiento poblacional de $3.5 \%$ registrado en el periodo intercensal de 1951 a 1954, que trae como consecuencia que el 46.6\% de la población sea menor de 15 años, es decir, escolarizable en el nivel primaria. Otros cambios que influyen en el momento de determinar las necesidades en educación son los que se refieren al rápido proceso de urbanización y al considerable aumento de la esperanza de vida al nacer.

En el campo de la economía, llama la atención la aún amplia preponderancia del sector agropecuario, tanto en la generación del PIB como en la participación, equivalente casi a la mitad de la población económicamente activa, en contraste con el bajo grado de instrucción de la mayor parte de los habitantes de las zonas rurales.

Ya en relación con el diagnóstico propiamente educacional, es interesante observar que la suma de los alumnos matriculados en primaria es solo ligeramente inferior al total de niños entre los 7 y los 12 años, lo que muestra que la oferta educativa sería prácticamente 
suficiente, en cuanto a cobertura, si no se dieran fenómenos distorsionantes como la extraedad. Por otra parte, el crecimiento de la capacidad del sistema, del $6.22 \%$ en los últimos años, ha sido superior al crecimiento de la población en edad escolar (4.42\%).

En cambio, es preocupante la baja eficiencia de la primaria que alcanza a retener solo un $26.77 \%$ de los alumnos que ingresan, mientras, por otra parte, el promedio de repitencia es del $17.7 \%$. En cuanto a la participación de la mujer, esta es igual a la de los hombres en la práctica

En educación media se sigue destacando la baja participación de las modalidades técnicas, en particular la agropecuaria y la industrial, ya que entre bachillerato académico y comercial alcanzan el $93 \%$ de la matrícula en este nivel, lo que implica una muy baja correspondencia entre la matrícula y el sector ocupacional y, si bien se está dando impulso a la educación diversificada a través de los INEM, esta no constituye de momento más que una buena intención. En cuanto al crecimiento general de la matrícula, este ha sido del $11.16 \%$ anual, muy superior a la tasa del $3.9 \%$, lo que señala el incremento de la población entre los 12 y los 18 años de edad.

En cuanto a la educación superior, ni el diagnóstico ni el plan se ocupan de ella, pues se supone que es responsabilidad del fondo universitario nacional y el Icfes, el cual, junto con la Asociación Colombiana de Universidades, había elaborado el llamado plan básico.

Se hace, sí, un análisis del gasto y de los costos en educación, así como la distribución del gasto entre la 
nación, los departamentos y los municipios. Si bien es aún fuerte la participación de los departamentos, la del presupuesto nacional aumenta considerablemente. Los recursos comienzan a ser administrados por los fondos educativos regionales de reciente constitución.

Finalmente, se hace una descripción de la estructura orgánica del sector, correspondiente a la reciente reforma cuyos objetivos fueron:

- Una descentralización funcional, a través de los nuevos institutos.

- La descentralización administrativa por medio de los FER.

- La reorganización de los organismos constructores del MEN.

- Un cambio en la estructura interna del ministerio.

El plan plantea como políticas la siguientes prioridades para cada nivel. En primaria:

- Llevar este nivel hasta $5 .^{\circ}$ en las zonas rurales.

- Aumentar los cupos hasta lograr la cobertura del $100 \%$ de la población en edad escolar.

- Mejorar la calidad de la educación mediante la capacitación del magisterio.

- Procurar incentivos para reducir la alta deserción escolar.

En educación media:

- Avanzar en la reforma de los programas hasta lograr la diversificación en este nivel de acuerdo con las necesidades laborales.

- $\quad$ Poner en marcha 19 INEM, y un grupo de planteles satélites en torno a cada uno de ellos. 
- Integrar varios planteles pequeños en otros de mayor tamaño.

- Estructurar el sistema de educación agrícola e industrial.

- Mejorar la calidad de la enseñanza mediante la capacitación y formación del profesorado.

- Poner en marcha programas de educación especial para alumnos sobresalientes.

En educación superior:

- Incrementar las llamadas carreras intermedias.

- Subsidiar aquellas carreras que sean consideradas prioritarias para el desarrollo del país.

- Fomentar la investigación científica en las universidades.

- Prestar asistencia técnica a las instituciones para el mejoramiento de la administración financiera, planeación y el bienestar.

- Mejorar la preparación del personal docente.

- En educación de adultos:

- Extender los programas educativos por radio y televisión.

- Estimular los proyectos de educación de adultos de acuerdo a las necesidades locales.

- Poner en marcha programas de educación ciudadana a través de los medios de comunicación social.

- Dar formación profesional a través del SENA.

La política del plan pone el acento en los siguientes problemas considerados básicos:

A. La universalización de la escuela elemental.

B. La formación y capacitación de maestros y profesores. 


\begin{tabular}{|c|c|c|}
\hline & & $\begin{array}{l}\text { C. La diversificación de la enseñanza media. } \\
\text { D. La alfabetización y educación funcional de adultos. } \\
\text { En cuanto a la extensión de la educación, el plan se } \\
\text { inicia con la primaria, en donde señalan tres alternativas } \\
\text { y se deja el nivel medio para 1975, una vez se haya } \\
\text { obtenido y evaluado los resultados del quinquenio. } \\
\text { Por último, como una forma de llevar adelante las } \\
\text { principales iniciativas propuestas, se enuncian cuatro } \\
\text { programas que deben realizar el Ministerio de } \\
\text { Educación. Tales programas son: } \\
\text { 1. Incorporación general a la educación primaria de la } \\
\text { población en edad escolar. } \\
\text { 2. Formación, capacitación, perfeccionamiento } \\
\text { y especialización de docentes para los niveles de } \\
\text { educación elemental y media. } \\
\text { 3. El programa para la educación funcional del adulto. } \\
\text { 4. El programa de desarrollo agrícola y pecuario. }\end{array}$ \\
\hline $\begin{array}{l}\text { Misael } \\
\text { Pastrana } \\
\text { Borrero }\end{array}$ & $\begin{array}{l}1970- \\
1974\end{array}$ & $\begin{array}{l}\text { Las cuatro estrategias: este plan de desarrollo parte con } \\
\text { una descripción del sistema educativo en el que se } \\
\text { señalan, además de las deficiencias de tipo cuantitativo, } \\
\text { algunas distorsiones como la falta de continuidad entre } \\
\text { los niveles, la desigual de distribución de la población } \\
\text { escolar entre los diversos tipos de ecuación y las } \\
\text { diferencias entre las zonas rural y urbana. } \\
\text { Por otra parte,se precisan cuatro equilibrios:en la relación } \\
\text { de los recursos humanos formados con las necesidades } \\
\text { de desarrollo; entre el contenido de la educación y las }\end{array}$ \\
\hline
\end{tabular}


necesidades del hombre; entre las necesidades educativas y los recursos financieros y desequilibrio regional entre regiones privilegiadas y periféricas.

Lo anterior lleva a plantear una política de integración de los niveles escolares: un nivel de educación básica con 9 años de escolaridad y un nivel de educación profesional que abarca los ciclos de enseñanza ocupacional, tecnológica y universitaria de los sectores oficial y privado, de los servicios complementarios prestados a la comunidad y de los diferentes programas y proyectos de las instituciones.

Esta integración se apoya en la reforma administrativa realizada a partir de 1969 para centralizar la política educativa, formulada por el Ministerio de Educación Nacional, y descentralizar la administración a través de los establecimientos públicos adscritos al primero.

Como metas, el plan propone la iniciación del programa de concentraciones de desarrollo rural, el diseño del currículo para los niveles del ciclo básico, la capacitación de los docentes, la iniciación de la reforma administrativa y la promoción automática entre los grados primero y segundo.

Paralelo al programa de concentraciones de desarrollo rural, se debía desarrollar el programa de extensión de la escolaridad, tanto en el sentido del ingreso al sistema como en el de la permanencia y promoción. Para ello, los instrumentos fundamentales son la promoción automática y la nucleación de escuelas. Como consecuencia inmediata, surge la necesidad de aumentar progresivamente el número de aulas y maestros. 


\begin{tabular}{|c|c|c|}
\hline $\begin{array}{l}\text { Alfonso } \\
\text { López } \\
\text { Michelsen }\end{array}$ & $\begin{array}{l}1974- \\
1978\end{array}$ & $\begin{array}{l}\text { Plan para cerrar la brecha: de acuerdo con la política } \\
\text { general de este plan de desarrollo social, económico y } \\
\text { regional para 1975-1978, el sector educativo considera } \\
\text { prioritario el sector de educación primaria, cuya } \\
\text { universalización, especialmente en el sector rural, se } \\
\text { plantea como parte de la ofensiva social tendiente a } \\
\text { favorecer el 50\% más pobre de la población colombiana. } \\
\text { Un argumento adicionalpara esta prioridad es el tradicional } \\
\text { de tipo económico que se basa en el supuesto de la mayor } \\
\text { rentabilidad de la inversión en educación primaria sobre } \\
\text { los demás niveles, lo que haría particularmente productivo } \\
\text { el gasto público en este nivel. } \\
\text { Por otra parte, en este como en los demás niveles, el } \\
\text { énfasis se sigue colocando en los aspectos cuantitativos, } \\
\text { por lo cual se da particular atención a la ampliación de } \\
\text { la capacidad del sistema. Así, el preescolar es confiado } \\
\text { en la práctica al ICBF, en el supuesto de que la Ley } 27 \\
\text { de } 1974 \text { debía generar los recursos suficientes para una } \\
\text { rápida extensión de este servicio. Para primaria se prevé } \\
\text { la habilitación, terminación, construcción y dotación } \\
\text { de } 32000 \text { aulas y la provisión de } 35000 \text { nuevas plazas } \\
\text { para maestros, con lo cual se espera incrementar los } \\
\text { cupos hasta cubrir el déficit en } 1978 \text {. En el nivel de } \\
\text { básica secundaria, el plan propone ampliar la capacidad } \\
\text { del mismo mediante la construcción y dotación de } \\
200 \text { nuevos planteles para } 300000 \text { estudiantes en } \\
\text { doble jornada, el aumento de las jornadas adicionales } \\
\text { y la integración de establecimientos para una óptima } \\
\text { utilización de su capacidad instalada. Para el nivel de } \\
\text { media vocacional e intermedia profesional, se programa } \\
\text { la construcción, dotación y funcionamiento de } 23 \\
\text { Centros Auxiliares de Servicios Docentes, CASD, y la } \\
\text { reestructuración de los INEM. Solo para la educación }\end{array}$ \\
\hline
\end{tabular}


superior no se plantea nuevas construcciones sino que el gobierno tratará de consolidar las universidades existentes y solo apoyará la creación de otras en aquellas regiones que generan recursos propios para su financiamiento. En cambio, se propone a apoyar y fortalecer los programas de universidad a distancia y organizar la universidad nocturna. Para adultos, el plan prevé programas de educación diversificada mediante la colaboración entre el Ministerio de Educación y el SENA. Finalmente, en la educación no formal e informal, se propone un impulso a los programas educativos a través de radio y televisión, reforzados mediante la distribución masiva de libros y materiales impresos, además del acceso de la mayoría de la población a los bienes de cultura y la recreación.

Los aspectos de racionalización y ordenamiento del sistema educativo van ligados a la reforma educativa promulgada mediante la Ley 43 de 1975 y los decretos 88,89 y 102 de 1976.

Mediante la primera, se nacionaliza la educación primaria y secundaria, en tanto que a través de los decretos se definen los modos de educación, se reestructura el Ministerio de Educación Nacional y el Icfes y se descentraliza la administración de los planteles nacionalizados.

Algunas acciones propuestas para el logro de una mayor eficiencia interna y para mejorar la calidad de la educación son: la reestructuración de los niveles del modo formal en educación preescolar, educación básica y secundaria, educación media e intermedia y educación superior; la promoción automática y el impulso a la escuela unitaria en el nivel primario; la integración de planes y servicios para secundaria y media vocacional; la creación de un sistema 


\begin{tabular}{|l|l|l|}
\hline Inificado de universidad estatal; un programa integrado de \\
capacitación de docentes, diseño y evaluación curricular, \\
producción y distribución de materiales educativos; el \\
uso de la tecnología educativa y de medios masivos en \\
la capacitación de docentes, el impulso a la investigación \\
educativa en las universidades, la integración con otros \\
sectores, programas para la prestación de servicios; el \\
recurso a una mayor participación de la comunidad. \\
Ayala
\end{tabular}


Las prioridades, por lo mismo, se refieren a todo el sistema educativo, si bien se da un cierto énfasis en el nivel primario, en la educación de adultos y en la de ciertos grupos que se hallan en situación de desventaja, como las minorías indígenas, las comunidades de colonos y los niños con problemas de aprendizaje.

También en los objetivos específicos se da un cambio de énfasis: en el nivel preescolar, la atención integral al niño se debe intensificar a través de los adultos, en particular de la familia; en primaria, el objetivos central no es ya el de la ampliación de la capacidad cuantitativa, dadas las altas tasas de ingreso a primer grado, sino el aumento de la retención a la zona rural y el mejoramiento cualitativo mediante una mayor adecuación de la educación a las condiciones económicas, sociales y culturales de la población y a sus necesidades de desarrollo; en secundaria se mantiene el objetivo de expansión, pero con un impulso a la diversificación de acuerdo con la vocación productiva de las diferentes regiones del país; en educación superior, se busca el impulso a la investigación, la organización de la educación tecnológica y una mayor vinculación al desarrollo nacional y regional; finalmente, se plantea un impulso a los modos no formal e informal como mecanismos de apoyo a la educación formal y para elevar el nivel educativo general.

Los mecanismos para logro de estos objetivos se sitúan en el terreno de lo académico, lo administrativo y lo financiero. En el primer aspecto tales mecanismos son: la investigación socio-educativa como fundamento de las acciones que se desarrollen en el sector; el mejoramiento a los agentes educativos; algunas acciones de apoyo como transporte escolar, ampliación de la escuela unitaria y de 


\begin{tabular}{|c|c|c|}
\hline & & $\begin{array}{l}\text { las concentraciones de Desarrollo Rural; por último, la } \\
\text { coordinación con otras entidades y programas. } \\
\text { En lo administrativo, el principal mecanismo es la } \\
\text { regionalización mediante la creación de los Servicios } \\
\text { Seccionales de Educación; la organización nuclear } \\
\text { regionalizada, para la educación superior, alrededor de } \\
\text { centros de excelencia cuya actividad principal será la } \\
\text { investigación y el postgrado; la coordinación e integración } \\
\text { de los diferentes programas de adultos, con ayuda del } \\
\text { SENA; los Centro Populares de Cultura y Recreación } \\
\text { como mecanismo de descentralización en lo informal. } \\
\text { Los mecanismos en lo financiero son: la revisión de } \\
\text { los criterios de distribución del Situado Fiscal en } \\
\text { concordancia con las necesidades de las regiones; la } \\
\text { prolongación de la vigencia de la Ley } 43 \text { de 1975; } \\
\text { una mayor participación de las regiones y localidades } \\
\text { en el funcionamiento de los programas educativos; el } \\
\text { incremento en el valor de la matrícula y ampliación de } \\
\text { crédito educativo para educación superior. } \\
\text { Finalmente, se espera lograr los objetivos del Plan } \\
\text { mediante su concreción en algunos programas: el } \\
\text { de fomento a la educación en el área rural y centros } \\
\text { poblacionales menores; el de educación para el trabajo } \\
\text { en los niveles de secundaria; media, intermedia } \\
\text { y tecnológica; el desarrollo cultural; el desarrollo } \\
\text { científico y tecnológico. }\end{array}$ \\
\hline $\begin{array}{l}\text { Belisario } \\
\text { Betancur }\end{array}$ & $\begin{array}{l}1982- \\
1986\end{array}$ & $\begin{array}{l}\text { Cambio con equidad: los puntos de política se centran } \\
\text { en la modernización, descentralización y planificación } \\
\text { participativa; comunicación intersectorial; adecuación } \\
\text { permanente del currículo a las necesidades y }\end{array}$ \\
\hline
\end{tabular}


características tanto del país como de cada región y grupo cultural; ampliación de oportunidades de acceso y permanencia en el sistema; participación comunitaria en el proceso de enseñanza y aprendizaje; desarrollo de la investigación científica y tecnológica; desarrollo cultural, recreacional y deportivo y eficiencia en la utilización de los recursos financieros.

Para lograr la organización, propone la creación y consolidación del Sistema Nacional de Educación, la cual debe partir del núcleo de desarrollo educativo, cultural y recreativo como unidad base del sistema con funciones de planeación, administración y coordinación de otros sectores; la segunda instancia regional la constituyen los distritos educativos; la tercera los servicios seccionales de educación que estarán integrados por las actuales Secretarías de Educación y las demás entidades que tiene que ver con la administración de la educación, la ciencia, la cultura, la recreación y el deporte. Por último, la cuarta instancia, la del nivel nacional, estaría constituida por el Ministerio de Educación e institutos descentralizados del sector, estos, en conjunto, deberán establecer relaciones orgánicas con otras entidades nacionales de los demás sectores, en especial con el SENA, ICBF y el Fondo de Capacitación Popular de Inravisión.

Para la gestión, el plan determinará el establecimiento de cuatro subsistemas: el académico-pedagógico, el administrativo, el de planeación y el financiero.

Para el logro de los objetivos, el plan propone: la campaña de instrucción "Camina", con proyectos en los campos de educación para adultos, infantes, población especial, tercera edad, indígena y programas integrados para zonas 
de frontera, de violencia y otras áreas especiales; el plan de fomento para áreas rurales y centros menores de población; fortalecimiento de la capacidad pedagógica del sector (diseño, producción y adquisición de texto, materiales, equipos, capacitación de agentes educativos para la generalización del nuevo currículo); organización de la planeación sectorial; sistema integrado de información; sistema de educación abierta y a distancia; desarrollo del sistema post-secundaria de educación por áreas del conocimiento; desarrollo de la investigación en las instituciones del sector; desarrollo nacional de la ciencia y la tecnología; centros de comunicación cultural; núcleos de educación física, recreación y deporte y la corporación banco educativo.

Los programas y proyectos del plan corresponden o bien a la continuación de otros planteados o iniciados en planes anteriores, o bien a etapas de procesos que vienen desarrollándose.

Así, la Campaña de Instrucción Nacional "Camina" recoge, desarrolla y organiza diversas acciones y programas de los planes anteriores relacionados con educación trascolar y adultos como una segunda oportunidad para todos, dentro del concepto de educación continuada, permanente e integral.

El plan de fomento de la educación para áreas rurales y centros menores que adelanta el Ministerio de Educación Nacional, constituye la concreción del primer programa propuesto por el PIN para educación, y lo mismo sucede con los dos proyectos encaminados a promover la investigación en la universidad y el desarrollo científico y tecnológico, que son ejecutados 


\begin{tabular}{|c|c|c|}
\hline & & $\begin{array}{l}\text { respectivamente por el Icfes en asocio con las } \\
\text { universidades y por Colciencias. } \\
\text { En relación con la calidad de la educación, e } \\
\text { instrumento central en el plan actual es la extensión } \\
\text { a todos los establecimientos educativos del nuevo } \\
\text { currículo que el Ministerio de Educación ha diseñado } \\
\text { y viene experimentando a partir de la reforma de } 1976 \\
\text { a través de los Centros Experimentales Piloto (CEP) en } \\
\text { varias secciones del país. } \\
\text { En los campos del desarrollo cultural, la recreación } \\
\text { y el deporte, los recursos humanos y la informática } \\
\text { el plan recoge las inquietudes planteadas en planes } \\
\text { anteriores y trata de ordenar y desarrollar las acciones } \\
\text { por ellos propuestas. } \\
\text { Por último, como una forma de responder a la creciente } \\
\text { demanda de educación postsecundaria y de aprovechar } \\
\text { las ventajas que puedan ofrecer los medios a distancia } \\
\text { en la expansión de la educación y del mejoramiento } \\
\text { cualitativo, teniendo en cuenta al mismo tiempo la } \\
\text { limitación de los recursos requeridos en la educación } \\
\text { presencial tradicional, el Gobierno Nacional plantea } \\
\text { como programa bandera en educación, la estrategia de } \\
\text { Universidad Abierta y a Distancia. }\end{array}$ \\
\hline $\begin{array}{l}\text { Virgilio } \\
\text { Barco }\end{array}$ & $\begin{array}{l}1986- \\
1990\end{array}$ & $\begin{array}{l}\text { Plan de economía social: este plan de desarrollo fue } \\
\text { concebido con una visión universal, no solo desde } \\
\text { nuestra perspectiva como nación, también como } \\
\text { expresión del concepto según el cual el progreso no es } \\
\text { posible si no se adelanta dentro de unos parámetros de } \\
\text { creciente participación comunitaria en los beneficios de } \\
\text { desarrollo. Los tres grandes objetivos del plan fueron: }\end{array}$ \\
\hline
\end{tabular}


1. Ordenamiento del cambio social para lograr mayor equidad en la distribución de las oportunidades del progreso. Primordialmente, se trató de integrar y definir los servicios que presta el Estado, para que los esfuerzos de las distintas instituciones concordaran con las necesidades de la comunidad beneficiaria y para elevar su calidad y extender su cobertura. El plan presentó políticas de trabajo y seguridad social; políticas educativas, como la Campaña de Instrucción Nacional "Camina", y la Universidad Abierta y a Distancia; políticas de salud; políticas de justicia y seguridad ciudadanas para solucionar el desempleo, la pobreza y el desamparo. Se procuró el desarrollo regional equitativo y la participación creciente de la comunidad.

2. La consolidación del desarrollo económico para preservar el crecimiento de la economía en niveles que permitieran la elevación constante de las condiciones de vida de la comunidad. El plan propuso adoptar una serie de políticas dirigidas a consolidar el proceso de desarrollo y a fortalecer los sectores productivos primarios, mediante el fomento al ahorro público, los incentivos a la capitalización industrial, el fortalecimiento del sector agropecuario, la comercialización de productos políticos de vivienda, política minera y energética y la ampliación del cubrimiento de los transportes y las telecomunicaciones.

3. La reactivación económica ante la inquietante conjunción de la recepción recesión con la inflación. El plan presentó para ello una perspectiva de crecimiento con estabilidad, políticas monetarias, crédito para la producción, protección al trabajo y a la industria nacional y salvaguardar la vivienda como un sector impulsor. 


\begin{tabular}{|l|l|l|}
\hline & $\begin{array}{l}\text { Revolución pacífica,plan de desarrolloysocial:sus objetivos } \\
\text { eran impulsar la modernización del Estado en lo político } \\
\text { y social, científico y tecnológico y en las relaciones de } \\
\text { Nación-Estado-Gobierno, apertura. Apertura significaba } \\
\text { una mayor participación de la población colombiana, la } \\
\text { participación política se lograría a través de la Asamblea } \\
\text { Nacional Constituyente. La apertura económica plantea } \\
\text { una reforma estructural e institucional. }\end{array}$ \\
\hline Gaviria & $\mathbf{1 9 9 4}$ & $\begin{array}{l}\text { Revolución pacífica, plan de desarrollo y social: sus } \\
\text { objetivos eran impulsar la modernización del Estado en lo } \\
\text { político y social,científico y tecnológico y en las relaciones } \\
\text { de Nación-Estado-Gobierno. Apertura significaba una } \\
\text { mayor participación de la población colombiana, la } \\
\text { participación política se lograría a través de la Asamblea } \\
\text { Nacional Constituyente. La apertura económica plantea } \\
\text { una reforma estructural e institucional. }\end{array}$ \\
\hline Pamper & $\mathbf{1 9 9 8}$ & $\begin{array}{l}\text { Pizano } \\
\text { Elsaltosocial:el plan de desarrollo se convierte en Ley dela } \\
\text { República,y por primera vez en sus elementos esenciales } \\
\text { y en la asignación de inversión, según la Constitución, } \\
\text { tendrá prioridad sobre otras leyes de presupuesto. Este } \\
\text { plan buscó beneficiar los sectores marginados y aumentar } \\
\text { el gasto en salud, educación, agua potable y vivienda. El } \\
\text { Estado pretendía compensar las desigualdades sociales } \\
\text { producidas por el desarrollo económico y el proceso } \\
\text { de apertura iniciada en la administración anterior } \\
\text { (César Gaviria Trujillo). Se propuso un pacto social para } \\
\text { controlar la inflación, que consistía en concertar con los } \\
\text { tres sectores encargados de la economía (el Estado, los } \\
\text { empresarios y los trabajadores), se propuso un aumento } \\
\text { anual de los precios de tal manera que en cada periodo } \\
\text { fuera menor hasta lograr establecer el costo de vida. }\end{array}$ \\
\hline $\mathbf{1 9 9 4}$
\end{tabular}




\begin{tabular}{|c|c|c|}
\hline & & $\begin{array}{l}\text { Otros objetivos eran lograr que la política social } \\
\text { jugara un papel protagónico en el desarrollo nacional, } \\
\text { consolidar al Estado como orientador del desarrollo, } \\
\text { formar un nuevo ciudadano colombiano en lo } \\
\text { productivo, en lo social, en lo político, en los derechos } \\
\text { humanos, en el respeto a la naturaleza, integrar los } \\
\text { objetivos económicos, sociales y ambientales, impulsar } \\
\text { el empleo productivo y la educación. }\end{array}$ \\
\hline $\begin{array}{l}\text { Andrés } \\
\text { Pastrana } \\
\text { Arango. }\end{array}$ & $\begin{array}{l}1998- \\
2002\end{array}$ & $\begin{array}{l}\text { Cambio para construir la paz: la paz fue la primera } \\
\text { estrategia, el hilo conductor de la propuesta, } \\
\text { acompañada de las otras estrategias: fortalecimiento del } \\
\text { tejido social, consolidación del desarrollo y reactivación } \\
\text { de la producción, teniendo como horizonte las } \\
\text { exportaciones y la competitividad regional. } \\
\text { Con el plan se pretendía ubicar de nuevo al país por una } \\
\text { senda de crecimiento sostenible con cohesión social.En el } \\
\text { plan los conceptos de sostenibilidad y de cohesión social } \\
\text { son tan o más importantes que la idea de crecimiento. } \\
\text { Ambas cosas se complementan mutuamente si se adopta } \\
\text { una visión según la cual sostenibilidad implica: } \\
\text { - Desde el punto de vista económico:que elcrecimiento } \\
\text { se fundamenta en criterios de productividad. } \\
\text { Desde el punto de vista ambiental: que el } \\
\text { crecimiento sea compatible con la preservación y } \\
\text { el manejo adecuado de los recursos naturales. } \\
\text { Desde el punto de vista social: que el crecimiento } \\
\text { sea generador de empleo, de capacidades y de } \\
\text { oportunidades también para los más pobres. } \\
\text { Desde el punto de vista político: que el proceso } \\
\text { de crecimiento sea en lo fundamental, equitativo y } \\
\text { participativo. }\end{array}$ \\
\hline
\end{tabular}




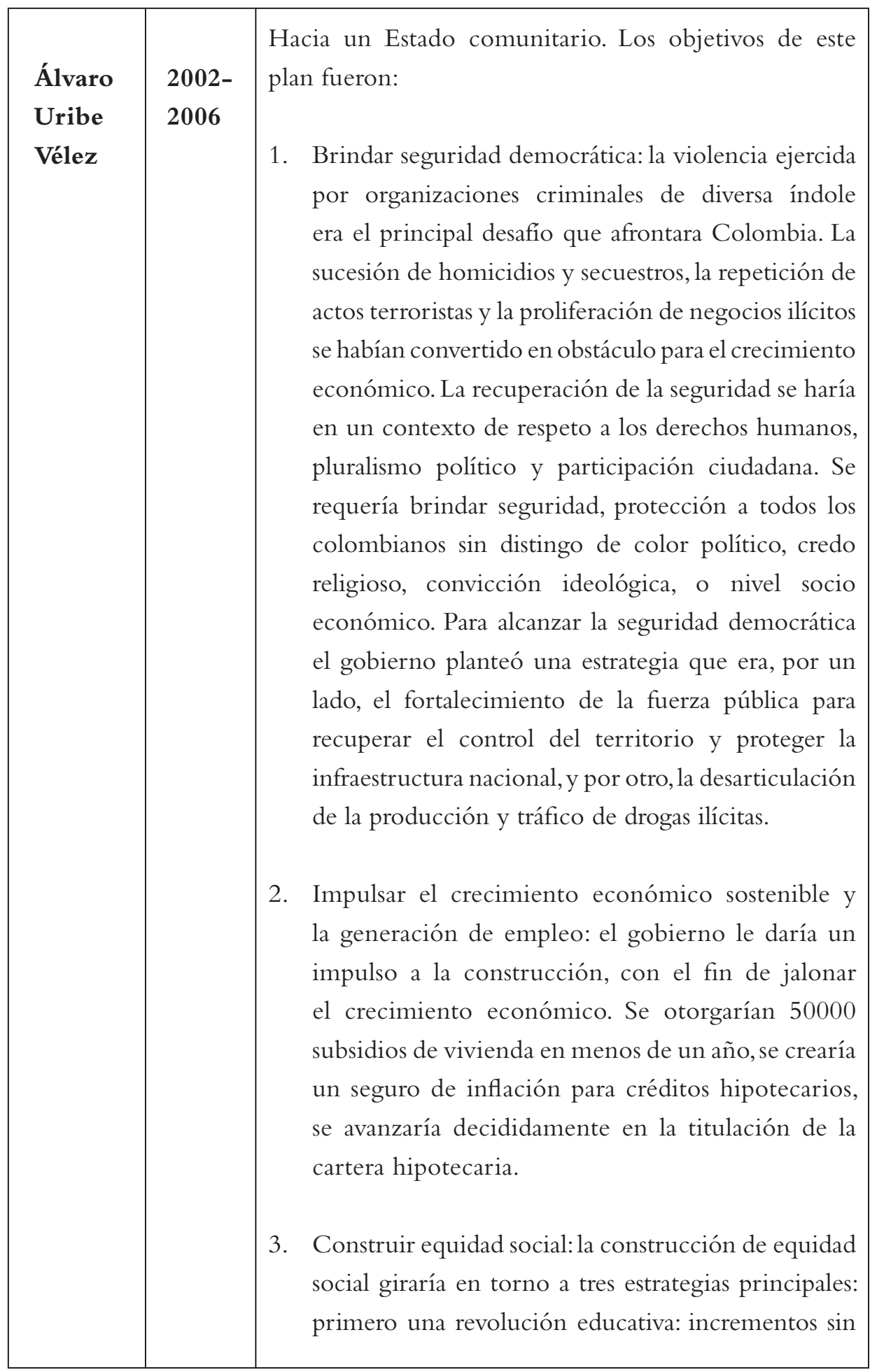




\begin{tabular}{|c|c|c|}
\hline & & $\begin{array}{l}\text { precedentes en la cobertura para todos los niveles de } \\
\text { instrucción, así como mejoramiento de la calidad. } \\
\text { Segundo: aumentos Sustanciales en salud, nutrición } \\
\text { y salud pública y el manejo social del campo que } \\
\text { contempla la protección del campesino como un } \\
\text { elemento primordial de la política económica y } \\
\text { comercial. Por último, impulso a la microempresa } \\
\text { y a la economía solidaria; en cuanto a los servicios } \\
\text { públicos la necesidad de que tanto ricos como pobres } \\
\text { tuvieran acceso a servicios públicos de calidad. } \\
\text { 4. Incrementar la transparencia y eficiencia del Estado: } \\
\text { la corrupción, la politiquería y la ineficiencia han } \\
\text { minado la confianza del público en la capacidad } \\
\text { del Estado para atender sus necesidades más } \\
\text { apremiantes. Para superar estas dificultades, el } \\
\text { Gobierno Nacional estaría comprometido con } \\
\text { una reforma de la administración pública, de las } \\
\text { relaciones interregionales y del ordenamiento } \\
\text { territorial del país. }\end{array}$ \\
\hline $\begin{array}{l}\text { Álvaro } \\
\text { Uribe } \\
\text { Vélez }\end{array}$ & $\begin{array}{l}2006- \\
2010\end{array}$ & $\begin{array}{l}\text { Estado comunitario: desarrollo para todos. El Estado } \\
\text { comunitario tiene un objetivo: que los recursos del } \\
\text { Estado sirvan al interés de la comunidad, a través } \\
\text { de la variable de equidad. Y tiene un medio: que } \\
\text { la comunidad participe ampliamente en la toma, } \\
\text { ejecución y supervisión de las decisiones del Estado, } \\
\text { para garantizar la transparencia. } \\
\text { La esencia del Estado comunitario: } \\
\text { se trabaja para construir confianza en Colombia, basados en } \\
\text { tres pilares: seguridad con alcance democrático, confianza } \\
\text { inversionista con responsabilidad social y cohesión social. }\end{array}$ \\
\hline
\end{tabular}


Todo alrededor del Estado y de la ciudadanía.Y ese Estado lo hemos denominado, comunitario.

El Estado comunitario no sustituye el concepto de Estado social de derecho, definido por el constituyente de 1991, sino que es una forma para que opere el concepto constitucional de Estado en Colombia y que quiere diferenciarse tanto de la tentación neoliberal que descuida el interés por la comunidad y va poniendo más peso en las fuerzas del mercado, como de la deformación que llevó a la socialdemocracia a degenerar en nuestro medio en expresiones clientelistas y en una corrupción rampante.

El Estado comunitario busca, primero que todo, que se cumpla con el postulado constitucional del Estado social de derecho que implica dos connotaciones básicas: el sometimiento del gobernante a la Ley y la puesta en práctica del principio de la solidaridad social.

Ese Estado comunitario tiene como único beneficiario de su acción y sus recursos a la comunidad, a partir de la construcción de equidad. Para lograrlo se necesita transparencia, que deviene en la medida en que la comunidad tenga mayor participación en la toma de las decisiones públicas, en su ejecución y en la vigilancia de cómo se ejecutan las tareas estatales.

Ahora bien, el Estado comunitario busca lograr un gran equilibrio entre la democracia participativa y la democracia representativa. La exigencia ciudadana permanente demanda sincero afán de los funcionarios, prudencia en el compromiso, diligencia en la acción, imaginación para explorar opciones y superar 
obstáculos. La presencia continua del funcionario, de cara a la comunidad, facilita el acceso a la información, el conocimiento de cifras, la conciencia sobre posibilidades y limitaciones y la reflexión sobre las obligaciones. Todo ello fomenta la credibilidad del pueblo en sus instituciones y recupera la fe popular en la democracia, porque promueve el carácter colegislador del pueblo, que es lo único que garantiza que los recursos lleguen directamente a la gente, que se construya equidad, que se logre transparencia y que se pueda asignar responsabilidad política a quienes fallen en la conducción de lo público.

Decisión, ejecución y vigilancia, eso es lo que finalmente crea confianza en las instituciones y en todas las expresiones del Estado: en la seguridad, en el marco legal para la inversión, en la transparencia de la política social.

No se cree en el desmantelamiento del Estado que recorre a América Latina, tampoco se cree en el Estado burocrático, en el Estado inflexible, en el Estado controlado por la politiquería o por los excesos sindicales, en el Estado del derroche, del clientelismo, del desgreño.

Se tiene la convicción de que poner el Estado al servicio de la comunidad es fundamental.

Objetivos del Estado comunitario:

1. Un Estado gerencial: administra lo público con eficiencia, honestidad, austeridad y por resultados. Para ello se planteó una doble estrategia: la reforma vertical, que consistía en el rediseño institucional de las entidades de la rama Ejecutiva del orden nacional, con 
el fin de aumentar eficiencia y disminuir presión fiscal; y una reforma transversal, para modernizar los procesos estructurales comunes a la administración pública. Logramos pasar así de la politiquería, de los excesos sindicales y el desgreño del Estado, a la eficiencia social.

Resultados de la reforma vertical:

- Se reestructuraron 465 entidades estatales (182 del gobierno nacional central, 244 hospitales y 39 empresas de servicios públicos), que representaron entre 2002 y 2010 un ahorro del 5,36\% del PIB.

- La sola reestructuración de los 244 hospitales públicos representó un ahorro de $\$ 785,8 \mathrm{MM}$. Se asegura la sostenibilidad y permanencia de las redes departamentales de prestación de servicios de salud y se liquidó Cajanal.

- Se salvaron empresas de servicios públicos domiciliarios como Emcali y la Distribuidora de Energía del Pacífico.

- En Ecopetrol se adelantaron las reformas: laboral, pensional y accionaria, lo que le permitió trasladar entre 2008 y $2009 \$ 11,3$ billones a la Nación.

- Telecom pasó, en 2002, de ser inviable en el corto plazo, con pérdidas anuales de $\$ 471000$ millones, a inversiones entre 2004 y 2009 por $\$ 2,2$ billones, y de una pérdida acumulada de $\$ 1843$ millones saltó a una utilidad acumulada de 2003 a 2009 de $\$ 493000$ millones.

Resultados de la reforma transversal:

- Modernización del empleo público: con la Ley 909 de 2004, aproximadamente 120 cargos se ofertan 


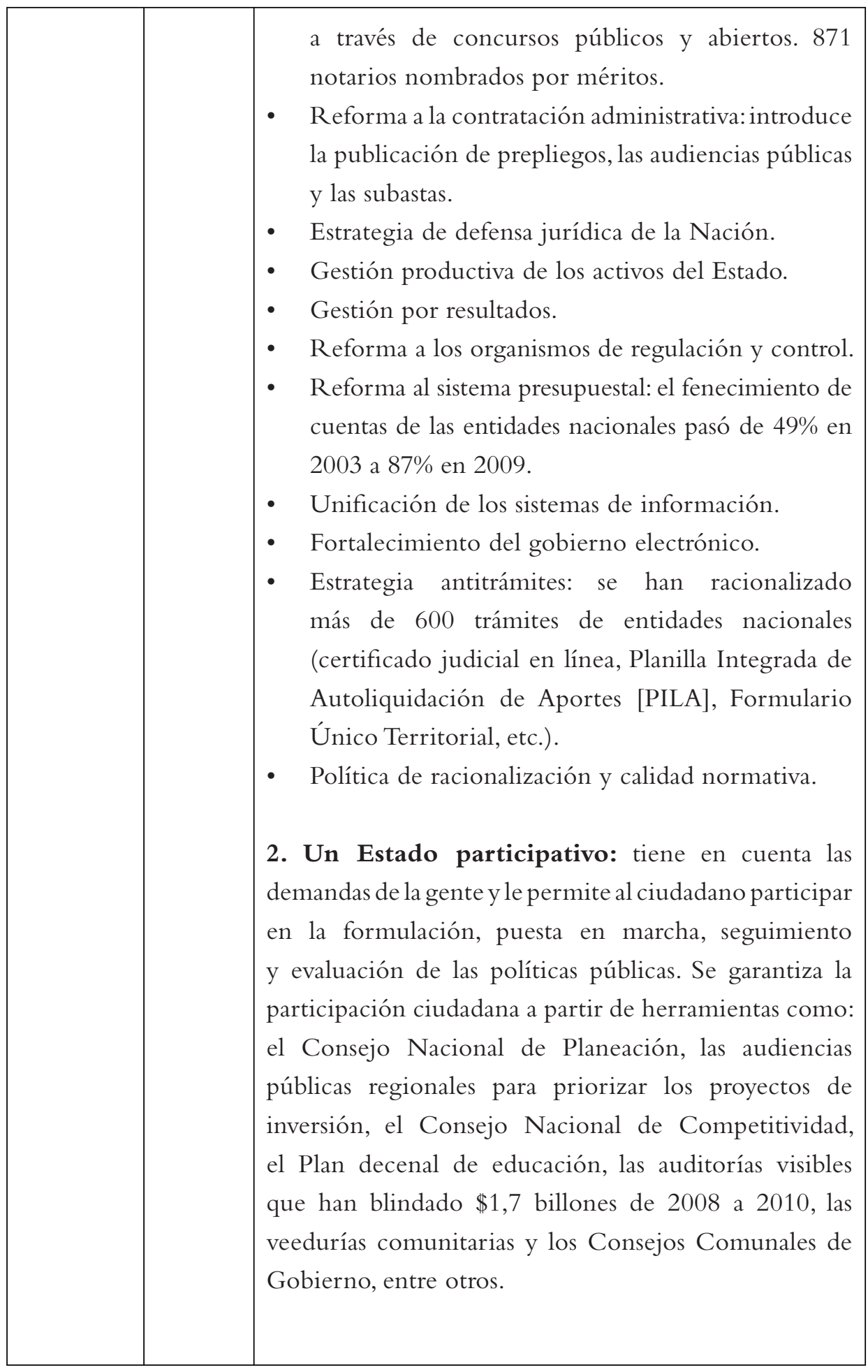


La participación ciudadana obliga a mejorar el acceso a la información, con la permanente rendición pública de cuentas. En nuestro gobierno se determinó la obligación por parte de todas las entidades estatales de entregar información en tiempo real sobre el avance en la ejecución de los proyectos públicos, estableciendo consecuencias jurídicas en caso de incumplimiento.

Se buscó, además, establecer una relación complementaria entre los sectores público y privado, porque no podrá haber un Estado social de derecho ni un Estado comunitario, sin un sector privado vigoroso y dinámico. Tampoco podrá haber un sector privado próspero sin un sector público que contribuya a la creación de capital social, que procure reglas ordenadas y que se cumplan para el funcionamiento de las empresas y de la economía en su conjunto, y que ofrezca una infraestructura social, económica y de seguridad democrática básica que estimule el desarrollo del país.

3. Un Estado descentralizado: administrativamente más cercano al ciudadano, lo cual implica, desde el punto de vista de su organización, un compromiso decidido con el fortalecimiento y profundización del traslado de competencias nacionales hacia los entes territoriales. Un Estado que tiene en cuenta las necesidades locales sin perjuicio del interés nacional y de la solidaridad regional.

Ejemplo de ello fue el Programa de Renovación de la Administración Pública (PRAP), que buscó una mayor delegación de funciones y competencias en el orden territorial, la eliminación de las duplicidades entre el gobierno central y los entes locales, la recuperación de la fortaleza del nivel intermedio de gobierno, la 
promoción de la acción conjunta y articulada de los diferentes niveles de la administración pública, a través de alianzas, asociaciones y convenios de delegación, y el incentivo de la integración de regiones, con un fin último: la liberación de recursos con destino a programas sociales al servicio de los ciudadanos.

Dos muestras claras de descentralización son la elección popular de alcaldes y gobernadores y la circunstancia de que el $52 \%$ de todo el gasto del Estado lo realizan las regiones.

Se hicieron, además, enormes esfuerzos por los recursos, por ejemplo, el Gobierno Nacional a través del Agustín Codazzi tiene el liderazgo para todo el catastro nacional, con excepción de Medellín, Antioquia, Bogotá y Cali. Entre 2000 y 2010, los avalúos catastrales a nivel nacional crecieron en promedio a una tasa del $11.1 \%$ anual, alcanzando para la vigencia $2010 \$ 520,1$ billones (443,5 billones en predios urbanos y 76,6 billones en predios rurales). El incremento entre 2000 y 2010 fue de $184.2 \%$, un aumento de más del doble del avalúo total nacional registrado para la vigencia 2000, que ascendía a $\$ 182.98$ billones de pesos corrientes.

Esto da respuesta a un viejo anhelo del país, no solamente más ingresos municipales, sino también más equidad en el gravamen de la tierra, en el gravamen de la propiedad inmobiliaria, en el gravamen de esa base de riquezas.

(Uribe, s. f.) 


\begin{tabular}{|c|c|c|}
\hline $\begin{array}{l}\text { Juan } \\
\text { Manuel } \\
\text { Santos }\end{array}$ & $\begin{array}{l}2010- \\
2014\end{array}$ & $\begin{array}{l}\text { Prosperidad para todos: el plan de la administración } \\
\text { del presidente Juan Manuel Santos es la Prosperidad } \\
\text { democrática.En torno a ellase sitúa el crecimiento sostenible } \\
\text { y la competitividad, la prosperidad social e igualdad de } \\
\text { oportunidades y la seguridad, justicia y derechos humanos. } \\
\text { Estas acciones se acompañan de ejes estratégicos } \\
\text { en materia de sostenibilidad ambiental, innovación, } \\
\text { buen gobierno y lucha contra la corrupción y } \\
\text { posicionamiento e inclusión internacional. } \\
\text { Todas estas acciones apuntan hacia un país con regiones } \\
\text { inmersas en la economía nacional e internacional, que } \\
\text { convergen hacia un Estado de mayor bienestar para } \\
\text { todos los colombianos. } \\
\text { Derechos humanos } \\
\text { - Implementar una política integral de Estado para la } \\
\text { - promoción y protección de los derechos humanos } \\
\text { - y el derecho internacional humanitario. } \\
\text { - Consolidar la cultura del diálogo social y la } \\
\text { participación ciudadana. } \\
\text { - Diálogo y colaboración entre el gobierno y las } \\
\text { administraciones departamentales y municipales. } \\
\text { Espacios de cooperación con la comunidad } \\
\text { internacional en materia de derechos humanos. } \\
\text { - Reforma política para profundizar la participación } \\
\text { - genartionar la reforma constitucional a la justicia. } \\
\text { - criterio estratégico la Dirección }\end{array}$ \\
\hline
\end{tabular}


Nacional de Estupefacientes para que lidere y ejecute la política colombiana de lucha contra las drogas.

- Promover el desarrollo integral y la igualdad de oportunidades para las poblaciones étnicas.

\section{Gestión internacional}

- Inserción de Colombia en Asia-Pacífico.

- Liderar el grupo de economías emergentes (Civets) para atracción de inversión y nuevas oportunidades de negocios.

- Ingreso de Colombia a la Organización para la Cooperación y Desarrollo Económico (Ocde).

- Profundizar la integración con América Latina y el Caribe.

\section{Administración eficiente de recursos}

- Generar un ambiente económico favorable para el emprendimiento y la inversión.

- Uso más equitativo de las regalías.

- Modernizar el sistema financiero y el mercado de capitales.

- Optimizar e incrementar el recaudo tributario.

\section{Seguridad}

- Consolidar las zonas recuperadas.

- Desarticular las bandas criminales, debilitar a las FARC y al ELN para que dejen de ser una amenaza a la seguridad nacional.

- Hacer de Colombia un territorio inviable para el narcotráfico.

- Fortalecer la seguridad ciudadana. 


\section{Tierra productiva}

- Restituir un millón 600 mil hectáreas a 160 mil familias campesinas.

- Formalizar títulos de un millón 500 mil hectáreas para 150 mil familias.

- Promover 641 alianzas de paz y desarrollo para generar 100 mil empleos.

- Identificar y aprovechar grandes espacios de desarrollo agrícola.

- Alianzas estratégicas para la investigación en el sector agropecuario.

\section{Empleo y salud}

- Reducir la tasa de desempleo nacional al 9\%.

- Formalizar 350 mil empleos y emplear a 150 mil jóvenes.

- Sacar a 2 millones y medio de personas de la pobreza e incluir en la Red Juntos las familias en pobreza extrema.

- Revisar, actualizar y unificar, en forma gradual y sostenible, los planes de beneficios del sistema de salud.

- Implementar un sistema de salud con una satisfacción de calidad mayor al $90 \%$.

\section{Energía}

- Alcanzar una producción de hidrocarburos de 1,4 millones de barriles diarios.

- Incrementar la producción anual de carbón de 73 a 124 millones de toneladas.

- Aumentar la cobertura del sistema interconectado del 95 al 98\% de la población. 


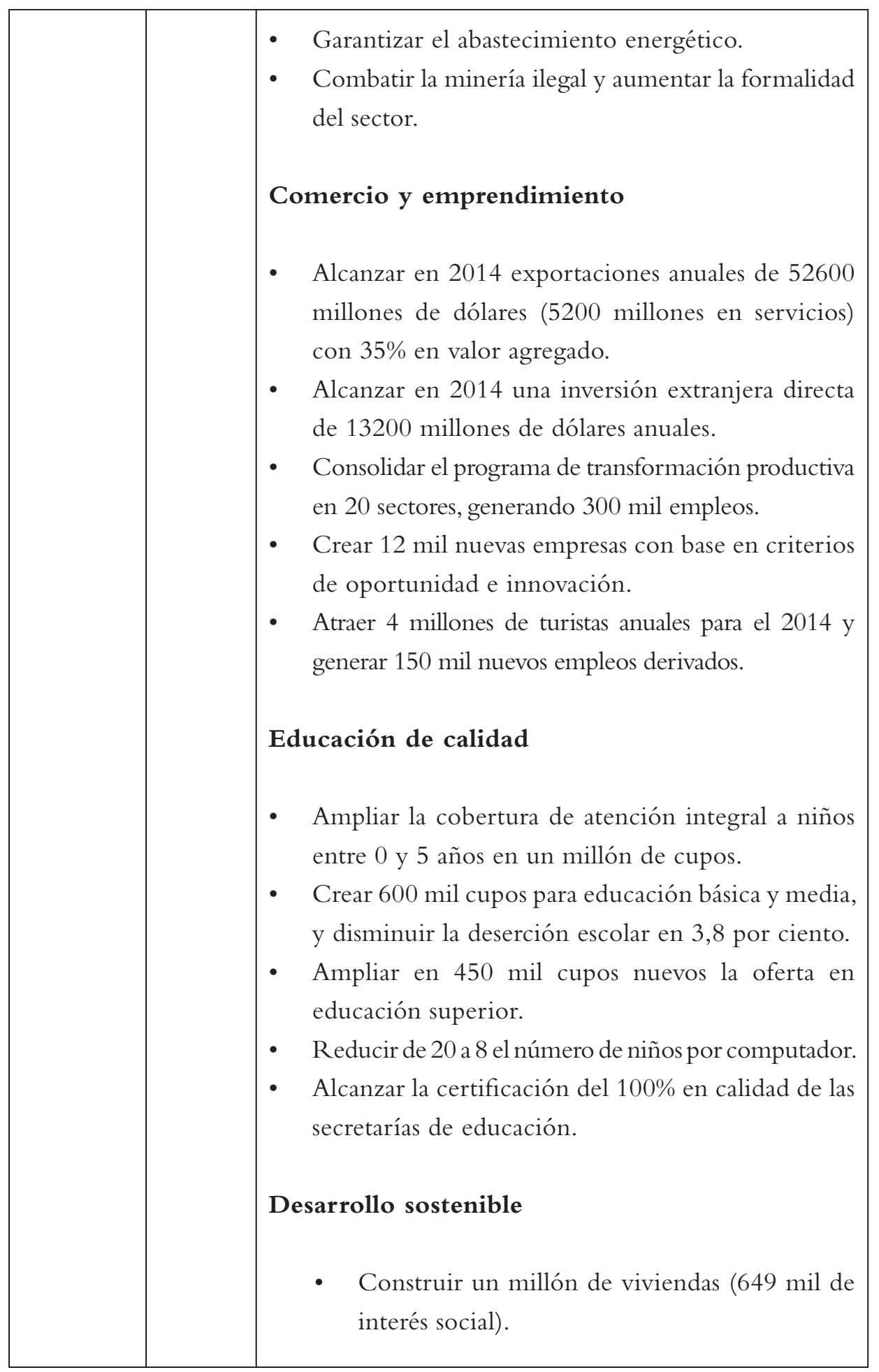


- Beneficiar a 2,9 millones de personas adicionales con el servicio de acueducto y a 4,7 millones con alcantarillado.

- Incorporar un millón de hectáreas al Sistema Nacional de Áreas Protegidas.

- Implementar la política nacional de cambio climático.

\section{Conectividad}

- Multiplicar por cuatro el número de conexiones fijas y móviles a internet, hasta 8,8 millones.

- Pasar de 27 a 50\% de hogares con conexión a internet.

- Pasar de 7 a 50\% de Mipymes con conexión a Internet.

- Triplicar (de 200 a 700) el número de municipios conectados a las redes de fibra óptica.

\section{Infraestructura y movilidad}

- Pasar de 900 a 2000 kilómetros de carreteras doble calzada.

- Pasar de 2000 a 4000 kilómetros de vías en el programa de rehabilitación y mantenimiento.

- 75 mil kilómetros de red terciaria "caminos para la prosperidad".

- Poner en operación 15 sistemas integrados de transporte masivo y el sistema estratégico de transporte público, y estructurar cuatro sistemas integrados. 


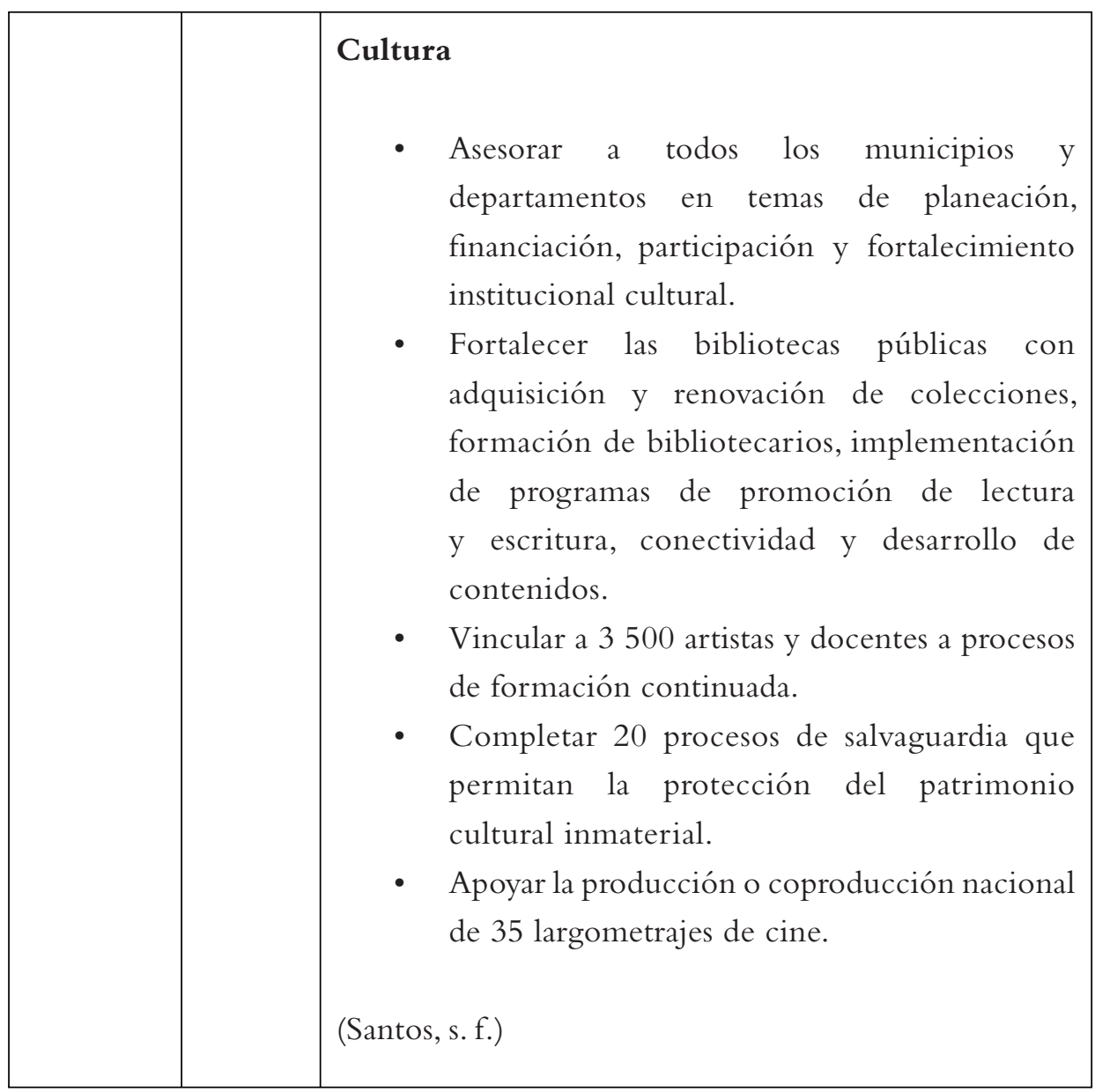

Fuente: elaboración propia.

\subsection{Las reformas educativas en Colombia}

La reforma es la modificación de una situación con la finalidad de mejorarla, es movimiento, es cambio, es rehacer, corregir. En general, es renovación. Es acción y efecto en precedente social cultural o político.

Las reformas educativas (education reform) devienen de reformas políticas (political reform), e inciden en el desarrollo social y cultural de las sociedades.

En Colombia, desde los años 50, las reformas educativas han estado implicadas en los planes de desarrollo y son consecuentes con una política de planificación, 
en tanto se renuevan procesos y procedimientos en lo que se propone y proyecta desde los planes de gobierno.

Colombia ha transitado por reformas educativas que significan procesos de centralización, desconcentración y descentralización, lo que da mayor autonomía a las regiones.

Se destacan la reforma del año 80, la contrarreforma del 90 y la contracontrarreforma del 2000.

\subsubsection{La reforma educativa del año 1980}

Esta reforma tiene como antecedentes el discurrir de intereses tanto del magisterio como de la nación, la organización sindical y política y la defensa de la educación pública en condiciones laborales y profesionales que permitan la transformación del país.

La organización es un elemento de significado histórico. El movimiento de maestros desde 1959 y los paros nacionales de 1972 y 1977 obligaron al Gobierno a negociar el estatuto nacional docente y a realizar una reforma educativa nacional.

Movimientos sociales constantes en pro de la mejora y calidad educativa son elementos que en Colombia se despliegan en los años 70, 80 y 90.

Así, el movimiento pedagógico, en palabras de Marco Raúl Mejía (sociólogo y pedagogo colombiano), surge por la confluencia de los procesos históricos de reforma educativa del Ministerio de Educación Nacional en el año 1980, el auge de los movimientos sociales que intentan construir proyectos educativos alternativos, (Mejía,s.f.) la emergencia de sujetos de pedagogía que pugnan contra los modelos hegemónicos y la emergencia de actores sociales y educativos con sentido en el quehacer pedagógico. Gantiva (1984) expresa que el movimiento pedagógico tiene la razón de ser a partir de la imposición de las políticas estatales del "Mapa educativo" (nuclearización de la educación) y la reforma curricular que buscaba la racionalización y mejora de la calidad de la educación. 
La reforma educativa de 1980 tiene como elementos centrales los procesos de transición y cambio del mundo en lo económico, así como también su incidencia en lo social (ascenso del modelo económico capital); la desconcentración administrativa de la educación con la creación en los departamentos de los Fondos Educativos Regionales (FER), las oficinas seccionales de escalafón docente y los Centros Experimentales Piloto (CEP), con acciones administrativas, jurídica y pedagógicas respectivamente.

La reforma educativa de 1980 tiene dos figuras:

1. La consolidación de un Estatuto Nacional Docente conocido como el Decreto Extraordinario 2277 de 1979, que clasificó los docentes en 14 grados de escalafón y permitió la apertura a la profesionalización de los docentes en Colombia.

2. La renovación curricular como apuesta formativa en el tipo de hombre, el tipo de educación y el tipo de sociedad a construir, expreso en los fundamentos generales del currículo, los marcos generales de este y la propuesta de programas curriculares para la educación básica (Decreto 2277, 1979).

\subsubsection{La contrarreforma educativa del año 1990}

La reforma educativa de 1990 tiene como antecedente los desarrollos de la renovación curricular de 1980, la puesta en marcha del Estatuto Nacional Docente de 1979 y los movimientos sociales y políticos de la década de 1980.

- Entre los grandes hechos que registra la historia colombiana en el periodo 1980-1990 se destacan:

- El premio nobel de literatura otorgado el 10 de diciembre de 1982 a Gabriel García Márquez por su destacada obra en lengua española.

- La toma del Palacio de Justicia el 6 y 7 de noviembre de 1985 por parte del grupo guerrillero M-19, con la idea de realizar juicio político al presidente de 
la República Dr. Belisario Betancur Cuartas. Este hecho dejó un triste recuerdo de 11 magistrados inmolados y un gran número de muertos y desaparecidos.

- La avalancha de Armero el 13 de noviembre de 1985 por la erupción del volcán Nevado del Ruiz, tragedia natural que arrasó con la población de Armero y sepultó a más de 23000 personas.

La visita del papa el 1 de julio de 1986, la extradición de Carlos Lehder el 4 de febrero de 1987, el triunfo de Lucho Herrera el 15 de mayo de 1987 en la vuelta a España, el magnicidio de Luis Carlos Galán Sarmiento el 18 de agosto de 1989.

Colombia: los ochenta, la década del miedo. Titula el diario Le Monde Diplomatique (12 de diciembre de 2013) en artículo de Carlos Fajardo.

En este periodo de gran movimiento social, surgió la iniciativa estudiantil de la Séptima papeleta ante las elecciones del 11 de marzo de 1990 de Colombia. Esta iniciativa propuso incluir un séptimo voto en el que se solicitaba la reforma constitucional mediante la convocatoria de Asamblea Constituyente. Este hecho dio origen a la Constitución Política de 1991.

La figura de la reforma educativa de 1990 es la Constitución Política de Colombia de 1991, de donde se desprende el marco educativo colombiano actual.

El artículo 67 de la Constitución explicita el derecho a la educación de la persona y lo justifica como obligación del Estado. La Carta Magna establece los derechos fundamentales, los derechos sociales, económicos, culturales y las garantías de protección y aplicación de los derechos.

De esta figura se despliegan la Ley 30 de 1992 (Ley de Educación Superior) y la ley 115 de febrero 8 de 1994 (Ley General de Educación), las cuales se constituyen en el referente educativo del Colombia. De ellas se consolida un país en función de derechos y oportunidades sociales a partir de la democracia, la participación y la autonomía. La contrarreforma educativa de 1990 potencia los procesos de descentralización y autonomía local. 


\subsubsection{Reforma educativa del 2000}

Colombia vive las transformaciones del mundo en lo económico, político, cultural y en especial los cambios en la revolución de las telecomunicaciones. El desarrollo de las tecnologías de la información y las comunicaciones relaciona los fenómenos de las redes sociales, la blogosfera, los espacios virtuales y las innovaciones en la conectividad.

La reforma educativa del 2000 se centra en la reorganización del sistema educativo en mirada de las relaciones técnicas: número de maestros, número de directivos, número de estudiantes, número de instituciones, en coberturas y eficiencias del aparato estatal.

Este periodo se denominó de reorganización técnico-administrativo de la educación. Se expiden la Ley 715 del 21 de diciembre de 2001 (Ley de Participaciones en Salud y Educación) y la Ley 734 de 21 de diciembre de 2001 (Código Único Disciplinario), las cuales son el referente de nuevos ajustes administrativos; además, son dispositivos para replantear los proyectos educativos institucionales, que se acercan a la nueva centralización de la educación. Discursos de mejoramiento de la educación y prácticas de dependencia de las directrices de la política educativa.

\subsection{Tendencias actuales en el currículum}

Las tendencias que actualmente transitan por el quehacer del currículum y que tienen incidencia en la educación se inscriben en temas-problema como la equidad de la educación, la calidad, la pertinencia y la corresponsabilidad en contexto. Los países en el desarrollo de sus políticas plantean procesos de democracia, participación y autonomía en la distribución del conocimiento, su acceso y desarrollo con altas calidades que implican transformaciones en el currículum.

En el marco de la descentralización curricular que vive América Latina, se caracteriza la transferencia de poder del centro del Estado a las periferias y las unidades departamentales y municipales con autonomía administrativa y financiera. 
Son grandes las transformaciones que se han vivido desde 1980, evidentes en reformas educativas (reforma de 1980, contrarreforma de 1990, contracontrarreforma del 2000 y la que vivimos en el presente), las cuales dan sentido a lo educativo como proceso de formación del sujeto, en especial como sujeto democrático, sujeto de derecho, sujeto autónomo, sujeto constructor de conocimiento, sujeto comprometido con la transformación de la sociedad.

Son evidentes grandes tensiones y posibilidades desde el desarrollo del currículo, en tanto es una gama, un espectro, una multiplicidad de acciones y relaciones en tramo complejo.

Desarrollos de la técnica, la tecnología y la ciencia en la llamada revolución científico-técnica se incorporan a la educación, y así el currículo responde a las exigencias de estos avances. Se reconocen limitaciones, pero se adelantan procesos de cualificación a la comunidad docente y educativa.

\subsubsection{Calidad educativa}

Una constante en América Latina y sus sistemas educativos es el tema de la calidad. Se reconoce que los sistemas educativos se han expandido en coberturas, el 88\% de los niños del grupo de 6 a 11 años de edad estaban matriculados en la enseñanza básica en 1990, en comparación con un 58\% en 1960 (CepalUnesco, 1992, p.42),

La expansión de la educación primaria a partir de los años cincuenta provocó, a su vez, la expansión de la educación media en las décadas siguientes, con tasas de crecimiento promedio de la matrícula superior al 10\% anual hasta comienzos de los años setenta. A partir de entonces, la tasa de crecimiento empezó a disminuir y cayó a 4\% en los años ochenta. En 1988, un 56\% de los adolescentes de 12 a 17 años estuvieron escolarizados y esa proporción sobrepasó el $70 \%$ en siete países. Si bien no se ha llegado a una real masificación de la enseñanza secundaria, la expansión no deja de ser sustancial cuando se la compara con una tasa promedio de escolarización media de apenas 15\% en 1960. 
Lo anterior señala la calidad de la educación en cuanto a cobertura, pero deja interrogantes en la equidad social, el desarrollo humano y la corresponsabilidad política y cultural.

\section{De la centralización a la descentralización}

En América Latina se avanza en el proceso de desconcentración-descentralización curricular. En diversos escenarios lo macrocurricular, lo mesocurricular y lo microcurricular da autonomía a los actores locales. Es el Ministerio de Educación quien expresa el lineamiento en la concepción de tipo de hombre de educación y sociedad a construir. Juan Casassus expresa que:

la desconcentración refleja procesos cuyo objetivo es el de asegurar la eficacia del poder central, mientras que... descentralización es un proceso que busca asegurar la eficacia del poder local... bajo esta perspectiva, con la salvedad de algunas pocas excepciones, hoy prácticamente todos los países están involucrados en el proceso de descentralización (Casassus, 1990, p.8).

En América Latina el Estado juega un rol central en la determinación del currículum, confiere poderes y atribuciones curriculares a la sociedad civil y a las instituciones educativas en el desarrollo de sus proyectos de formación, como se expresa en Colombia en el artículo 67 de la Constitución Política de 1991, la educación es un derecho. Por otro lado, la Ley 115 de febrero 8 de 1994 (Ley General de Educación) define en su artículo V las finalidades de la educación, y el decreto 1860 de 1994 dimensiona los proyectos educativos institucionales con criterios de participación, democracia y autonomía.

El currículum es un proceso en el desarrollo del poder que es atinente como lo señala Cristian Cox:

el currículum es resultado de relaciones al interior y entre campos complejos de fuerzas que se establecen entre agentes y/o instituciones en lucha por una forma específica de poder cultural: el poder de definición de los parámetros mayores de la 
transmisión cultural de la escuela. Intrínseca al concepto de campo es la noción de un espacio de posiciones estructurado en términos de una disputa específica y generativa de competencias e intereses específicos. Un campo funciona simultáneamente como instancia de inculcación y mercado donde diferentes competencias reciben su precio. Es propio a la naturaleza del funcionamiento de los campos su auto-referencia, vale decir, su relativa clausura operativa respecto a su "afuera". El análisis de las fuentes del currículum debe poder identificar cuáles son los campos en juego y el grado de auto-referencia que los caracteriza, porque son estas relaciones inter e intra campos las que especifican la relación genérica, y por demás conocida, entre cultura y contenidos culturales seleccionados para su transmisión escolar. (Cox, 1991, p.10)

\section{Centralismo contra descentralización curricular}

El desarrollo del currículum es el paso de la acción jerárquica a la participación de actores en los contextos locales. Por lo general, el currículo históricamente ha sido elaborado en los centros y desplazado a las regiones.

Entre los nuevos roles del Estado en el desarrollo curricular está brindar autonomía a la región en desafios de democratización, de la formación de ciudadanos en el marco de la globalización, mundialización e internacionalización.

\section{Autonomía curricular de las instituciones educativas}

La autonomía curricular de las instituciones educativas ha sido conceptualizada como un aspecto de modernización del sistema educativo.

La descentralización significa entonces autonomía, sentido de proyecto, identidad institucional, e iniciativa y capacidad de gestión radicadas dentro de los propios centros educativos. La autonomía curricular se expresa en las decisiones de los organismos de gestión local para transitar por el tipo de hombre a formar, y el tipo de sociedad a construir. En el contexto colombiano, dicho proceso se desplaza desde el marco constitucional, las leyes de la República y normativas, como la del proyecto 
educativo institucional, (Decreto 1860 de 1994) donde cada vez más se incorporan las comunidades a la toma de decisiones, en representación de diferentes estamentos: padres de familia, docentes, estudiantes, sociedad civil y sector productivo

\section{La descentralización curricular desde las políticas públicas. El caso de Colombia}

Los países de la región suramericana han promulgado leyes que tienden a crear espacios de autonomía y descentralizar el currículum. Tal es el caso de Colombia, que en la Ley 115 de 1994 expresa lo siguiente: como se expresa en el libro Currículo, educación para la democracia y modernidad de Abraham Magendzo, quien señala textualmente que:

Artículo 76. Concepto de Currículo. Currículo es el conjunto de criterios, planes de estudio, programas, metodologías y procesos que contribuyen a la formación integral y a la construcción de la identidad cultural nacional, regional y local, incluyendo también los recursos humanos, académicos y físicos para poner en práctica las políticas y llevar a cabo el proyecto educativo institucional (1996).

Artículo 77. Autonomía escolar. Dentro de los límites fijados por la presente ley y el proyecto educativo institucional, las instituciones de educación formal gozan de autonomía para organizar las áreas fundamentales de conocimiento definidas para cada nivel, introducir asignaturas optativas dentro de las áreas establecidas en la ley, adoptar áreas a las necesidades y características regionales, adoptar métodos de enseñanza y organizar actividades formativas, culturales y deportivas, dentro de los lineamientos que establezca el Ministerio de Educación Nacional.

Parágrafo segundo. Las secretarías de educación departamentales o distritales o los organismos que hagan sus veces, serán las responsables de la asesoría para el diseño y desarrollo del currículum de las instituciones educativas estatales de su jurisdicción, de conformidad con lo establecido en la presente ley. 
Artículo 78. Regulación del currículo. El Ministerio de Educación Nacional diseñará los lineamientos generales de los procesos curriculares, y en la educación formal establecerá los indicadores de logros para cada grado de los niveles educativos, tal como lo fija el artículo 148 de la presente ley.

Los establecimientos educativos, de conformidad con las disposiciones vigentes y con su proyecto educativo institucional, atendiendo los lineamientos a que se refiere el inciso primero de este artículo, establecerán su plan de estudio particular que determine los objetivos por niveles, grados, áreas, la metodología, la distribución del tiempo y los criterios de evaluación y administración.

Cuando haya cambios significativos en el currículo, el rector de la institución educativa oficial o privada lo presentará a la Secretaría de Educación Departamental o Distrital o a los organismos que hagan sus veces, para que esta verifique el cumplimiento de los requisitos establecidos por la presente ley. (Ley 115, 1994).

Con respecto a esta ley, son muy acertados los comentarios que hace Ricardo Sánchez director del Instituto para el Desarrollo de la Democracia, Luis Carlos Galán de Colombia, cuando hace ver que con el advenimiento de la concepción tecnológica del currículum "la personalidad de las escuelas y colegios fue paulatinamente borrada sin ofrecer posibilidades reales creativas de diseñar una nueva para las instituciones escolares dentro de su marco común” (Sánchez, 1995, pp. 18-20).

\subsection{La concepción de educación}

\subsubsection{Conceptos de educación}

Todo pueblo que alcanza un cierto grado de desarrollo se halla por naturaleza inclinado a practicar la educación, por ser ella el principio mediante el cual el grupo humano conserva y transmite su peculiaridad física y espiritual. 
La educación es un proceso de socialización de los individuos. Ellos asimilan y aprenden conocimientos. La educación implica una concienciación cultural y conductual, donde las generaciones adquieren los modos de ser y existir.

El proceso educativo materializa habilidades, destrezas, capacidades y valores que producen cambios intelectuales, emocionales y sociales en el individuo. También, encierra el proceso de formación y despliega la potencialidad de este.

La educación, al igual que la formación, es natural, no termina nunca: Aristóteles señalaba que "la vida está en el movimiento", en la continua plasmación de potencialidades. Así, el hombre pasa de la infancia a la adolescencia y de esta a la madurez.

La primera acepción de formación (el desarrollo natural de un cuerpo o de un individuo) no puede entenderse de un modo completamente aislado de los otros significados de la palabra. De todos modos, no podemos hacer mucho en algunas dimensiones de este desarrollo: la fisonomía de nuestro cuerpo o de nuestro rostro nos viene dada (solo se puede vigilar que la alimentación sea adecuada, y eso ya es un factor cultural). "Nadie puede añadir un solo codo a su estatura". Javier Aranguren (1954).

Los griegos con la paideia pretendían formar ciudadanos capaces de gobernar la polis. ¿Qué tipo de ciudadano es ese? Se trata de un hombre con un amplio elenco de habilidades y procedimientos, experto en geometría, álgebra, gimnasia, retórica y filosofia. Es un deseo de formar, de educar.

En su monumental obra Verdad y método, Gadamer realiza un estudio sobre la noción moderna de formación, palabra que en el contexto alemán se traduce como bildung, y que es uno de los conceptos básicos del humanismo. Para Gadamer la formación desde la perspectiva de la Ilustración "designa el modo específicamente humano de dar forma a las disposiciones y capacidades naturales del hombre” (1977, p.39). ¿Qué es lo más específicamente humano? Lo que nos haga lo más humanos posibles, esto es, aquellos aprendizajes a los que les acompaña la capacidad de potenciar la acción del sujeto, la libertad. Por eso, señala Kant que existe la obligación de "no dejar oxidar los propios talentos" (Kant citado por Gadamer, 1977, p. 37), y si eso es una obligación, quiere decir que realmente los talentos pueden echarse a perder. Para el 
hombre (el alumno) ser libre está en sus propias manos, tanto de cara al triunfo como ante la posibilidad del fracaso (Aranguren, 1954).

\section{Grecia y Roma}

El mundo griego de los siglos anteriores a la era cristiana se caracterizó por su educación en tres momentos: la educación homérica que remite a la época mítica, la educación clásica donde surge propiamente el logos filosófico, del cual Sócrates es el maestro más sabio, y la educación enciclopédica o helenística donde se pierde el sentido de unidad de la paideia y comienza la confluencia de otras culturas. Ese fue el momento de la decadencia griega. Durante muchos siglos el proyecto educativo se basó sobre el concepto fundamental de la areté que se transforma con cada momento educativo. En la educación homérica el ideal remite al héroe y la areté se insinúa en el vigor que se realiza en el cuerpo, a través de la gimnasia, en la educación clásica (en la cual Atenas es la referencia) la virtud se transforma en ideal teorético e intelectual y posteriormente en la decadencia esta referencia es un ideal de erudición.

areté: remite excelencia, mérito, calidad sobresaliente, fuerza, virtud, ideal que invita a los sujetos hacia una ambición de ser y sobresalir. La areté implica aristocracia y nobleza, el ser virtuoso, estar en vecindad con la divinidad. Es contraria a lo vulgar y lo ordinario, a lo bárbaro. A partir de la conjugación de los conceptos de areté y de armonía del proceso educativo, se creó el ideal de paideia, que remite a la cultura, es decir, el espacio donde se despliegan los ideales de la cultura griega, donde un sujeto se realiza.

\section{Homero el educador}

Cuenta Platón que era una opinión muy extendida en su tiempo que Homero había sido el educador de toda Grecia. Desde entonces, su influencia se extendió mucho más allá de los límites de la Hélade. La apasionada crítica filosófica de Platón al tratar de limitar el influjo y la validez pedagógica de toda poesía, no logra conmover todo su dominio. La concepción del poeta como educador de su pueblo, en el sentido más amplio y más profundo, fue familiar desde el origen y mantuvo constantemente su importancia. Solo que Homero fue el ejemplo más notable de esta concepción general y, por decirlo así, de su manifestación clásica. 
El areté homérico es la categoría distinta y superior del Homero heroico, del guerrero noble, virtuoso y audaz, poseído de la ética del honor. Aquiles como uno de estos héroes, encuentra su lección de areté como un ser supremo, a través del ejercitamiento con las alarmas, el esfuerzo físico y de la palabra.

"Ser siempre el mejor y mantenerse superior a los demás" (Homero, 1965) se lograba a través de la práctica en las artes marciales-guerrero y orador por el manejo de la palabra.

Es así como en la tradición homérica, la educación se enriqueció con las costumbres y fueros familiares. La mujer es a la vez madre y maestra, a pesar de los menesteres del hogar. En este periodo, la educación es patrimonio de los nobles, sobre quienes recae todo el poder político; por tanto, a ella acceden aquellos que por sus tradiciones sociales y ascendentes hereditarios eran aretés en potencia, en los que se encontraría la fuerza para las armas, la palabra y el honor dado por la declamación de la Iliada y la Odisea.

\section{Esparta}

La educación espartana agrupaba a todos los ciudadanos en campamentos de iletrados. Lo que retomó valor fue la disciplina militar. Jaeger (1973) afirma: "La educación homérica tuvo por objeto formar al héroe personal y Esparta, en cambio, es la ciudad en donde todos fueron héroes a pesar de ser iletrados". Este ideal educativo se distancia bastante del verdadero sentido de lo democrático, la educación continúa con la tradición homérica en donde solo se accede a partir de la tradición aristocrática y genesiocrata. El areté futuro es el niño que manifieste la posibilidad de ser un buen soldado, un hombre fuerte y robusto de armas al servicio de la ciudad. Sobre la familia recae el cuidado de la infancia y a partir de los 7 años el Estado lo toma, esto en caso de que haya merecido vivir para las armas. Su proceso formativo inicia desde los siete años hasta los once o catorce años y desde los quince hasta los diecinueve o veinte años; a partir de ese momento la población juvenil entra en la etapa de efebia. Hasta ese entonces se concebía una pedagogía de las armas y disciplina que a partir de los veinte años se convierte en una efebogogia para la educación del joven. Desde los veinte años en adelante, la polis continúa con la educación del adulto a partir de los criterios de guerra y fuerza corporal, es decir, a partir del vigor. 
Los proyectos educativos espartanos encuentran su espíritu en la formación del carácter individual y colectivo para una politeia propia. Un areté político colectivo que no ha dejado de resurgir ni siquiera en nuestro siglo XXI.

\subsubsection{A manera de colofón educativo curricular}

La puesta en escena de la palabra como trayecto hacia nuevas formas de concepción y relación entre educandos y educadores, maestros y discípulos, iniciados y aprendices sitúa como vital otras comprensiones de lo humano y lo educativo, donde la sensibilidad, el pensamiento y el conocimiento son pilares del actuar en congruencia con el devenir humano, el reconocernos en epistemes fundantes, en campos intelectuales, en intereses, en lenguajes y en los modos de ser y hacer educación.

La relación de pedagogía y currículo nos sitúa ante el paisaje educativo desde las concepciones de la escuela, la enseñanza y el currículo y afrontan desafíos como:

- ¿El asunto educativo se basa en la pedagogía para pensar lo humano que remite al sujeto vivo, común y potente?

- ¿Cuál es el sentido último de la educación?

- ¿Qué es lo que acontece en el acto educativo?

- ¿Qué significa ser maestro?

La aproximación para responder el problema de ser maestro remite al fundamento que lo estructura como sujeto del saber que, a su vez, remite a la pedagogía y enfrenta el estigma de convertirse en un técnico de la información y operario del conocimiento que no referencia la cultura. El ser maestro implica la permanencia de un rol que transfigura con la educación y la sociedad.

El rol y el saber se fusionan, dispersándose este último al enfrentar la estratificación de la división del trabajo con el ser maestro. El oficio ocupa el lugar del ser y el profesor el del maestro, tendremos entonces el oficio del profesor especializado y parcelado en una disciplina. En esta situación queda marginado el ser pedagogo. 
En la antigüedad, el rol del maestro derivaba en multiplicidad de oficios y en prácticas educativas que remiten a la realización de los ideales de cultura, es decir, la paideia. Lo anterior se evidencia desde el citarista encargado de la educación musical y la poesía que declamaba la Ilíada y la Odisea, hasta el paidotriba (el que golpea al niño), quien dirigía la palestra donde se realizaban los ejercicios gimnásticos y deportivos; a través de estos se forjaba un cuerpo sano, hermoso y se templaba el carácter por medio de la competencia, esto implicaba el despliegue ético y estético. Por medio del deporte se llegaba al autodominio, al control de las pasiones y a ser fuerte moralmente.

El pedagogo en la antigüedad se entendió como un oficio de gobernar al niño -futuro ciudadano que era libre-. Sabiendo el pedagogo que no era libre, o sea esclavo, su don consistía en guiar, en acompañar en la travesía. Al hacer camino con este era como el espacio que permitía el habla de encuentro antes de ir y después de venir de la palestra, de estar con el paidotriba y el citarista que impartían las enseñanzas. El individuo se entrenaba para la guerra, se debía al Estado totalmente.

Posteriormente van a aparecer otros oficios. El didaskalos, el que enseña al niño, lo inicia en la lectura y la escritura y le imparte una educación básica en contacto con los grandes poetas griegos: Homero, Hesíodo, Píndaro Teognis, y el gimnasiarca encargado del gimnasio donde se perfecciona la perfección deportiva y la filológica. Por los 18 años el joven entraba en la efebia, periodo de adiestramiento militar que en Atenas duraba hasta los 20 años y en Esparta hasta los 30 años. Atenas acentúa la educación intelectual y Esparta, la militar.

En Esparta la orientación social se dirigía más hacia campamentos, mientras que en Antenas se direccionaba a la construcción de la polis (ciudad). Esto implica preparar al individuo para gobernar la polis. En este contexto se sitúa Sócrates, como maestro que es juzgado por la polis bajo el cargo de pervertir a los jóvenes, de orientarlos a conocerse a sí mismos, a esculpir su obra de vida. A diferencia de Esparta, el individuo reflexiona acerca del Estado y emerge la humanidad.

Sócrates: el oficio de partear, tal como yo lo desempeño, se parece en todo lo demás al de las matronas, pero difiere en que yo lo 
ejerzo sobre los hombres y no sobre las mujeres, y en que asisten al alumbramiento, no los cuerpos sino las almas. La gran ventaja es que me pone en estado de discernir con seguridad si lo que el alma de un joven siente es un fantasma, una quimera o un fruto real... Intenta, pues, de nuevo, Teetetes, decirme en qué consiste la ciencia, no me alegues que esto supera tus fuerzas, porque si el Dios quiere, y si para ello haces un esfuerzo, llegarás a conseguirlo.

Teetetes: Después de tantas excitaciones de tu parte, Sócrates, sería vergonzoso no hacer los mayores esfuerzos... Me parece, que el que sabe una cosa, siente aquello que él sabe, y en cuanto puedo juzgar en este momento, la ciencia no se diferencia mucho de la sensación.

Sócrates: Se trata ahora de examinar el conjunto si esta concepción de tu alma es, sólida o frívola. ¿La ciencia es la sensación, según dices?

\section{Teetetes: Sí.}

Sócrates: Esta definición que das de la ciencia no es de despreciar, es la misma que ha dado Protágoras, aunque se haya expresado de otra manera el hombre, dice, es la medida de todas las cosas, de la existencia de las que existen, y de la no existencia de las que no existen. Tú has leído sin duda su obra.

Teetetes: Sí, y más de una vez.

Sócrates: ¿No es su opinión que las cosas son, con relación a mí, tales como a mí me parecen, y con relación a ti, tales como a ti te parecen? Porque somos hombres tú y yo. (Platón, 1968, pp.15, 16 y 17$)$.

Posteriormente, los pedagogos se orientan al clero, a la iglesia y pasan a hacer una función religiosa, sagrada y espiritual (Clemente de Alejandría).Ya no se guía o 
se acompaña, se instala en la contemplación de la vida interior del ascetismo, es la entrega a la oración, a dirigirse a Dios, es un recogimiento en sí mismo.

Posteriormente, el pedagogo se transforma en aquel oficio que refiere al que tiene el método de enseñar o didáctica para enseñar en un sitio encerrado todo a todos (Comenio). Maestro es aquel que sabe del método y además lo aprende.

Tiempo después, el pedagogo se propone como aquel tutor que acompaña a descubrir el mundo a Emilio (Rousseau), le enseña y descubre para Emilio la naturaleza contrario a los espacios cerrados y mundo finitos, le expone la condición de lo humano abierta y abismalmente en la experiencia. Luego, el pedagogo remite a aquel que teoriza, que deduce la teoría de enseñar o teoría de la educación (Kant, Herbart). En esta dirección se despliega la educabilidad y enseñabilidad, poder explicar de modo universal lo que ocurre con el hecho educativo.

Posteriormente, el pedagogo decae en el sentido de humanidad y se dispone un carácter instrumental, de enrarecimiento del ser y marginamiento del saber pedagógico, este como tal transfigura en lumbrales teóricos que tratan de explicar el hecho educativo pero también predecirlo, anunciarlo, controlarlo, desarrollarlo en un conjunto de técnicas sistemáticas acompañadas de conocimientos prácticos para diseñar, probar y hacer funcionar lo instruccional (Robert Gagné). El pedagogo es un experto que no vive en contexto escolar, lo interviene. Así, el profesor de nuestro tiempo, en el vacío que produce el experto, se llena de miedo y deviene la crisis, la cual es la crítica que hay que pensar.

El ser maestro es eminencia que por pasos se insinúa. Llegar a ser maestro no es una aparición repentina es, en cambio, el fruto de un lento amanecer, en ocasiones tan prolongado como la vida misma. Ser maestro involucra la existencia, el saber y el don de la verdad crítica que decae y emerge para situarse como certidumbre-incertidumbre.

Sin duda, hay profesores y hay maestros. Cuando nos referimos al profesor reconocemos en él su habilidad para brindar explicaciones diáfanas y comprensivas, pero solo en muy pocos profesores se da el atrevimiento, la transfiguración de la rostricidad de iniciado maestro. Reconocemos en este último algo más que la entrega de un saber, 
la entrega a plenitud de todo su ser, esto es sin duda lo que deja una profunda huella en nosotros. Este es el sentido más elevado de un maestro, aquel que más allá del dominio de sus conocimientos comparte con sus aprendices o discípulos su esencia, su propio ser y convierte en intimidad el acto sublime educativo.

Un maestro es aquel capaz de dirigir a su aprendiz no solo en lo intelectual (trasteando por una asignatura), sino de aquel que a razón de la enseñanza esculpe el ser habitante en su aprendiz. Tal como lo haría un artista con su obra de arte, el maestro esculpe una obra de vida consigo mismo, da sentido a su aprendiz para que haga lo propio consigo mismo, para agenciar, transfigurar o traicionar la propia obra de arte; para ser sí mismo o develarse en ser otro.

No hay que esperarlo todo del maestro, no esperemos que enseñe todo lo que sabe y domina, esperemos que cultive con emoción de obtener una gran cosecha, su siembra será de aciertos y desaciertos, de asomo de conocimientos. Esperemos del aprendiz la conciencia de ser frutos exquisitos que se forjan a lo largo de la vida, como un proceso de aprendizaje, que se origina en una pequeña semilla, que con cuidados florece y emerge como posibilidad de un saber, no forjado totalmente de un maestro, sino a partir de fundamentos, agenciamientos, relaciones, transfiguraciones, concatenaciones y traiciones. Es del aprendiz la lección de "suplir y formar su interior, construir su existencia". Es del maestro la lección, el esmero, la constancia, el tacto pedagógico de "enseñar lo que sabe y compartir todo su ser-enseñanza vital-potente".

\subsection{La concepción curricular}

En las interacciones maestro a maestro, en procesos de formación y actualización pedagógica, Gustavo Arias Arteaga, Lina Rosa Parra Bernal, Jaime Fayad y Luis Hernando Amador (2012) dialogan sobre el currículum y sus concepciones, parten de la experiencia, de su formación y expresan su apuesta. Historia, historialidad e historicidad es el trazo.

Desde las lecciones de Sócrates a los atenienses prima la enseñanza del humanismo por parte de los sofistas, que invitaba al llamado interior espiritual, en donde la mente del aprendiz trasegó su propio sendero y descubrió otra existencia "inteligencia". 
Tradicionalmente, las técnicas de enseñanza se hacen tangibles en mallas curriculares estáticas y saturadas de asignaturas, en donde la discusión central se realiza en torno al horario y tiempos de duración de una asignatura, es más que un listado de actividades, un temario, una lista de contenidos a cubrir, un plan de aprendizaje, una prescripción de fines, métodos y contenidos, ni mucho menos un listado de objetivos. El currículo como construcción no debe aprisionarse o saturarse, debe traspasar lo visible, lo tangible e informativo y la simple necesidad de que "algo" "se aprenda", la apuesta es por la transformación de la esencia del hombre (como lo deseaba Platón), la conversión del alma al ser.

El currículo como la construcción del sujeto vivo, como posibilidad de humanidad debe contemplar la construcción de la existencia y el profundo significado de la valorización, la enseñanza potente no está representada en asignaturas, números o letras, esta se sitúa en dimensión del trabajo proclive de la existencia, es decir, de humanidad expandida. Hay que reconocer al sujeto que se está educando, que se debate en un paisaje aglomerante y complejo. El currículo deberá ampliar su espectro hacia el conjunto mínimo pero potente de referencias al pensamiento (logos) que posibilite el empleo de todas las capacidades y perciba empatías y oscilaciones entre certezas e incertidumbres del saber. Esta concepción debe propiciar el estilo, el quantum, la fuerza que movilice a los sujetos ante los paisajes del mundo.

La preocupación no es la formación para el empleo y el diseño de estructuras que respondan a esta necesidad a través de las disciplinas y áreas de instrucción, es establecer como vital en el currículo la dimensión humana desde la cual se puede propender por un contacto con la vida desde los saberes, expresiones, conocimientos y ciencias. La emergencia curricular no puede desligarse de la problematización vital:

- ¿Quiénes somos?

- ¿Qué debemos enseñar?, ¿debe primar lo local sobre lo global?

- ¿Cuál es nuestra historia?

- ¿Cuál es la forma propia y necesaria de visión de nuestro mundo?

Estas interrogaciones nos sitúan ante una reconceptualización, reorganización y reforma del pensamiento, del conocimiento y la gestión curricular del saber. 
Hay que reconocer que las dinámicas actuales exigen estrategias curriculares abiertas, flexibles y reformadoras del pensamiento, en las que el currículo podrá concebirse como cuerpo, como palabra, como relaciones y como intelecto. La nueva configuración curricular en tanto que relacionar y gestionar el saber en nuestros paisajes de mundo, requiere de una visión de cultura y sociedad que apuesta por una conceptualización del conocimiento en las nuevas sociedades, basadas en flujos de información, en sistemas asociados o en red, que sin duda alguna se convierten en posibilidades hacia nuevas relaciones, hacia nuevas formas del conocimiento, nuevos estilos de pensamiento y nuevas formas de aprendizaje que se consolidan en nuevas formas de bios social.

El bios social se orienta a vislumbrar horizontes curriculares basados en la incertidumbre, el caos, la crisis y la complejidad, ¿cómo hacer de la existencia, la formación y las sociedades mismas un asunto vital del currículo?

Por tanto, la emergencia curricular debe atender a múltiples miradas, donde se aborde el currículo como:

- Un proceso de construcción.

- Un proceso de adaptación.

- Una opción para contextualizar.

- Una búsqueda de la verdad.

- Un proceso de formación integral.

- Una opción de crecimiento.

- Un proceso de negociación.

- Una estrategia de apropiación de...

- Un camino de transformación.

- Una posibilidad de..., para...

- Un proceso de desarrollo de...

- Un pacto de convivencia para...

- Un proceso de construcción de la cultura.

- Un proyecto de vida.

- Un texto.

- Una mediación. 


\section{Episteme curricular: del saber pedagógico al saber escolar}

Entender el currículo desde la pedagogía como un saber, de naturaleza neta disciplinar, implica que la naturaleza de los conocimientos y saberes que circulan en torno a ella son diversos, alega que sus perfiles epistemológicos se enmarcan desde una perspectiva compleja, en el sentido que se evidencia diversidad de formas de pensamiento que remiten a epistemes distintas como: los mitos, la filosofía, las ideologías, las ciencias y las artes. El sustento de los conocimientos que afecta dichas epistemes remite a una tradición teórica, y la forma como se presentan para el cosmos mental remite a una estructura esencial, distinta a conocimientos y saberes que indican una tradición problemática y que en su configuración envían a una estructuración a partir de las prácticas que corresponden al acontecimiento.

El modo como el acontecimiento curricular estratifica a la pedagogía corresponde a la visión de lo pensado y lo impensado. Lo pensado corresponde a las dinámicas que se dan en torno a la ley y los desarrollos que corresponden a la escuela, la enseñanza, el aprendizaje, la formación y la trasposición didáctica que se institucionaliza y genera una organización jerárquica que delimita el campo de conocimiento escolar, estratificado por categorías como acontecimientos, conceptos, conocimientos escolares, imágenes de pensamiento, entre otros. Por otra parte, se da la dimensión de lo impensado, que corresponde al movimiento de la memoria activa del saber pedagógico que afecta el campo y renueva de modo caótico la estructuración del campo. Derivado de este proceso se resignifica el modo de entender la escuela, las prácticas docentes, las propuestas curriculares, los proyectos pedagógicos, los sistemas educativos y el saber pedagógico mismo, a partir del sujeto que produce prácticas y no teniendo como referencia la institución, la ciudad o el Estado, que emergen a partir de este.

En esta perspectiva hay que distinguir que no se trata de imponer un modo de análisis epistemológico a priori a un conjunto de conocimientos, sino que se trata de instalarse en las condiciones como aparecen los conocimientos para componer o producir un modo de análisis epistemológico. No se trata de un ejercicio de formalización, validación y adaptación especulativo de los conocimientos a lo epistemológico, sino de reconocimientos, rastreo, experimentación, encuentro de las condiciones de 
producción de los conocimientos en un espacio determinado, donde estos aparecen inscritos en las prácticas de conocimientos que agrupan creencias, hipótesis no verificadas (que con el tiempo pueden ser demostradas o refutadas) y elecciones conceptuales provisionales que se evidencian en el modo de los discursos que remiten a un saber.

El proceso de análisis epistemológico puede proceder con referencia a la práctica discursiva, que aparece como evidencia de los acontecimientos que se inscriben en el orden del pensamiento, a través de los conceptos usados para rastrear un saber que se puede construir en una ciencia o no, que, a su vez, remite a una epistemología arqueológica y genealógica (Fayad, 2010).

La epistemología arqueológica y genealógica nos ubica en una perspectiva que se puede encontrar con la problemática de situarse en la naturaleza de un saber que aparece difuso y poco demarcado en su formalización epistemológica, pero que configura epistemes. Como el saber pedagógico, que se concentra a partir de conceptos, saberes y discursos en una dinámica recurrente, en contraste con la epistemología cuando se piensa en ella como aquella búsqueda que se constituye en un rastreo de estructuras inmutables dentro de las cuales deba estar contenido el conocimiento, la vida, la sociedad y la cultura.

La forma de estas dimensiones influye a los sujetos y deriva en procesos de determinación. Lo que implica pensar de un modo diferente la perspectiva epistemológica (como en el saber pedagógico), estratificando nuevos espacios, nuevas condiciones que permitan reflexionar; donde se están creando, a partir de las múltiples experiencias de los sujetos, nuevas formas de indagar, de pensar, de conocer, que remiten a epistemes que bien podrían ser valoradas por los análisis epistemológicos para el despliegue del campo de conocimientos escolares. Este campo puede estar agenciado por epistemes que emergen y desaparecen de acuerdo a las orientaciones del momento.

Debido a la saturación del espacio escolar con las rupturas de los distintos tipos de conocimiento y las distintas formas de pensamiento, gatillados por prácticas de distintos perfiles, se ponen de manifiesto las competencias de conocimientos que aíslan, fragmentan, especializan, desvirtúan el sujeto. Dicho esnobismo da pie a la colonización del sujeto por parte del imperio. 
¿Qué hacer para que la escuela responda de modo crítico, es decir, desde una perspectiva ético-política a la colonización del imperio? Hay que recomponer la potencia de las prácticas docentes a partir de una mirada de conjunto y conocimientos escolares pertinentes que dialoguen con los diferentes tipos y perfiles epistemológicos de los conocimientos.

El conocimiento pertinente es el que es capaz de situar toda información en su contexto y, si es posible, en el conjunto en la que esta se inscribe. Inclusive, es posible decir que el conocimiento progresa, principalmente no por sofisticación, formalización y abstracción sino por la capacidad para contextualizar y totalizar. Morin (2002).

Tal pretensión de recomponer un fuerte sentido simbólico del conocimiento escolar permite la instrumentalización del conocimiento, pero al mismo tiempo la cualificación de este, el análisis y la síntesis, la tematización y la conceptualización, la separación y el encuentro y potenciar los modos de producción de este. El despliegue en bucle enseñanza-conocimiento, escolar-aprendizaje debe corresponder a la condición humana,

para afrontar la dificultad de la comprensión humana habría que recurrir no a enseñanzas separadas sino a una pedagogía conjunta que agrupe al filósofo, al psicólogo, al sociólogo, al historiador, al escritor y estos se conjugarían con una iniciación de la lucidez. Morin (2002)

La emergencia del currículo es un ejercicio crítico, desplaza y transforma al sujeto vivo que trasiega el camino, que se pregunta por el método que resuena en un agonismo con el a-método.

En comunidad se evidencian las seducciones, los amores y desamores de la relación altamente espiritual entre maestro y el aprendiz, las certezas e incertidumbres con el conocimiento, las demarcaciones de los campos disciplinares. Fundar comunidad y desarrollar currículo en emergencia implica reconocer al otro en sus contradicciones, en sus miedos, en sus claridades, en sus búsquedas, tantear la 
esencia del propio ser en la dialógica interactiva que nos permite experimentarnos como aprendices soberanos, saber cuál es el límite que el otro remite al tacto pedagógico, a la prudencia y a la lozanía.

\subsubsection{La conceptualización del currículo}

Ariel Ruiz Aguilera (2009) en el documento Teoría y práctica curricular, encara el asunto de la conceptualización de los currículos. Supone, en primer término, diferenciar la teoría del hecho curricular. Esta diferenciación cobra peculiar significación en el caso de las ciencias pedagógicas, tradicionalmente confundidas con un quehacer empírico, un arte o una técnica.

Adentrarse en los problemas epistemológicos sobre los currículos, en la construcción de su teoría, presenta ambigüedades en relación con el propio objeto de estudio.

La concepción curricular se ha centrado en el diseño de asuntos del deber ser. Sobre corrientes de pensamiento:

El positivismo, que señala el contenido como eje principal de los currículos. La Escuela Nueva y su énfasis en la relación profesor-alumno y la metodología en el hacer curricular, la tecnología educativa, que restringe a los problemas tecnológicos del hacer curricular.

Las corrientes reproductivas que parten desde la sociología del conocimiento y destacan la función conservadora de la educación, a reproducir el orden social imperante en una determinada sociedad.

Ariel Ruiz Aguilera en Teoría y práctica curricular realiza un recorrido de las concepciones curriculares, en especial desde la aparición en 1918 del libro de Bobbit denominado The curriculum, así:

- H. Taba (1962) es de la opinión de que los currículos son "un plan para el aprendizaje, en el que todo lo que se conoce sobre el proceso de aprendizaje y de desarrollo del individuo debe ser tenido en cuenta para su elaboración". 
- J. R. Johnson (1967) considera que los currículos son "una serie estructurada de resultados esperados (deseados) de aprendizaje, que prescribe (o al menos anticipa) los resultados de la enseñanza y no establecen los medios, o sea, las actividades, los materiales, o aun el contenido de enseñanza que se emplea para lograrlos”.

- R.W.Tyler (1973) señala que los currículos pueden ser considerados como "todo aquello que transpira en la planificación, la enseñanza y el aprendizaje de una institución educativa para sus propósitos, los currículos comprenden solamente los planes para un programa educativo".

- R. S. Zais es del criterio de que el término currículo es utilizado ordinariamente por los especialistas de dos maneras:

- Para indicar un plan para la educación de los alumnos (significado prescriptivo).

- Para identificar un campo de estudio (como disciplina). Es de la opinión que currículo es "aquello que debe ser llevado a cabo en las escuelas, es el plan o la planificación, por la cual se organizan los procesos escolares de enseñanza-aprendizaje”.

- R. Rodríguez sobre este aspecto brinda algunas concepciones de currículos que según su opinión, se han venido desarrollando a lo largo de la historia de la educación colombiana y donde aparecen conceptos de:

- Currículos como sinónimo del plan de estudio, donde se considera la distribución de asignaturas a lo largo de diversos años y semestres con una duración determinada.

- Currículos como sinónimo de disciplina, donde prevalece el criterio de que lo fundamental es el programa de estudio.

- Currículos como sinónimo de producto, donde lo predominante es la definición previa de los resultados que se espera obtener de los estudiantes. 
- Currículos como sinónimo de proceso, donde se considera el sistema como un esquema en el que existe una entrada (imput) y la salida (out-put), con una relación entre la entrada y la salida, sino tener dispuesto todos los elementos y aspectos que se encuentran en el proceso.

- Currículos como sinónimo de recorrido, que lo que se trata fundamentalmente es identificar y definir todos los espacios, los momentos y las acciones por medio de los cuales el estudiante va a pasar.

- Currículos como sinónimo de educación, en la que se distinguen las siguientes consideraciones:

- Currículo es todo lo que hace y ofrece la institución educativa para preparar a los individuos.

- Currículo es la suma de las experiencias que bajo la orientación de la institución educativa se ofrece a los niños.

- T. T. Da Silva (1994) dice que los currículos son "la creación, selección y organización del conocimiento escolar".

- O.Mader (1977) es de la opinión de que los currículos son “una representación del proceso educativo, que se fundamenta en la estructura de la personalidad y que abarca no solo el resultado propuesto sino también las vías hacia ese resultado y el progreso temporal derivado de las vías aplicadas".

- I. Stenhouse (1981) en este sentido expresa "nos encontramos al parecer, ante dos puntos de vista diferentes a cerca del currículum. Por una parte, es considerado como una intención, un plan o una prescripción, una idea a cerca de lo que desearíamos que sucediese en las escuelas. Por otra parte, se le conceptúa como el estado de cosas existente en ellas, lo que de hecho sucede en las mismas. Me parece esencial que el estudio del currículum se interese por la relación entre sus dos acepciones. Como intención y como realidad". 
- P. McLaren (1984) plantea que "los teóricos críticos de la educación (pedagogía crítica en la que él se incluye) ven los currículos como una forma de política cultural, esto es, como parte de la dimensión sociocultural del proceso escolar".

- E.A.Lucarelli (1985) presenta también algunas formulaciones desde diferentes perspectivas:

- Currículos como propuesta: conjunto de actividades que ofrece la educación educativa (sea cual fuere la amplitud de este concepto).

- Currículos como recurso material: documentos básicos instrumentales que norman y orientan el desarrollo del proceso de aprendizaje sistemático.

- Currículos como acción personal: conjunto de experiencias que vive el educando bajo la responsabilidad de la institución educativa en función de los objetivos de la educación.

- Currículos como logro personal (individual o social): resultado del aprendizaje alcanzado por el educando en función de los objetivos de la educación y bajo la orientación de la institución escolar.

- C. Coll (1987) considera el concepto de currículos “como el proyecto que preside las actividades educativas escolares, precisa sus intenciones y proporciona guías de acción adecuadas y útiles para los profesores que tienen la responsabilidad directa de su ejecución. Para ello, los currículos proporcionan información concreta sobre qué enseñar, cuándo enseñar, cómo enseñar y qué, cómo y cuándo evaluar".

- M. I. Castro (1989) es de la opinión que "los currículos plantean de manera estructurada los resultados que se esperan del proceso de aprendizaje, poniendo una determinada selección y organización de los conocimientos y 
ciertos criterios de evaluación, pero no determinan las estrategias didácticas que se utilizan para lograr dichos resultados".

- A. de Alba (1994) en este sentido expresa: "por currículos se entiende a la síntesis de elementos culturales (conocimientos, valores, costumbres, hábitos) que conforman una propuesta político-educativa pensada e impulsada por diversos grupos y sectores sociales cuyos intereses son diversos o contradictorios, aunque algunos tiendan a ser dominantes o hegemónicos y otros tiendan a oponerse y resistir a tal dominación o hegemonía”. Aunque más adelante al plantear que "los elementos culturales se incorporan en él no solo a través de sus aspectos formales-estructurales, sino que también, por medio de las relaciones sociales cotidianas en las cuales los currículos formales se despliegan, deviene práctica concreta", se produce una coincidencia con Mader en considerar a los currículos no solo una propuesta, sino también práctica concreta.

- El Ministerio de Educación Nacional de Colombia (1994): el currículo en el espíritu de la nueva educación debe ser entendido como el conjunto de actividades y procesos que intencional y consensualmente se programen para cumplir con los objetivos de la educación expresados en la Ley 115 y en cada proyecto educativo institucional.

Estos, como el estudio también de otros prestigiosos autores tales como: R. M. Gagné (La planificación de la enseñanza, 1967); D. Engler (Intructional technology and the curriculum, 1970); D. Ausubel (Algunos aspectos psicológicos de la estructura del conocimiento, 1973); A. Díaz Barriga (Didáctica y currículum, 1984); M. W. Apple (Ideología y currículo, 1982), posibilitan llegar a la conclusión de que las distintas concepciones conceptuales sobre currículos pueden agruparse de forma general en:

- Las que consideran los currículos como contenido.

- Las que consideran los currículos como planificación.

- Las que consideran los currículos como realidad interactiva.

Ariel Ruiz Aguilera en el documento Teoría y práctica curricular expresa paradigmas curriculares predominantes que están determinados según las posiciones que se adopten desde el punto de vista filosófico, epistemológico, sociológico y psicológico. 
Ruiz (2009). En lo filosófico y en lo epistemológico existen diferentes clasificaciones teóricas del conocimiento:

1. Por la posibilidad del conocimiento:

El dogmatismo: certeza absoluta de la realidad sujeto-objeto, el conocimiento es inexistente.

El escepticismo: niega la posibilidad de la relación sujeto-objeto.

No existe la verdad.

El subjetivismo: muy vinculado con el escepticismo. No existe la verdad universal, sino la verdad individual.

El relativismo: también vinculado al escepticismo. No existe la verdad absoluta. La verdad es relativa, depende de factores externos.

El pragmatismo: también vinculados a los escépticos. La verdad es lo útil.

El criticismo: acepta la existencia del conocimiento pero examinado, reflexivo y crítico. Posición intermedia.

2. Por el origen del conocimiento:

El racionalismo: la razón es la fuente principal del conocimiento, necesaria, universal.

El empirismo: la experiencia sensible como único origen del conocimiento.

El intelectualismo: tanto la experiencia como el pensamiento contribuyen a la construcción del conocimiento. 
El apriorismo: mediador entre el racionalismo y el empirismo. Elementos a priori que no dependen de la experiencia.

3. Por la esencia del conocimiento:

El objetivismo: relación sujeto-objeto. El objeto determina en el sujeto.

El subjetivismo: relación sujeto-objeto. El sujeto determina en el objeto a través de la conciencia.

La dialéctica:

- Interaccionismo simbólico: solo es relevante lo vivido.

- Dialéctica: tanto el hecho como el propio creador del sujeto.

El realismo: existen cosas reales fuera de nuestra conciencia. Las cosas son tal como las percibimos.

El idealismo: niega la existencia de las cosas reales independientemente de nuestra conciencia.

El fenomenalismo: punto intermedio entre realismo e idealismo. No reconoce las cosas como son en realidad, sino como nos parece que son. Las cosas son pero no son.

\section{Etimología del currículo}

Etimológicamente currículo se deriva de la expresión latina currículum, cuyo significado es "carrera", "caminar", "jornada", contenido en sí, la idea de secuencia y continuidad. El concepto currículo ha sufrido variaciones debido a cambios sociales y culturales: a la evolución de la ciencia, a las transformaciones técnicas y tecnológicas.

En la Europa medieval, donde la escuela estaba en la élite, el currículo se refería a las asignaturas que componían el Trivium (gramática, retórica y didáctica) en el primer ciclo, y al Quadrivium (aritmética, geometría, música y astronomía) en el 
segundo ciclo. Para el resto de la población, el aprendizaje se limitaba a adquirir un oficio mediante la observación del maestro.

Después aparecen las lenguas clásicas y orientales, la historia y la literatura en el espacio curricular. Ya en el siglo XVI por el trabajo científico, se modifica el concepto vigente del hombre, la naturaleza y el universo, situación que incide en la estructura curricular. Se logra incorporar la ciencia en los currículos universitarios, los cuales se siguen considerando como asignaturas a curar. Dicho concepto perduró hasta el siglo XIX, época en que John Dewey, de la Universidad de Chicago, trata de demostrar que el alumno aprende mejor a través de la experiencia, iniciando el cambio conducente al "currículo a base de experiencia", que tendría amplia aceptación a partir de la década de los treinta.

La primera definición de currículo significando conjunto de experiencias de aprendizaje, surgió con Bobbit (1918): "serie de actividades que los niños y los jóvenes deben hacer y experimentar a fin de desarrollar habilidades que los capaciten para decidir asuntos de la vida adulta”.

En 1935, Caswell, quien considera poco fructífero el papel de los textos en la instrucción, adopta el concepto de currículo como experiencia: "el currículo escolar comprende todas las experiencias del alumno bajo la orientación del profesor”.

En 1950, el propio Caswell amplía el concepto diciendo: "Currículo es todo lo que acontece en la vida de un niño, en la vida de su país y de sus profesores. Todo lo que rodea al alumno en todas las horas del día, constituye materia para el currículo. En verdad el currículo ha sido definido como el ambiente en acción”.

Harold Rugg (1927) había establecido que en la planeación del currículo se requerían tres aspectos: objetivos, actividades y materiales requeridos y la organización de los mismos.

\subsubsection{Fundamentación teórica del currículo}

Para el Ministerio de Educación Nacional de Colombia en el año 1980, se generó la discusión por el tipo de hombre a formar. Para ello, se planteó el documento 
fundamentos generales del currículo, así:

\subsubsection{Fundamentos filosóficos}

La educación constituye uno de los procesos utilizados por la sociedad para moldear a su imagen las nuevas generaciones. Mediante ella, re-crea en los educando sus modos de pensar, de sentir y de actuar, y les ofrece a estos las posibilidades para desarrollar su personalidad y participar en la transformación de la realidad.

Las ideas, valores, sentimientos y costumbres que definen la identidad de una sociedad, definen también el prototipo de hombre propio de dicha sociedad.

\section{A. El hombre como ser cultural}

Como producto de la cultura, el hombre puede, a su vez, crear cultura, conservarla, transformarla y perfeccionarla. Gracias a su ser cultural, el hombre es el único que, en forma dialéctica, es simultáneamente "creador y criatura", el único que puede decidir cómo se organizará socialmente, el tipo de instituciones que lo regirán, el conjunto de valores que orientarán su comportamiento y las creencias que fortalecerán sus esperanzas.

Se debe destacar que el mundo cultural actual está profundamente condicionado por la ciencia y por la técnica. Su uso se ha hecho tan imprescindible que el hombre solo podrá vivir y sobrevivir en la futura cultura mundial, en la medida en que sea capaz de apropiarse de la ciencia y la técnica del mundo posindustrial.

\section{B. El hombre como ser histórico}

Las creaciones culturales definen finalmente la historia. Una historia sin meta prefijada, precisamente, porque la tendencia fundamental que rige su devenir es la toma de decisiones por parte del hombre, su protagonista. Esto explica en buena parte, entre otras cosas, la variedad y al mismo tiempo el devenir de las culturas: el hombre estará siempre en plan de crear su propia cultura y de transformarla de conformidad con el acontecer histórico, al mismo tiempo que se crea y se transforma a sí mismo. 
En esta historicidad del hombre, radica su grandeza y su dignidad. En el pasado se pensó que el carácter de "inacabado" del hombre era expresión de su inferioridad. Hoy en día, la toma de conciencia del significado de la historia, el saber que el futuro está en sus manos y que a partir de su libertad puede moldear su ser individual y social, es la base de su dignificación y de la dignificación de todo trabajo humano.

\section{El hombre como ser social}

La sociedad es una totalidad estructurada económica, política y culturalmente. Tanto ella como sus elementos están sometidos al devenir histórico en forma relacionada e interdependiente. Por consiguiente, el hombre formado dentro de una estructura social dada estará sometido a la historicidad de la misma.

El proceso educativo, en cuanto medio utilizado por la sociedad para moldear nuevas generaciones, necesariamente tendrá que ajustarse a la historicidad del ser social y a las exigencias de la cultura en su devenir histórico.

\subsubsection{Fundamentos epistemológicos}

Nuestra sociedad, como muchas otras del globo, está afrontando el desafío de armonizar la identidad cultural alcanzada a lo largo de una tradición histórica de raíces indígenas, ibéricas y africanas con las tendencias modernizantes de la llamada “cultura científica y tecnológica”. No basta la yuxtaposición de elementos tradicionales conservados sin razones teóricas y por un cierto romanticismo, con elementos científico-técnicos adoptados por el deslumbramiento y, reducidos en muchos casos, a una mera erudición que en nada ayuda a comprender y a transformar nuestra realidad, sino que es necesario apropiarnos oportuna $y$ creativamente de los resultados de las ciencias y las tecnologías foráneas, creando productos científicos y tecnológicos adecuados a nuestra propia realidad.

\subsubsection{Fundamentos sociológicos}

El proceso educativo no solamente presupone una concepción del hombre sino que debe tener en cuenta el tipo de sociedad en función de la cual deberá 
organizarse dicho proceso. De aquí la necesidad de comprender las relaciones que existen entre sociedad y educación.

\subsubsection{Fundamentos psicológicos}

La pedagogía siempre se ha basado en las ideas que la sociedad tiene sobre la infancia y el desarrollo humano en general. Dicho conocimiento ha generado una cultura pedagógica que orienta el diseño del currículo y el proceso enseñanza-aprendizaje. Hoy en día, por las razones de limitación de los estudios e investigación hechos en la psicología, el desarrollo humano se trata en relación con los siguientes aspectos de actividad:

- Psicomotricidad.

- Inteligencia.

- Socio-afectividad.

\subsubsection{Plan de estudios}

El plan de estudios es una estrategia para desarrollar intencionalmente el currículo de la educación formal. Debe dar respuestas en cuanto al qué, al cómo, al para qué y al cuándo del quehacer educativo, con miras a satisfacer las necesidades y expectativas que la comunidad y cada estudiante tienen con respecto a la institución. Los mismos interrogantes se plantean para la evaluación y seguimiento de los procesos formativos y administrativos de acuerdo con el proyecto educativo institucional.

Los grupos de áreas obligatorias y fundamentales, las áreas optativas y los temas de enseñanza obligatoria se organizan para conformar el plan de estudios propio de una institución. Su enseñanza no se desarrolla siguiendo estrictamente la lógica interna del área, como se hace tradicionalmente, de acuerdo con un determinado programa curricular, sino que sus contenidos se utilizan como instrumentos (criterios, fuentes de conocimientos, de métodos, de estrategias), para lograr los propósitos de los proyectos pedagógicos sobre bases teóricas construidas y apropiadas por los involucrados en el proyecto. 
El plan de estudios se estructura con base en principios, normas, criterios y enfoques que orientan la concepción y desarrollo de cada uno de los grupos de áreas obligatorias y fundamentales y de áreas optativas, así como la de los temas de enseñanza obligatoria. Incluye, por lo tanto, la explicitación de objetivos por niveles y grados, la organización y distribución del tiempo, el establecimiento de criterios didácticos (metodológicos) y criterios de administración y evaluación de acuerdo con el proyecto educativo institucional y con las disposiciones legales vigentes.

Lo que hace el plan de estudios es organizar a través de proyectos pedagógicos (asignaturas u otro tipo de actividades), el conjunto de arras y temas previstos en la ley y en el proyecto educativo institucional, de tal manera que les de la organicidad necesaria para adelantar el proceso pedagógico con la sistematicidad requerida.

Dentro de esta nueva manera de desarrollar el plan de estudios, además de los trabajos por proyectos, puede haber, como parte de ellos, clases formales de las áreas para ampliar, estructurar o afinar lo ya trabajado, para facilitar una nueva sesión del proyecto o para despertar inquietudes hacia niveles más avanzados de conocimiento. Pero en todo caso no se trata de desarrollar dos currículos paralelos y repetitivos.

\subsection{4. Área de conocimiento, disciplinas y áreas de formación}

Un área de conocimiento está estructurada por una o varias disciplinas. Una disciplina se caracteriza por poseer un cuerpo propio de conceptos, principios, teorías, etc., y un cuerpo propio de métodos y procedimientos que facilitan la construcción y apropiación de ese conocimiento.

Un área de formación se estructura con propósitos de desarrollo integral a partir de diferentes disciplinas provenientes de una o más áreas del conocimiento.

Si el proceso educativo está centrado en el educando y si lo que busca es el pleno desarrollo de sus potencialidades, se hace necesario que el concepto de área también sea revisado. En la medida en que la necesidad de aprender se presenta durante toda la vida, el desarrollo de las áreas debe dar importancia al cultivo de habilidades para descubrir; criterios para analizar y tomar decisiones; 
desarrollo de valores, actitudes emprendedoras, conciliadoras, solidarias; estrategias cognoscitivas, comunicativas y ante todo, gusto por la búsqueda y el uso consciente del conocimiento.

Para ello, cada área debe concebirse como un espacio que posibilita experiencias educativas, donde se plantean y analizan diversas formas de entender el mundo, de explicarlo, de argumentar, de dar sentido a la acción; donde se conocen procedimientos para anticiparse a los problemas, para afrontarlos y resolverlos; donde se incentiva desde varias perspectivas el cultivo de las múltiples potencialidades y aptitudes humanas, se viven procesos que permiten a cada uno ubicarse, comprometerse y crecer en sus relaciones con el ambiente, con los demás y consigo mismo; se descubren fuentes de criterios y de conocimientos; se aprende a ser autónomo y a tomar decisiones responsablemente, se abren espacios y tiempos para valorar y disfrutar el mundo, etc. Pasearse por las ciencias y las artes y descubrir cómo entienden, analizan, afrontan, viven y disfrutan la vida los filósofos, los literatos, los artistas, los matemáticos, los sociólogos, etc., constituye una experiencia que hace de la institución educativa un espacio que incentiva a cada uno de sus integrantes a buscar su pleno desarrollo y a comprometerse en la búsqueda del bien común. Para dar un ejemplo, veamos como María Elena Ronderos concibe el área de educación artística:

El objeto de estudio de la educación artística es la experiencia estética: un modo particular de comprender el mundo, de sentir, de contemplar, de expresar, de representar y de apreciar la naturaleza, los demás, la producción y reproducción cultural y la historia; un modo particular de disfrutar el mundo.

Esta concepción exige un trabajo interdisciplinario y un desarrollo no lineal de las áreas. Los materiales educativos computarizados al introducir y generalizar el manejo de menús están socializando el acceso a los temas según el interés del estudiante y no según la lógica de la estructura interna del área de conocimiento. Para resolver las dudas que puedan presentarse, los menús ofrecen ayudas y tutorías. Este hecho cuestiona la forma actual de desarrollar los planes de estudio. En forma similar, si para una actividad de las que se desarrollan en un proyecto se necesitan conocimientos que no han construido los estudiantes, habrá que 
ofrecer paralelamente algunas jornadas de estudio de una o varias áreas, pero la tendencia es a no esperar largos periodos para tratar el tema que se necesita o que interesa.

Los grupos de áreas obligatorias y fundamentales y de áreas optativas, se constituyen en instrumentos para la comprensión, el análisis y el tratamiento de los problemas que se han seleccionado en esa síntesis cultural de la que hablábamos antes.

Desde hace unas décadas tanto el currículo como el plan de estudios han estado centrados en las áreas. Desarrollar el programa de cada una ha sido una tarea a la cual hemos dedicado grandes esfuerzos, animados por la convicción, honesta pero tal vez falsa, de que al "cumplir" con los programas se garantizaba la formación integral y el desarrollo humano. Ahora se estudiarán las áreas con una visión que se ha venido proponiendo y que algunos han llevado a la práctica pero todavía no se ha generalizado, y es la de que se las trabaje en cuanto contribuyan a la formulación, el análisis y las propuestas de solución de los problemas seleccionados, ya no por ellas mismas. Esto exige cambios profundos en la mentalidad, en la metodología empleada y en los resultados esperados.

Los maestros y maestras y los alumnos y alumnas que comprendan y analicen las áreas en forma semejante tendrán metas diferentes a las tradicionales, así como también asumirán roles y metodologías diferentes.

\section{Áreas obligatorias y fundamentales y áreas optativas}

El concepto de área obligatoria y fundamental hace referencia a un cuerpo de conocimientos y valores, habilidades y destrezas, estrategias cognoscitivas y actitudes que, según la Ley General de Educación, no pueden faltar en la formación integral del individuo. El concepto de área optativa hace referencia a un cuerpo de conocimientos y valores que, de acuerdo con la filosofía del PEI y la fundamentación conceptual del currículo, interesan específicamente a ciertas personas, dadas sus inclinaciones vocacionales y las necesidades sociales, y, que por lo tanto, es necesario ofrecer, de manera que los estudiantes puedan escoger libremente. Las áreas optativas deben estar integradas al plan de estudios de tal manera que se articulen con las demás en igualdad de condiciones. No pueden 
ser consideradas como agregados de segundo orden, como las "costuras" que se incluyen en los planes de estudios actuales.

\section{Asignatura y proyectos pedagógicos}

Una asignatura es, en el marco de lo que venimos planteando, un momento, un periodo de tiempo que se destina en el horario semanal para llevar a cabo ciertas actividades propuestas dentro del plan de estudios. En una asignatura se establecen relaciones entre distintos elementos de una o de varias áreas (obligatorias y optativas y de temas de enseñanza obligatoria), para realizar un propósito determinado de un proyecto pedagógico que se desarrolla a través de diferentes estrategias pedagógicas.

Así entendida, la asignatura permite acudir a las áreas, no como fines en sí mismas, sino como medios para satisfacer necesidades e intereses, resolver problemas, desarrollar potencialidades y valores, satisfacer expectativas, etc. Cada asignatura constituye entonces un ambiente educativo donde se discute el conocimiento subjetivo y se confronta con el de los otros, a la luz del saber socialmente acepado y formalmente presentado desde cada ciencia o disciplina.

Como ya lo habíamos insinuado, una asignatura hace parte de un proyecto pedagógico (aunque estos no se agotan en asignaturas), de tal manera que entrando en relación con otras actividades programadas para desarrollarlo, se garantiza la flexibilidad necesaria para no tener que seguir una secuencia temática muy rígida, que como sucede ahora, hace que los maestros corran durante todo el año para alcanzar a cumplir el programa.

Una asignatura no necesariamente corresponde con un área; ella puede integrar los contenidos de varias áreas, con el rigor necesario, buscando siempre que la formación se produzca a partir de un aprendizaje con sentido y significado para los estudiantes. Ahora bien, una asignatura puede tener como eje una disciplina particular, pero alrededor de ella puede integrar las áreas que sea pertinente por su afinidad epistemológica, o por el interés y significado que tenga para el grupo de estudiantes. 
En conclusión, las asignaturas más que una secuencia temática de contenidos pertenecientes a una ciencia, deben ser un tiempo y un lugar para el conocimiento y la formación integral, donde se sistematizan contenidos y problemáticas afines entre sí y con la cultura y los intereses de los y las estudiantes.

Un proyecto pedagógico es un conjunto de actividades programadas para alcanzar objetivos propios de la formación integral de las personas que participan de él. Se caracteriza por que no se desarrolla en un tiempo y con una secuencia temática rígida. Puede girar en torno a una problemática o un tema específico, pero su relación con la vida y la cotidianidad es mucho más directa, de tal manera que tal problemática será asumida de manera holística para atender la complejidad y la diversidad con que se manifiesta la vida. Aunque las actividades de evaluación se desarrollen permanentemente, deben preverse, además, momentos especiales para retomar lo hecho y proyectar el camino a seguir.

Los proyectos pedagógicos le darán cauce al currículo en su conjunto. Por ello, se pueden programar para la educación formal, la no formal y la informal. Aquellos proyectos relacionados con los planes de estudio de la educación formal, pueden desarrollar una o varias asignaturas simultáneamente.

Dentro de esta concepción, el proceso formativo no se limita a lo estrictamente académico previsto en las asignaturas, sino que abarca también todos aquellos contenidos, académicos o no, que se desarrollan dentro de un proyecto pedagógico, ya sea con fines de sistematizar contenidos específicos, o de llevar a cabo lo que comúnmente se ha denominado como actividades complementarias, como un centro literario, una salida de campo, una feria, un concurso, etc., que no estaban previstos dentro de ninguna de las asignaturas. Como puede apreciarse, un proyecto pedagógico contempla tanto asignaturas, como actividades de formación y sistematización y actividades complementarias que surgen espontáneamente durante su desarrollo.

\subsubsection{Marcos generales del currículo}

El Ministerio de Educación, en el año 1980, como proceso de la renovación curricular colombiana, estudia los objetos curriculares por cada área de saber, 
convocando a los técnicos de los Centros Experimentales Piloto, quienes desde su saber y experiencia plantean por cada área su marco general, así:

\section{Área de ciencias sociales}

Esta área pretende formar un alumno capaz de comprender y explicar los fenómenos sociales de manera integrada desde una perspectiva interdisciplinaria. Razón por la cual, además de geografia, historia y cívica, contiene elementos de economía, antropología, sociología, política, arte y religión.

El enfoque tiene en cuenta la vida cotidiana, puesto que allí el niño encuentra los elementos que más tarde van a constituir la explicación científica. En la vida cotidiana tenemos afirmaciones, observaciones, creencias, normas y valores que pueden analizarse sistemáticamente. De esta manera, se busca crear conciencia en el niño de que los fenómenos sociales pueden ser estudiados científicamente. Dicho en otros términos, en sociales hay observaciones, se hacen conjeturas, se formulan y aprueban hipótesis, se sacan conclusiones, hay inferencias, se plantean problemas y se pueden proponer soluciones.

Es importante advertir que las ciencias sociales tienen una naturaleza propia. No es lo mismo explicar un fenómeno físico que uno socio-cultural, en donde entre otras cosas, entran en juego muchos intereses, sobre todo aquellos que tienen que ver con la formación para el ejercicio de la democracia, es decir, para participar libremente en la vida social y política, respetar otros puntos de vista, tomar sus propias decisiones.

La estructura del área comprende no solo las relaciones espacio-temporales sino las relaciones económicas, jurídico-políticas y saberes y expresiones colectivas.

El alumno además de conocer el pasado debe tener claridad, en su momento, de los fenómenos de la producción del mercado, del consumo; debe tener conocimiento de la organización política, debe familiarizarse con los elementos del arte, y entender las costumbres, los modos de vida de cada región, las creencias religiosas, los mitos, las leyendas. 


\section{Área de ciencias naturales y salud}

Por la naturaleza del área, se pretende contribuir en la formación de una concepción científica del mundo por parte del estudiante. Más que la transmisión de un conjunto de conocimientos, importa la formación integral del alumno, en correspondencia con los elementos sociales de su región y el país. Que el estudiante interactúe con la naturaleza, se formula preguntas y dé sus propias respuestas, busque sus propios resultados, en fin, que construya los conceptos de acuerdo a los intereses y necesidades que se le presenten.

El área está concebida a partir de la estructura del universo, organizado en grandes y pequeños sistemas que tiene como base la materia y la energía, que se encuentran en el espacio y en el tiempo. Por ejemplo: las galaxias, el sistema solar, el planeta tierra, con diferentes estados de los elementos y compuestos, la fuerza y el movimiento, los biomas, los ecosistemas, las comunidades, las poblaciones y los individuos. Se tienen en cuenta los cambios y la conservación de los distintos componentes de los sistemas que interactúan.

Con esto se pretende que el alumno adquiera y desarrolle habilidades, destrezas, conocimientos, actitudes, hábitos y valores que le permitan participar en la comprensión y solución de la vida diaria. Como en las demás áreas, se procurará integrar las distintas disciplinas que la conforman, ellas son: biología, física, química, las ciencias de la tierra y del espacio y la salud, que se desarrollan en todos los grados, siguiendo los procesos de enseñanza-aprendizaje activo, de modo que a partir de totalidades o sistemas globales, se avanza abordando el mundo macroscópico o explorando el mundo microscópico.

\section{Área de matemáticas}

El área de matemáticas busca superar algunas de las dificultades que durante muchos años han impedido una buena educación en esta área.

La propuesta requiere del docente un trabajo continuado de reflexión sobre la construcción del conocimiento por parte de los alumnos y sobre la búsqueda y construcción permanentes de una metodología apropiada que permita partir de 
su realidad, y apoyarse en sus vivencias para construir y organizar los conceptos y emplear símbolos inventados por ellos o aceptados culturalmente.

Después de comprobar que el procedimiento pedagógico usual de pasar de los sistemas simbólicos a los conceptuales lleva, en muchos casos, a la manipulación mecánica de símbolos y a la repetición de definiciones de memoria, se considera conveniente partir de la investigación de los sistemas matemáticos (y aun prematemáticos) que ya se han vuelto concretos y que ya manejan de alguna forma los alumnos, para que con la actividad sobre ellos surjan los sistemas conceptuales que se desea que ellos contribuyan. Cuando ya se manejan los conceptos en forma de modelos mentales, actividades motrices, gestos y lenguaje ordinario, se procede a introducir los sistemas simbólicos como abreviaturas de dicho lenguaje, a inventar nuevos sistemas simbólicos y a traducir estos a los sistemas usuales de los libros de matemáticas.

De acuerdo con lo anterior, cualquier sistema matemático comprende:

- Sistemas simbólicos que aparecen a primera vista, con símbolos verbales del lenguaje ordinario y con símbolos formales u otros sistemas de representación gráfica.

- Sistemas conceptuales, que son los más importantes.

- Sistemas concretos, que no necesariamente son objetos materiales, sino sistemas matemáticos (y aun prematemáticos) que ya maneja el alumno, y que por la familiaridad con ellos han pasado de ser abstractos a ser concretos para ellos.

Cada uno de estos sistemas incluye:

- Un conjunto de componentes, elementos u objetos con los que juega.

- Un conjunto de trasformaciones, operaciones u acciones sobre ellos.

- Un conjunto de relaciones entre los mismos.

Con este sencillo análisis de cada sistema matemático que quiere trabajar con sus alumnos, el docente puede plantear las actividades que conduzcan a 
la construcción del sistema conceptual por parte del alumno y a su eficiente manejo simbólico.

\section{Área de español y literatura}

El área de español y literatura es básica para la formación y el desarrollo integral del alumno. Se propone un enfoque y una metodología mediante la cual el alumno utiliza su lengua para la comunicación y entendimiento con los demás y para la adquisición de conocimiento y construcción del pensamiento.

La estructura de los programas curriculares está centrada en dos grandes bloques: el primero es la lengua como instrumento del pensamiento, del conocimiento y de la comunicación y el segundo, la lengua como objeto de estudio.

Es fundamental que el alumno maneje con propiedad la lengua, que sea capaz de hacerse entender oralmente y por escrito, y pueda interpretar todos los signos apropiadamente.

La lectura comprensiva, crítica y productiva; la narración de historias y cuentos; los diálogos, descripciones de objetos y situaciones; la interpretación adecuada de todo signo; el conocimiento y uso racional de los libros y medios de comunicación masiva, serán los instrumentos para el desarrollo de procesos y habilidades comunicativas.

La lengua se toma especialmente en su uso cotidiano y en lo relacionado con su expresión estética que es la literatura.También se estudia la lengua científicamente según sus propias normas y se analiza desde la perspectiva fonética y fonológica en la entonación y pronunciación; la morfosintáctica, en el orden del discurso y de las palabras y principalmente desde el punto de vista de la semántica es decir, el de la significación.

\section{Área de educación estética}

En esta área se busca, en primer lugar, que el niño se familiarice con las manifestaciones estéticas de su región: que avance hacia las manifestaciones culturales de la nación y finalmente se aproxime a las diferentes manifestaciones 
estéticas de nivel universal. En la estructura del área se concibe la educación estética como otro lenguaje que se expresa en función de los diferentes sentidos, y cada uno de estos se va a concretar en una determinada manifestación estética, sea desde el punto de vista plástico, como sería en la pintura, la escultura, la arquitectura o desde el punto de vista musical. En la música se busca familiarizar al niño con los ritmos y los instrumentos de la región y acercarlo a otras posibilidades. A todo lo anterior se agrega la expresión corporal, que se presenta particularmente en la danza, el teatro y la pantomima y en el movimiento y ritmo poéticos.

Como el caso de las otras áreas, en educación estética también se acentúan los procesos, es decir, no se busca que el niño memorice datos sobre música, pintura, arquitectura, etc., si no que se dé la oportunidad de manipular sus elementos constitutivos; se busca sobre todo no limitarlo y darle oportunidad para que se exprese libremente, buscando estimular la sensibilidad, la expresión y la creatividad en orden a la promoción de las actividades de valores estéticos.

\section{Área de educación física, recreación y deporte}

La educación fisica se presenta como un área cuyo objeto de estudio es el movimiento humano para contribuir a la formación, capacidad y mejoramiento integral del individuo. Es considerado como una unidad psicofísica que comprende aspectos motrices, de pensamiento, personalidad e interacción social, en busca del desarrollo, capacitación, fortalecimiento, conservación, equilibrio, recreación e identificación de las personas para que se desenvuelvan adecuadamente en su medio. Aquí se contemplan etapas referidas al proceso de madurez del educando en los aspectos que implican la secuencia motriz y con base en ellos, se propone los contenidos y actividades del área. Se toma como punto de referencia su potencialidad fisica, en un proceso de enseñanza y aprendizaje del movimiento, en forma global y específica.

Las etapas de presentación y enseñanza tienen en común el movimiento y el ejercicio que van cobrando complejidad en la medida en que avanza las edades y grados de escolaridad, desde la espontaneidad hasta la solución de problemas complejos como el deporte en una proyección que abarque las expectativas del hombre en cualquier nivel. Las rondas, los juegos; en general, la gimnasia, el atletismo, los deportes y los bailes folklóricos, constituyen la base del trabajo práctico. 
La recreación es un componente importante de los programas, debe fomentarse en el alumno y está implícita en el desarrollo de las diferentes áreas y apoyada en las actividades complementarias.

\section{Área de educación religiosa y moral}

Para comprender la presencia de esta área es preciso tener en cuenta el ordenamiento jurídico de la Nación, y el hecho de que el cristianismo es un componente fundamental de nuestra cultura dentro del respeto a la libertad de las conciencias y de los cultos.

Todos los programas se elaboran y desarrollan con la participación de instituciones, entidades y personas que conocen de la materia.

La estructura y la presentación de los programas del área de educación religiosa, se rigen por los mismos principios y por el mismo marco con los cuales trabaja la división de currículo, los objetivos y contenidos del área son definidos por la Conferencia Episcopal de Colombia.

La estructura comprende los siguiente componentes: la fe, entendida como experiencia religiosa y que como contenido de conocimiento se encuentra el Credo; Dios, como ser personal, considerado como el fundamento de la vida, de los valores y como modelo que responde a las aspiraciones más profundas del hombre. La iglesia, como comunidad que se prolonga en la historia al servicio del hombre como imagen de Dios y como capacidad para trascender la dimensión temporal de la vida y, finalmente, el mundo, como resultado de la acción divina y que el hombre debe crear.

\section{Área de idioma extranjero}

Además de los propósitos tradicionales de entrar en contacto con otra culturas y de disponer de un instrumento útil para la comunicación y la investigación, los programas recalcan en la importancia de la comprensión de lectura, debido a la necesidad que tienen los estudiantes que ingresan a la universidad de leer textos y los que se vinculan al mercado laboral en ciertos campos. Desarrollar la habilidad 
de la lectura, en cualquier idioma, es una exigencia frente a la gran cantidad de información escrita que se produce en nuestro tiempo.

Pero la lectura no es la única habilidad que se busca desarrollar.También el habla, la escucha y la composición escrita tienen lugar importante en el proceso de enseñanzaaprendizaje, según las características de los alumnos, sus intereses y necesidades.

Los programas, así mismo, proponen el enfoque comunicativo, con el propósito de enfatizar la competencia comunicativa antes que la gramatical.

\section{Área de educación en tecnología}

El área de educación en tecnología contribuye a la formación integral del educando. Tiene en cuenta la relación hombre-trabajo-naturaleza-cultura, en el proceso de construcción, difusión y, principalmente, de aplicación del conocimiento en la producción de bienes y servicios requeridos por la sociedad. También en la interacción regional de personas y la que se da con los objetos e instrumentos de trabajo. Así mismo, el área busca la racionalización de los procesos y productos mencionados para solucionar problemas y satisfacer necesidades básicas, procurando la seguridad personal, la higiene individual y el bienestar social.

El área se proyecta a través de todos los niveles del sistema educativo acentuándose en básica secundaria y especialmente en media vocacional. En esta última se ofrece a través de modalidades en agropecuaria, comercial, industrial, promoción de la comunidad, salud y nutrición, entre otras, dejando abierta la posibilidad de modalidades u opciones según las necesidades e intereses regionales o locales.

Todos los institutos docentes, de acuerdo con su disponibilidad, ofrecerán en básica secundaria y media vocacional uno o más programas de educación en tecnología. Si el plantel tiene orientación tecnológica, los programas de educación en tecnología de básica secundaria, deben orientarse hacia la modalidad seleccionada por el plantel; si hay dos o más modalidades, se ofrecerán programas de forma rotativa, procurando la debida secuencia de acuerdo con lo previsto, siempre en la perspectiva de generar y asumir valores, actitudes y comportamientos tecnológicos y contribuir a la trasformación y mejoramiento de la realidad. 
Como síntesis de las concepciones curriculares se ubica la tabla 10, en la cual se dan las tendencias desde el año 1950 hasta el año 2015.

Tabla 10. Concepciones curriculares

\begin{tabular}{|c|c|c|}
\hline DÉCADA & AUTORES & TENDENCIAS \\
\hline \multirow[t]{2}{*}{ De los 50} & Sailor y Alexander (1954) & Calificar los resultados escolares. \\
\hline & $\begin{array}{l}\text { Smith, Stanley y Shores } \\
\text { (1957) }\end{array}$ & $\begin{array}{l}\text { Disciplinar la escuela y los escolares, desde el } \\
\text { pensamiento grupal. }\end{array}$ \\
\hline \multirow[t]{3}{*}{ De los 60} & Kearney y Cook (1969) & Aprendizaje guiado. \\
\hline & Dottrens (1962) & Programación escolar. \\
\hline & Jonson (1967) & Guía educativa y de enseñanza. \\
\hline \multirow[t]{6}{*}{ De los 70} & Taba (1973) & Preparación cultural. \\
\hline & Rule (1974) & Experiencias escolares y de aprendizaje. \\
\hline & King (1976) & Psicopedagogía cultural. \\
\hline & Beauchamp (1977) & Planeación institucional. \\
\hline & Clazman y de Ibarrola (1978) & Objeto, unidades y dominios del aprendizaje. \\
\hline & Yung (1979) & Distribución social del conocimiento. \\
\hline \multirow[t]{9}{*}{ De los 80} & Berstein (1980) & Conocimiento educativo considerado publico. \\
\hline & $\begin{array}{l}\text { Acuña (1980) Glazman } \\
\text { y Figueroa (1980) Díaz- } \\
\text { Barriga (1981) }\end{array}$ & Adaptación social. \\
\hline & $\begin{array}{l}\text { Helibner (1981) Mc Neil } \\
\text { (1983) }\end{array}$ & Acceso al conocimiento. \\
\hline & Arredondo (1981) & $\begin{array}{l}\text { Contextos, fines y objetivos educativos, } \\
\text { recursos y medios para lograrlos. }\end{array}$ \\
\hline & Schuber (1985) & $\begin{array}{l}\text { Materias, actividades, tareas, conocimientos, } \\
\text { valores y actividades por desarrollar. }\end{array}$ \\
\hline & Whitty (1986) & Respuesta a valores y creencias sociales. \\
\hline & Apple (1986) & $\begin{array}{l}\text { Selección, organización y evaluación de } \\
\text { conocimientos. }\end{array}$ \\
\hline & Sarramona (1987) & $\begin{array}{l}\text { Programación de actividades socialmente } \\
\text { aprobadas. }\end{array}$ \\
\hline & Arnaz (1989) & Plan institucional de enseñanza y aprendizaje. \\
\hline
\end{tabular}




\begin{tabular}{|l|l|l|}
\hline De los 90 & Sacristán (1991) & $\begin{array}{l}\text { Conjunto temático } \\
\text { interdisciplinariamente. }\end{array}$ \\
\cline { 2 - 3 } & J. Tormes (1992) & $\begin{array}{l}\text { Lo explícito (intenciones, normas, contenidos) } \\
\text { y lo oculto (valores, actitudes, conocimientos } \\
\text { y destrezas) que se enseñan y se aprenden. }\end{array}$ \\
\cline { 2 - 3 } & Lundken (1992) & $\begin{array}{l}\text { Fines, contenidos, destrezas y métodos de la } \\
\text { enseñanza. }\end{array}$ \\
\hline $\begin{array}{l}\text { Siglo XXI } \\
\text { comienzos }\end{array}$ & Lafrancesco (1998) & $\begin{array}{l}\text { Principios, propósitos y procesos de formación } \\
\text { integral y social y medios para lograrla. }\end{array}$ \\
\hline
\end{tabular}

Fuente: elaboración propia.

\subsection{El código educativo colombiano}

El código educativo colombiano para el presente estudio se sitúa en la reforma, en la contra-contrarreforma y en la contra-contra-contrarreforma educativa, el proceso se visualiza en el presente cuadro. 
Tabla 11. Marco normativo colombiano

\begin{tabular}{|c|c|}
\hline NORMA & OBJETO \\
\hline Decreto 2277 de 1979 & Estatuto Nacional Docente \\
\hline $\begin{array}{l}\text { Constitución Política de } \\
\text { Colombia de } 1991\end{array}$ & Proyecto Político de País \\
\hline Ley 30 de 1992 & Ley de Educación Superior en Colombia \\
\hline Ley 115 de 1994 & Ley General de Educación \\
\hline Decreto 1860 de 1994 & Proyecto Educativo Institucional \\
\hline Decreto 1742 de 1994 & Estímulos para los investigadores \\
\hline Decreto 1902 de 1994 & $\begin{array}{l}\text { Subsidio familiar para la educación no } \\
\text { Formal }\end{array}$ \\
\hline Decreto 2904 de 1994 & Sistema Nacional de Acreditación \\
\hline Decreto 804 de 1995 & Atención educativa para grupos étnicos \\
\hline Decreto 707 de 1996 & Estímulos docentes \\
\hline Decreto 709 de 1996 & Programas de formación de educadores \\
\hline Resolución 2343 de 1996 & $\begin{array}{l}\text { Indicadores de logros para la educación } \\
\text { formal }\end{array}$ \\
\hline Ley 715 de 2001 & Sistema General de Participación \\
\hline Ley 734 de 2001 & Código Único Disciplinario \\
\hline Decreto 1278 de 2002 & $\begin{array}{l}\text { Nuevo Estatuto de Profesionalización } \\
\text { Docente }\end{array}$ \\
\hline Decreto 230 de 2002 & $\begin{array}{l}\text { Currículo, evaluación y promoción de } \\
\text { educandos }\end{array}$ \\
\hline Decreto 1290 de 2009 & Sistema de Evaluación y Promoción escolar \\
\hline
\end{tabular}

Fuente: elaboración propia. 



\section{CAPÍTULO 3 \\ REFERENTE METODOLÓGICO}

\subsection{Enfoque investigativo}

L

a investigación "Currículo regional en el departamento de Caldas, Colombia" es cualitativa de corte histórico-descriptivo, porque permite comprender racionalmente la vida, la cultura, la acción y el acontecer humano sin reducirlo a la simplicidad mecanicista, sin suprimir al sujeto, "sin negar la multiplicidad de perspectivas teóricas, ni la multiplicidad de lenguajes y de sentidos que caracterizan al ser humano" (Flórez, 1999, p.9), inmerso en contextos concretos de actuación con otros en los que produce significados que ponen en tensión el ethos instituido a la vez que re-significa su vida en relación, y se posiciona en un mundo al que constituye y por el que es constituido. Un mundo que se construye con la mediación del lenguaje y es interpretado también mediante el lenguaje. El currículo significa y se re-significa permanentemente.

La investigación cualitativa en su búsqueda de comprensión de la realidad social no es otra cosa que el resultado de un proceso participativo de construcción de los sentidos que los actores sociales le atribuyen a sus experiencias vitales, o dicho de otro modo, es una mirada desde adentro a lo que acontece en el afuera de la interacciones sociales, a lo que es rescatable desde la percepción, el sentimiento, la emoción y también la razón de quienes han vivido la experiencia y tienen la oportunidad de revivirla haciéndola consciente y refiriéndose a ella mediante el lenguaje como acontecimiento que les pertenece, en tanto, los ha constituido. Para Galeano (2003, p. 21), "la investigación cualitativa rescata y asume la importancia de la subjetividad, la intersubjetividad es vehículo por medio del cual se logra el conocimiento de la realidad humana y es su garante".

Además, "solo la perspectiva cualitativa permite asumir metodológicamente un carácter dialógico respecto a las creencias, las costumbres, los prejuicios, los sentimientos y las emociones, entendidos como elementos de análisis utilizados para producir conocimiento sobre la realidad humana" (Roldan, 2006, p. 27). Es en este acercamiento dialógico donde se recuperan los rasgos de subjetividad que 
subyacen en los procesos que se han construido socialmente. Es precisamente el encuentro entre el director con los actores, mediante la conversación profunda, el instrumento que más potencia la práctica interpretativa, razón de ser de todo estudio cualitativo, en la medida que "ofrece a ambos, al yo actuante y al observador que interpreta, no solo el simple acto significativo y el contexto o configuración de significado al que este pertenece, sino todo el mundo social es perspectivas plenamente diferenciadas" (Schutz, 2003, p. 38).

El estudio tiene enfoque cualitativo y se enmarca en un trabajo de tipo históricodescriptivo del currículo. Explora, y determina un análisis contextual del currículum y su relación con la productividad, con el ánimo de auscultar sus interacciones con la cultura y su incidencia en las prácticas pedagógicas.

\subsubsection{Características metodológicas}

Las características de la investigación signan un proceso así:
a. Constructo teórico-rastreoteórico
b. Confrontación teórico-práctica.
c. Investigación de campo.
d. Caracterización curricular.
e. Planteamientos curriculares.
f. Sistematización

\subsection{Procedimiento}

La investigación tránsito por las fases procedimentales así:

\section{Fase 1. Lectura comprensiva}

Consistió en un proceso de revisión y búsqueda de información sobre tópicos, teorías, y conceptos del currículo. Su análisis documental y el proceso experiencial.

\section{Fase 2. Lectura intertextual-comparativa}

Después de seleccionar y revisar antecedentes, teorías y conceptos curriculares, se organiza el conocimiento en lo que respecta a postulados y teorías de autores e instituciones que han abordado el currículo. 


\section{Fase 3. Relectura crítico-interpretativa}

Con base en las derivaciones de las fases previas, la investigación construyó arquitectónicamente su discurso desde una perspectiva crítico-interpretativa, con la intencionalidad de generar finalmente un aporte teórico y praxiológico del currículo en el contexto regional.

Como se puede evidenciar, este procedimiento de investigación permitió desarrollar las fases del paradigma racionalista crítico, el cual según Padrón (1998), "permite pasar de los datos al problema, del problema a las hipótesis o premisas de investigación, de las hipótesis a las teorías que sustentan la investigación, y de las teorías al aporte al conocimiento" (p. 43), el cual constituye el corpus de reflexiones teóricas.

\section{Fase 4. Planteamientos y emergencias curriculares}

El ejercicio de la caracterización curricular permite asumir una visión curricular en emergencia desde lo epistémico lo filosófico y pedagógico.

\subsection{Técnicas e instrumentos}

La investigación "currículo regional en el departamento de Caldas, Colombia" toma el camino teórico como su método, y los procedimientos para recolección de la información, que identifican y que complementan la comprensión curricular en el departamento.

Las técnicas como mecanismos para recolectar y analizar la información, ubican los instrumentos a utilizar en el trabajo de campo. Los instrumentos utilizados: la observación, la revisión documental, análisis de experiencias curriculares significativas y sistematización de fichas.

\subsection{Unidad de trabajo}

La unidad de trabajo la constituye el departamento de Caldas, 26 municipios y 187 instituciones educativas. 
En este proceso de unidad de trabajo se hace el análisis curricular y se le da comprensión a las dinámicas curriculares y sus tensiones en el contexto de actuación: el proyecto educativo.

\subsection{Unidad de análisis}

En el proceso de análisis desde la experiencia vital del investigador, se transita por la desconcentración y descentralización de la educación, que implica reformas y modernizaciones del Estado, expresa Silvio Cardona (1996). A los esfuerzos de reforma y modernización del Estado y la configuración del nuevo municipio colombiano le subyacen aún problemas educativos de eficacia y eficiencia administrativa, que retardan la prestación del servicio en términos relacionados con la satisfacción de necesidades de los ciudadanos. Entre esos problemas está el de calidad y cobertura:

- El municipio tiene la obligación de garantizar la calidad del servicio educativo que ofrece a través de las instituciones de los sectores que representan, acorde con lo planteado por la Constitución y la ley, las políticas educativas mundiales, nacionales, regionales y locales, los avances científicos y tecnológicos que permitan educar.

- Todos los municipios colombianos en términos de los planes: el Salto educativo y el Plan decenal, contarán con una organización administrativa que les permita desarrollarlos eficaz y eficientemente. Los municipios con el apoyo de sus diferentes sectores, el de los departamentos y del Ministerio de Educación Nacional, se organizarán para cumplir sus funciones administrativas, como son la planificación, el mantenimiento del sistema de información, la administración del personal, la evaluación de gestión y la inspección y vigilancia de los centros educativos.

- El municipio es una entidad prestadora del servicio educativo, a través de las instituciones y los sectores que representan (educación formal y no formal). Por consiguiente, de manera holística, es una empresa pública en la medida en que haya usuarios y por lo tanto, toda acción de la empresa deberá tener como propósito último la satisfacción 
de las necesidades básicas de los ciudadanos, entre la que aparece la educación. De allí que sea importante que las instituciones y los sectores realicen un trabajo de planificación educativa local y gerencia integral para alcanzar los fines que se plantea la educación y enfrentar una época de complejidades, expresados en los retos de la modernidad, los desafios del nuevo orden mundial, la situación de violencia que a diario vivimos, la interpretación equivocada de los valores y el divorcio entre la academia y el poder político. Aquí la planificación educativa local y la gerencia integral del sistema educativo tiene su cometido para construir un modelo de gestión intersectorial que de verdad ubique la educación como eje de desarrollo del país, como lo expresan el Salto educativo y el Plan decenal.

- Tradicionalmente, en la administración y organización de la educación en lo local, han imperado el pensamiento administrativo centralista, las estructuras formales y verticales, el proceso administrativo (Planeación, organización, dirección, control y evaluación) como etapas secuenciales y, de manera restringida el enfoque humanista, que si bien es cierto, mantuvieron el sistema educativo en un proceso dinámico, este no logró una capacidad institucional que le permitiera ser un factor de desarrollo y competitividad.

- La teoría tradicional de las instituciones u organizaciones y los sectores que representan han prestado atención, ante todo, al carácter de sus estructuras internas y, por consiguiente, enfocan los problemas mucho más en términos de sistema cerrado que de un sistema abierto.

- El servicio educativo va más allá de los servicios de comunicaciones, obras públicas, salud. Este es más complejo, más extenso y cumple un papel más noble, el de educar al ciudadano colombiano; para alcanzar este fin se requiere de un sistema de Planificación Educativa Local y Gerencia Integral, de los cuales aún se carece; que abarquen todas las facetas de la institución u organización en busca de una competitividad. 
- En las normas de descentralización administrativa de la educación, solo se persiste excesivo centralismo local en la dirección de la educación, solo se comienza a configurar una cultura de planificación educativa local y de la participación, el consenso, la negociación, el trabajo en equipo, el control de gestión y de resultados para avanzar en la construcción de tan esperada autonomía local.

\section{Experiencias significativas de Caldas}

El análisis curricular en el departamento de Caldas se consolida en elementos que dan sentido a lo educativo, que para Colombia se ha denominado experiencias significativas. En tanto tienen impacto en los contextos locales, algunas experiencias son:

Las experiencias curriculares del departamento de Caldas son diversas, enfocan temas locales y responden a problemáticas a incluir en la formación. Se deprenden de los lineamientos curriculares del Ministerio de Educación Nacional y destacan el liderazgo y compromiso de los maestros.

Tabla 12. Experiencias significativas del departamento de Caldas

\begin{tabular}{|l|l|l|}
\hline Experiencia & $\begin{array}{l}\text { Instituto o } \\
\text { centro educativo }\end{array}$ & Lugar \\
\hline $\begin{array}{l}\text { Acreditación de la excelencia en } \\
\text { educación y formación }\end{array}$ & $\begin{array}{l}\text { Institución Educativa } \\
\text { Riosucio }\end{array}$ & $\begin{array}{l}\text { Riosucio, } \\
\text { Caldas }\end{array}$ \\
\hline $\begin{array}{l}\text { Competencias laborales en la } \\
\text { Institución Educativa Francisco } \\
\text { José de Caldas }\end{array}$ & $\begin{array}{l}\text { Institución Educativa } \\
\text { Francisco José de } \\
\text { Caldas }\end{array}$ & $\begin{array}{l}\text { Supía, } \\
\text { Caldas }\end{array}$ \\
\hline $\begin{array}{l}\text { Formación del maestro hoy, desde } \\
\text { una perspectiva social cognitiva }\end{array}$ & $\begin{array}{l}\text { Escuela Normal } \\
\text { Superior Sagrado } \\
\text { Corazón de } \\
\text { Aranzazu }\end{array}$ & $\begin{array}{l}\text { Aranzazu, } \\
\text { Caldas }\end{array}$ \\
\hline $\begin{array}{l}\text { Implementación de proyectos } \\
\text { productivos agropecuarios en el } \\
\text { aula paralela }\end{array}$ & $\begin{array}{l}\text { Institución Educativa } \\
\text { El Placer, sede Unión } \\
\text { Baja }\end{array}$ & $\begin{array}{l}\text { Marquetalia, } \\
\text { Caldas }\end{array}$ \\
\hline
\end{tabular}




\begin{tabular}{|c|c|c|}
\hline $\begin{array}{l}\text { Modalidad agropecuaria: una } \\
\text { oportunidad para generar empresa }\end{array}$ & $\begin{array}{l}\text { Institución Educativa } \\
\text { San Pablo }\end{array}$ & $\begin{array}{l}\text { Victoria, } \\
\text { Caldas }\end{array}$ \\
\hline $\begin{array}{l}\text { Posprimaria el Rosario, nuestra } \\
\text { alternativa de progreso }\end{array}$ & $\begin{array}{l}\text { Institución Educativa } \\
\text { Antonio María } \\
\text { Hincapié, sede El } \\
\text { Rosario }\end{array}$ & $\begin{array}{l}\text { Supía, } \\
\text { Caldas }\end{array}$ \\
\hline $\begin{array}{l}\text { Sistema de gestión integral } \\
\text { centrada en la administración } \\
\text { colegiada por la calidad y el } \\
\text { desarrollo institucional }\end{array}$ & $\begin{array}{l}\text { Escuela Normal } \\
\text { Superior Claudina } \\
\text { Múnera }\end{array}$ & $\begin{array}{l}\text { Aguadas, } \\
\text { Caldas }\end{array}$ \\
\hline $\begin{array}{l}\text { Aula multigradual y multiedad } \\
\text { para niños, niñas y jóvenes } \\
\text { adultos con discapacidad }\end{array}$ & $\begin{array}{l}\text { Colegio Integrado Villa } \\
\text { del Pilar }\end{array}$ & $\begin{array}{l}\text { Manizales, } \\
\text { Caldas }\end{array}$ \\
\hline $\begin{array}{l}\text { Bachillerato rural focalizado con } \\
\text { énfasis en proyectos productivos. } \\
\text { Una experiencia en educación } \\
\text { para el trabajo }\end{array}$ & $\begin{array}{l}\text { Instituto Técnico } \\
\text { Francisco José de } \\
\text { Caldas-INTE }\end{array}$ & $\begin{array}{l}\text { Supía, } \\
\text { Caldas }\end{array}$ \\
\hline Mineros tercer milenio & $\begin{array}{l}\text { Institución Educativa } \\
\text { Marmato }\end{array}$ & $\begin{array}{l}\text { Marmato, } \\
\text { Caldas }\end{array}$ \\
\hline $\begin{array}{l}\text { Bachillerato rural focalizado con } \\
\text { énfasis en formación laboral }\end{array}$ & $\begin{array}{l}\text { Institución Educativa } \\
\text { Francisco José de } \\
\text { Caldas }\end{array}$ & $\begin{array}{l}\text { Supía, } \\
\text { Caldas }\end{array}$ \\
\hline Propuesta etno-educativa & $\begin{array}{l}\text { Institución Educativa } \\
\text { Cañamomo y } \\
\text { Lomaprieta }\end{array}$ & $\begin{array}{l}\text { Supía, } \\
\text { Caldas }\end{array}$ \\
\hline Tras las huellas de los grandes & $\begin{array}{l}\text { Institución Educativa } \\
\text { Santa Luisa De } \\
\text { Marillac }\end{array}$ & $\begin{array}{l}\text { Villamaría, } \\
\text { Caldas }\end{array}$ \\
\hline $\begin{array}{l}\text { Teaching english with a magic } \\
\text { touch called arts }\end{array}$ & $\begin{array}{l}\text { Normal Superior de } \\
\text { Caldas }\end{array}$ & $\begin{array}{l}\text { Manizales, } \\
\text { Caldas }\end{array}$ \\
\hline $\begin{array}{l}\text { Los teselados de escher como } \\
\text { motivación para la construcción } \\
\text { de isometrías }\end{array}$ & $\begin{array}{l}\text { Colegio Seminario } \\
\text { Redentorista San } \\
\text { Clemente }\end{array}$ & $\begin{array}{l}\text { Manizales, } \\
\text { Caldas }\end{array}$ \\
\hline $\begin{array}{l}\text { La magia de la música y la } \\
\text { gimnasia cerebral, maravillosas } \\
\text { potenciadoras del aprendizaje }\end{array}$ & $\begin{array}{l}\text { Normal Superior de } \\
\text { Caldas }\end{array}$ & $\begin{array}{l}\text { Manizales, } \\
\text { Caldas }\end{array}$ \\
\hline
\end{tabular}




\begin{tabular}{|l|l|l|}
\hline Pintando con ciencias de verde & $\begin{array}{l}\text { Institución Educativa } \\
\text { Nacional Auxiliares de } \\
\text { Enfermería }\end{array}$ & $\begin{array}{l}\text { Manizales, } \\
\text { Caldas }\end{array}$ \\
\hline $\begin{array}{l}\text { La profundización en ecoturismo } \\
\text { en col asunción }\end{array}$ & $\begin{array}{l}\text { Institución Educativa } \\
\text { la Asunción }\end{array}$ & $\begin{array}{l}\text { Villamaría, } \\
\text { Caldas }\end{array}$ \\
\hline $\begin{array}{l}\text { La comunicación activa y efectiva } \\
\text { para el mundo de hoy }\end{array}$ & $\begin{array}{l}\text { Institución Educativa } \\
\text { Bosques del Norte }\end{array}$ & $\begin{array}{l}\text { Manizales, } \\
\text { Caldas }\end{array}$ \\
\hline $\begin{array}{l}\text { La planificación como proceso } \\
\text { metacognitivo esencial en } \\
\text { la resolución de problemas } \\
\text { matemáticos }\end{array}$ & $\begin{array}{l}\text { Institución Educativa } \\
\text { Hojas Anchas }\end{array}$ & $\begin{array}{l}\text { Supía, } \\
\text { Caldas }\end{array}$ \\
\hline $\begin{array}{l}\text { Viajando por el mundo de la } \\
\text { enseñanza de la matemática en la } \\
\text { formación inicial: la semiosis de } \\
\text { las R }\end{array}$ & $\begin{array}{l}\text { Institución Educativa } \\
\text { Escuela Normal } \\
\text { Cardona }\end{array}$ & $\begin{array}{l}\text { Anserma, } \\
\text { Caldas }\end{array}$ \\
\hline
\end{tabular}

Fuente: elaboración propia.

En el análisis curricular del departamento se sitúan las investigaciones realizadas por los maestros en procesos de profesionalización y cualificación (título de especialistas, magísteres y doctores), las cuales permiten develar múltiples sentidos de lo educativo y nuevas apuestas curriculares. Ver anexo, ficha de investigación. 


\section{CAPÍTULO 4 \\ ANÁLISIS DE PROBLEMÁTICAS CURRICULARES EN EL DEPARTAMENTO DE CALDAS}

as problemáticas curriculares se sitúan en términos de discursos y prácticas
que permiten observar crisis y perspectivas curriculares. Se denota falta de
socialización y fundamentación en varias de las propuestas curriculares, hay confusión metódica, metodológica, la participación docente comunitaria es relativa en ciertos centros, falta conceptualización del currículo, lo que indica un monismo metodológico.

Se denota hegemonía y poder en el desarrollo curricular desde la gestión directiva, lo que impide aperturas curriculares. Hay desvinculación en incongruencias de los temas y problemas curriculares con la realidad institucional social. Se denota en gran medida la instrumentalización curricular.

Algunos factores potenciadores del desarrollo curricular en el departamento de Caldas y que afectan el desarrollo intersectorial de la educación, son:

\subsection{Factores inhibidores}

El desarrollo curricular en el departamento de Caldas se desenvuelve en resolver las preguntas del ¿qué enseñar?, ¿a quiénes?, ¿para qué?, ¿cuándo? y ¿cómo?, desde los lineamientos del Ministerio de Educación Nacional. Es evidente un avance significativo en la comprensión curricular, pero aún es notoria la parametrización, la fragmentación y la positivización curricular. En tanto los currículos son intencionales, es decir, adecuados a finalidades instrumentales, esto es como mediaciones de la formación.

El análisis curricular en el departamento de Caldas presenta factores que inhiben su desarrollo como lo son:

- Falta de trabajo en equipo. Dada las condiciones sociohistóricas del departamento, es evidente la individualización y la centralidad 
en entornos de orden económico, político y cultural. Los trabajos en equipo requieren de mayores sinergias y comprensiones de lo democrático y participativo de la educación.

- Desconocimiento de la realidad educativa. A pesar de los procesos de desconcentración y descentralización educativa, el departamento aún no configura un conocimiento de la realidad social y educativa con el objeto de crear nuevas pertinencias curriculares. Se avanza en la zonificación del departamento por regiones.

- Falta de capacitación en planificación. Urge la formación de talento humano en procesos de gerencia y gestión educativa, que gesten la dinámica educativa en términos de participación, democracia y autonomía.

- Escasos recursos económicos.La dinámica financiera del departamento es débil, los esfuerzos se centran en la infraestructura y poco en la inversión social. Son débiles las partidas a la educación que solo refieren coberturas en términos de transferencia de recursos.

- Baja participación. La participación en lo educativo solo aduce proceso desde las normativas, en la mayoría de los casos. Es evidente una apertura de Estado y de la institucionalidad a generar procesos participativos en educación, pero la multiplicidad de acciones impiden su dinamismo.

- Bajo desarrollo tecnológico. La región y el país están en avance en el desarrollo tecnológico, de acuerdo con las políticas de Estado y los planes de inversión.

- Distanciamiento entre el sector económico y educativo. Urge un acercamiento con el sector productivo y generar reestructuración curricular para atender a las demandas productivas y los desarrollos técnicos y tecnológicos en la región. 
- Dependencia del nivel central. Es notoria la autonomía local desde las normativas, pero en lo esencial se denota gran dependencia del nivel central: Ministerio de Educación Nacional. Es evidente la condicionalidad de la política frente a la inversión y la generación de alternatividad curricular.

- Planificación sectorial. Urge planificar como región y sector.

- Acentuado individualismo. Urge el ejercicio colegiado en los diferentes sectores económicos políticos y culturales.

- Intervención política. Los líderes políticos deben implicarse en el asunto educativo pero no solo desde el discurso, también en las prácticas con programas y proyectos de desarrollo local de corte educativo-formativo.

- Uso inadecuado del tiempo. La planificación y el desarrollo infieren uso adecuado del tiempo en el diseño, transferencia e inversión. Son evidentes los trastornos en el desarrollo educativo por la tediosa tramitología.

\subsection{Factores potenciadores}

El departamento de Caldas es potencia para el desarrollo curricular dada su ubicación geoestratégica en el suroccidente colombiano. Es una región con condiciones productivas excelentes, su desarrollo se ubica en el Eje Cafetero, la infraestructura vial es importante y la aérea igual. Sus centros de investigación y las universidades se convierten en gran posibilidades. Es una región en visión productiva permanente.

El análisis curricular del departamento de Caldas presenta factores potenciadores:

- Alianzas estratégicas. El trabajo en red-alianza para unir esfuerzos, unir recursos y generar impactos.

- Eliminar el carácter partidista en educación. Asumir lo educativo desde una visión política, no solo de partidos y de personas. 
- Investigación. Desarrollo de procesos de investigación con pertinencia educativa y sociocultural.

- Desarrollo tecnológico. Ampliar la oferta de desarrollo técnico y tecnológico en la región.

- Fortalecer procesos de descentralización. Permitir la autonomía económica y política para gestar el desarrollo curricular.

- Consejos regionales de educación.

- Diagnóstico educativo real.

- Conformar redes de educación.

- Educación en valores.

- Educación en enfoques modernos de planificación. 


\section{CAPÍTULO 5 \\ ALCANCES DEL CONOCIMIENTO}

L os alcances del conocimiento de este proceso de investigación se expresan en la reconfiguración de la noción del currículo en el departamento de Caldas, donde se asumen múltiples elementos culturales (conocimientos, saberes, prácticas, valores, creencias, mitos y técnicas) que conforman las propuestas de formación para diversos grupos y sectores sociales que tienen intereses diversos.

El currículo en el departamento de Caldas presenta la tensión entre procesos hegemónicos y de dominación política, lo cual infiere una ausencia de proyectos políticos sociales, que respondan al interés de grupos y sectores que piensan e impulsan su desarrollo.

El currículo en el departamento de Caldas insinúa proceso de deconstrucción para reconfigurar el accionar educativo, donde se genere conocimiento situado, el cual tiene que ver con el lugar y el tiempo que se vive y la relevancia de dicho conocimiento para construir territorios. El conocimiento incorporado que reconoce e incorpora el saber de las personas, los grupos, las organizaciones, la cultura local y el conocimiento implicado que ubica la perspectiva de los actores sociales, le dan significado particular al currículo desde los acervos de los saberes cotidianos y la relación con los conocimientos científicos y tecnológicos de la época.

El currículo en Caldas implica la reformulación de proyectos y agendas de investigación para generar conocimiento pertinente en las subregiones. También requiere de la pregunta para generar conocimiento a partir de la capacidad de asombro, y de la imaginación para resolver los procesos sociales e incidir con capacidad de pensamiento estratégico, en momentos de coyuntura, crisis y emergencia de lo social. 


\subsection{Propuesta emergente curricular para el departamento de Caldas}

Fruto del proceso de investigación curricular en el departamento de Caldas, se plantea la siguiente propuesta curricular, así:

Título: Programación curricular emergente para el departamento de Caldas

\section{Presentación}

A partir de la Constitución Política de Colombia de 1991, el país ha observado la generación de ideales de vida sobre los postulados de autonomía, participación y democracia. El proceso a la vez establece en la Ley General de Educación la operacionalización de dichos principios en los fines y objetivos de la educación.

La Ley 29 de 1990, la Ley 115 de 1994 (Ley General de Educación) y la Ley 715 de diciembre de 2002) aproximan el rol y el protagonismo de la nueva vida municipal y sus actores en líneas de desarrollo educativo y social.

El departamento de Caldas acorde con los principios constitucionales, con las competencias de ley y con la participación interinstitucional, interdisciplinaria e intersectorial, impulsa la integracion de procesos de índole curricular mediante el diseño y puesta en marcha de planes, programas y proyectos de gestión.

\section{Prioridades de gestión curricular}

- Hacer realidad el principio que postula la educación alcanza significado y sentido histórico en la medida en que sirva a la construcción del proyecto de Nación.

- Avanzar en la integración de la educación con la sociedad.

- Fomentar la participación ciudadana y comunitaria alrededor de lo educativo.

- Promover la concertación social y política y fortalecer la sociedad civil e instituciones que hacen, apoyan y dirigen la educación.

- Brindar una dinámica de realidad interactiva, educación y productividad al currículo regional. 


\section{Estrategias generales}

- Focalizar el quehacer educativo en tres núcleos: conocimiento, ética y estética para su desarrollo curricular.

- Incentivar en el desarrollo curricular la investigación científica, tecnológica y social.

- Implantación de una educación bivalente que prepare para el trabajo y eduque para la vida (unir academia y tecnología).

- Dinamizar el sistema regional de educación (gestión administrativa, gestión financiera, gestión pedagógica, gestión curricular y gestión comunitaria).

- Establecer secuencialidad e integralidad en los niveles del sistema educativo formal en Caldas.

\section{Un horizonte educativo y cultural}

- La educación se circunscribe a la familia y a la institución escolar.

- La educación es un compromiso de toda la sociedad.

- La educación es vida y cotidianidad.

- Vincular estrechamente al sistema escolar con su entorno sociocultural y hacerle partícipe del proceso educativo.

- Impulsar, difundir y extender programas de ciudad educadora, propugnando por hacer que los espacios públicos de ciudad (municipio) posibiliten experiencias educativas a la ciudadanía.

- Reforzar el papel educativo de la radio y la televisión.

- Dedicar importantes esfuerzos al deporte participativo.

- Impulsar y reformar la educación artística, y lograr así la apertura de espacios para el desenvolvimiento de vocaciones artísticas.

- Fomentar el vigor de las manifestaciones culturales.

- Generar acciones de transversalidad curricular en los proyectos educativos institucionales así:

$\checkmark$ Desarrollar programas y experiencias de formación en gestión cultural.

$\checkmark$ Fomentar en el departamento a través de las instituciones educativas centros de educación artística, planes de recreación y educación física. 
$\checkmark$ Implementar programas de educación masiva mediatizada con Tecnologías de Información y la Comunicación (canales regionales y municipales, emisoras, escenarios deportivos religiosos y comunitarios).

\section{Objetivos generales de la propuesta}

Contribuir a los procesos de cualificación curricular en el departamento de Caldas. Mediante el desarrollo de procedimientos innovadores y de transferencia de tecnología, familiarizar los actores potenciales del nivel local e institucional con las tendencias curriculares como compromiso de Estado y de la sociedad civil.

\section{Objetivos específicos de la propuesta}

Establecer mecanismos de formación continuada a la comunidad educativa de tal manera que se conviertan en elementos activos y dinamizadores de procesos de transformación y cambio.

Desarrollar alternativas innovadoras de carácter curricular, metodológico, didáctico e investigativo que respondan a las realidades de autonomía y desarrollo del proceso histórico actual.

Impulsar las líneas de diseño e implementación curricular en la educación del departamento de Caldas.

Apoyar la gestión local e institucional mediante procesos de participación y generación de proyectos que ayuden a complementar el desarrollo curricular.

\section{Ejes temáticos y/o problemáticos}

- Conceptualización

Contexto socio-educativo-político

Currículo y temas transversales

Lineamientos curriculares por áreas 
- Los proyectos educativos

Sentido y significación de los proyectos.

Los mecanismos de participación comunitaria en la construcción de los proyectos educativos.

- Diseño y concreción curricular

Historia y currículo

Las innovaciones curriculares

La sistematización de experiencias curriculares

- Los niveles de concreción curricular

La Nación

El departamento

El municipio

La institución

- Currículo y transversalidad

La educación en valores

El diálogo interactivo

La comunicación

Educando, educador y currículum

Elementos básicos del currículum, la enseñanza y la evaluación.

\subsection{Hallazgos y conclusiones}

En el departamento de Caldas se acogen los conceptos de currículo desde diferentes teorías y enfoques. En sí, la noción del currículo es la síntesis de elementos culturales (conocimientos, valores, costumbres, creencias, hábitos) que conforman una propuesta política-educativa, pensada e impulsada por diversos grupos.

Además, el currículo en el departamento de Caldas se asume en varias instituciones desde una perspectiva Kantina, en tanto reconoce la facultad que tiene el hombre para generar ideas que le otorgan significado y sentido a la vida social (comunidad espiritual). En esta vida social se generan sectores 
sociales cuyos intereses son diversos y contradictorios, aunque algunos tiendan a ser dominantes o hegemónicos, y otros tiendan a oponerse y resistirse a tal dominación o hegemonía.

Por otro lado, se lee el currículo en otras instituciones desde la perspectiva Gramsciana, donde el currículo parte de la reconceptualización de la noción de Estado. Estado como sociedad política y no como un equilibrio entre la sociedad política y la sociedad civil (iglesias, sindicatos, escuelas). Este es un proceso que se da a través de diferentes mecanismos de negociación e imposición social, propuestos por aspectos estructurales formales y procesales prácticos, así como también por dimensiones generales y particulares que interactúan en el devenir del currículum en las investigaciones sociales educativas.

El currículo en perspectiva se lee en el departamento de Caldas con un carácter profundamente histórico y en devenir constante que se expresa en distintos niveles de significación.

\section{Tensiones}

El currículo en el departamento de Caldas presenta tensiones, en tanto su despliegue deviene en prácticas concretas de formación. El currículo se asume como sistema congruente y articulado frente a las mismas contradicciones, negociaciones e imposiciones. Por otro lado, implica un carácter de lucha en el departamento de Caldas, expresado en distintas maneras que se desarrollan, tanto en la conformación inicial como en su desarrollo y evolución.

El currículo en el departamento de Caldas incorpora elementos culturales dominantes y se expresa en la estructura de espacios, planos y mezclas curriculares. (Bourdieu y Passeron, 1970). El currículum es un arbitrario cultural; sin embargo, tal arbitrario está conformado por elementos de diversas conformaciones culturales y su carácter es el de una estructura dinámica o relativamente estable (Lefebvre, 1968 y Sánchez Vásquez, 1968).

En la región del departamento de Caldas la modernización curricular compromete la concepción de una modernidad que se realiza en procesos de cientifización y 
tecnologización, procesos de desarrollo económico, procesos de consolidación de la democracia y procesos de formación en la autonomía individual, por lo que responde a experiencias de la racionalidad cognitiva, política, socioeconómica y cultural. Entonces, en modernidad, el currículo es una red de cientificidad medida en la praxis formativa del educar.

El complejo de cientificidad que es el currículo, obedece a que el mismo se presenta como una organización (auto-organización) de los saberes respecto a las profesiones y viceversa. Es potenciada por la metodología disciplinar interdisciplinar, transdisciplinar. El primer referente del currículo es la ciencia, en la perspectiva en-ciclo-pedía (circulo virtuoso) que permite la pluralidad, la multiplicidad, la flexibilidad y la estructuración curricular. Esta relación currículo-ciencia es un primer criterio de validación del mismo, el cual se suma al segundo criterio de validación: la enseñanza. Allí donde currículociencia y enseñanza se aúnan, emerge el criterio epistemológico-pedagógico de enseñabilidad; en orden a la relación enseñanza, organización de la ciencia, método científico, método didáctico.

En el departamento de Caldas la producción, distribución y transmisión de la ciencia, no elige el criterio epistemológico-pedagógico de enseñabilidad, ni se rige por el patrón tradicional de racionalidad positiva, individual, neutral y objetiva, sino por la racionalidad alternativa que cobija aspectos estéticos, políticos, ambientales. Entonces, cabe decir que el currículo es, también, un proceso histórico-social de la construcción de la ciencia que se democratiza dentro de las llamados "sociedades del conocimiento". Así emerge la relación currículo y comunidad científica, que en la sociabilización del conocimiento obedece al criterio de legitimación. El criterio de validación del currículo (frente a las ciencias y su enseñanza) y el criterio de legitimación (frente a la comunidad académica) se completan con el criterio de acreditación frente a políticas de educación, por el cual consulta los principios legislados y conceptuados de la programática, ciencia, tecnología, sociedad y desarrollo.

En palabras de German Guarín filósofo colombiano de la Universidad de Manizales, la pedagogía como epistemología propia de una ciencia de la educación busca desde la investigación una complexión de teoría y praxis de 
su estatuto histórico, didáctico, metodológico y fundamental de cientificidad. Currículo-ciencia-comunidades científicas-políticas-educativas se prensan en la pedagogía, en la manera como ella se proyecta a la enseñanza en su íntima vinculación con la investigación y el contexto.

Como emergencia y hallazgo curricular, se plantean procesos de formación curricular, así:

1. Currículo y la comprensión de la modernidad del sentido científicopolítico. Los diversos discursos de la primera modernidad.

- Empirismo.

- Racionalismo.

- Positivismo.

- Ilustración.

- Idealismo.

\section{Currículo y ciencia}

- De la enciclopedia a la en-ciclo-pedia.

- Disciplinariedad y profesión.

- Estructura curricular.

\section{Currículo y enseñanza}

- Los métodos de las ciencias.

- Mediaciones pedagógicas.

- Evaluación cualitativa.

\section{Currículo y comunidades académicas}

- Comunicación e información: sociedades del conocimiento.

- Interdisciplinariedad y transdisciplinariedad.

- Investigación. 


\section{Currículo y políticas educativas}

- Ciencia, tecnología y sociedad.

- Educación comunidad y cultura.

- Desarrollo humano.

\section{Metodología de la propuesta: el seminario}

Como metodología de los seminarios se plantea una metodología interpretativa en el amplio espectro cognitivo de las ciencias humanas. Es la oportunidad filosófica integral para cultivar una interdisciplinariedad placentera y profunda, y de este modo abrir el horizonte de sentidos a la modernidad, al currículo, posibilitar su vida, su decadencia, su muerte, su desarrollo, siempre dialectizando, algo así como en un proceso de disolución-resolución. El interpretar es, en cierto sentido, asumir la negación, el vacío del concepto, la ausencia de verdad, es afrontar el problema, la paradoja, el dilema. El método del interpretar es problematizar el sentido, y en ello no hay distancia entre teoría y método, pues se aúnan en el pensar. El método es pensar.

\subsection{Recomendaciones del estudio}

Se recomienda enfrentar en el departamento de Caldas situaciones que afectan la construcción de comunidad y desarrollo educativo desde el currículo como:

- El conformismo, educación tradicional, arraigada, esquemas mentales que cierran la creatividad.

- la falta de voluntad y un cambio de actitud para que el departamento de Caldas se constituya en comunidad académica.

- La falta de personal capacitado, falta de gestión educativa.

- La falta de compromiso, desconocimiento de muchos programas, negligencia, desmotivación, falta de comunicación.

- La capacidad de investigación, el espíritu conformista que nos caracteriza. 
Se recomienda elevar el promedio de alfabetismo para la región (83.41\%), pues está por debajo del promedio nacional establecido por el Plan decenal entre $89 \%$ y $91 \%$. La cobertura en educación primaria es del 70\%, que se considera satisfactoria a pesar de estar por debajo del promedio nacional.

Fortalecer la educación superior, la cual ha aumentado enormemente su cobertura pero sigue por debajo del promedio nacional (11.5\%).

Potenciar las políticas oficiales sobre costos educativos. Parece estar desanimanda la inversión privada en educación primaria y media.

Reducir el índice de asistencia en secundaria, está por debajo del promedio nacional (47\%).

Dedicar en la región mayor tiempo de aprendizaje, dado que se presentan déficits hasta del 33\% de tiempo legal del año escolar.

Superar las deficiencias de aprendizaje de los estudiantes de la región. En el nivel primario han sido calificados como "notables" por parte del estudio Saber (2012) en lo relacionado con habilidades cognoscitivas indispensables para el desarrollo en ciencia y tecnología.

Elevar los resultados del Icfes en la región, dado que se encuentran entre bajos y muy bajos, sobre todo en el área de ciencias y particularmente en Química.

Redistribuir a los docentes para orientar su área de dominio, dado que el área de ciencias es orientada en la educación básica y media en muchos casos por profesores de otras áreas.

Avanzar en el nivel de conocimiento de innovación y su aplicación a la enseñanza por parte de docentes y directivos.

Redimensionar las bibliotecas escolares como centros de apoyo educativo. 


\section{REFERENCIAS BIBLIOGRÁFICAS}

- Amador, P., Areteaga, G., y Cardona, S. (2004). Educación, sociedad y cultura. Manizales: Universidad Católica de Manizales.

- Amador, P., Arias, O., y Quiroz, P. (2012). Construcciones y tejidos curriculares embera chami. Manizales: Capital Graphics.

- Bobbit, J. F. (1918). The Curriculum. Nueva York: Cornell University Library.

- Bourdieu, P., y Passeron, J. (1970). La reproducción. Barcelona: Laia.

- Casassus, J. (1990). Descentralización y desconcentración de los sistemas educativos en América Latina: fundamentos y dimensiones críticas. en Unesco y Orealc, Boletín proyecto principal de educación en América Latina y el Caribe (pp. 7-18). Santiago de Chile: Unesco y Orealc.

- Cox, C. (1991). Sociedad y conocimiento en los 90. Puntos para una agenda sobre currículum del sistema escolar [Documento de trabajo Flacso].

Santiago de Chile: Flacso.

- DANE (Departamento Administrativo Nacional de Estadística). (2015). Proyección de población municipal del departamento de Caldas. Bogotá: DANE.

- Fayad, J. (2010). Rastrear la estructura del saber pedagógico desde una perspectiva epistemológica: arqueología, genealogía (Investigación Colciencias).

- Flórez, R. (1999). Evaluación pedagógica y cognición. Bogotá: McGraw Hill.

- Gantiva S. J. (1984). Orígenes del movimiento pedagógico. Educación y Cultura. Fecode, 1, p. 13.

- Gadamer, H. G. (1998). Verdad y Método. Salamanca: Ediciones Siguiente.

- Gadamer, H. G. (1977). Verdad y Método. Salamanca: Sígueme.

- Galeano, M. E. (2003). Diseño de proyectos en la investigación cualitativa. Medellín: Eafit.

- Gobernación de Caldas. (2005). Revista Caldas integrado. Manizales: Gobernación de Caldas.

- Gran enciclopedia de Colombia. (1993). Biografías, tomo 9. Bogotá: Círculo de lectores.

- Homero. (1965). La Ilíada. Madrid: Ediciones Ibéricas.

- Jaeger, W. (1973). Paideia. Los ideales de la formación clásica. México: Fondo de Cultura Económica.

- Kant, I. (2000). Crítica de la razón pura. Madrid:Tecnos. 
- Magendzo,A. (1996). Currículum, educación para la democracia en la modernidad. Bogotá D. C.: Instituto para el desarrollo de la democracia Luis Carlos Galán.

- Mejía, M. R. (s. f.). Educación (es) en la (s) globalización(es). Editorial Desde Abajo- pág. 290.

- Padrón, J. (1998). La estructura de los procesos de investigación. Recuperado de: https://www.researchgate.net/publication/277249442_ LA_ESTRUCTURA_DE_LOS_PROCESOS_DE_INVESTIGACION

- Platón. (1968). Teetetes o de la ciencia. En Diálogos. Madrid: Ediciones Ibéricas.

- Roldán, O. (2006). La institución educativa: escenario de formación política, que se configura desde el ejercicio mismo de la política (tesis de doctorado). Universidad de Manizales.

- Ruiz, A. (2009). Teoría y práctica curricular. Blog currículo. Recuperado de: http://unefacurriculo.blogspot.com.co/2009/04/teoria-y-practicacurricular.html

- Santos, J. M. (s. f.). Plan nacional de desarrollo. Prosperidad para todos. Recuperado de: https://www.sites.google.com/site/diegovergaraolaya/ plan-de-desarrollo

- Secretaria de Educación. (2013). Anuario estadístico Gobernación de Caldas. Manizales: Secretaría de Educación.

- Secretaría de Educación. (s. f.). Plan territorial de formación docente Caldas 2012-2015. Manizales: Secretaría de Educación. Recuperado de: https:// www.mineducacion.gov.co/1759/articles-319469_archivo_pdf_Caldas.pdf

- Sacristán, J. (1991). El currículum: Una reflexión sobre la práctica. Madrid: Editorial Morata.

- Sacristán, J. (1995). Comprender y transformar la enseñanza. Madrid: Editorial Morata.

- Uribe, A. (s. f.). Estado comunitario. Recuperado de: http://www. alvarouribevelez.com.co/es/content/estado-comunitario

- Amador, P., Quiroz,A. (2012). Avizoramientos de Política Pública, Apuestas Territoriales.

- Amador, P., murcia, P. (2012). Aprendizaje colaborativo, senderos enraizados de la cultura caldense. Manizales: Red Suma.

- Bruner, J. (1990). Desarrollo Cognitivo y Educación. Madrid: Morata.

- Carr,W, y Kemmis, S. (1988). Teoría crítica de la enseñanza.

Barcelona: Martínez Roca. 
- Charter, R. (1995). El mundo como representación. Barcelona: Gedisa.

- Díaz Barriga, A. (1994). El currículo escolar, surgimiento y perspectivas. Buenos Aires: Aique Grupo editor.

- Díaz Villa, M. (1993). El campo intelectual de la educación en Colombia. Cali: Universidad del Valle.

- Grundy, S. (1991). Producto o praxis del currículo. Madrid Morata.

- Kemmis, S. (1988). El currículum: más allá de la teoría de la Reproducción. Madrid: Morata.

- Lafrancesco V. (2003). Nuevos fundamentos para la transformación curricular: a propósito de los estándares. Bogotá D. C.: Editorial Magisterio.

- López Jiménez, N. E. (1996). Retos para la construcción curricular. De la certeza al paradigma de la incertidumbre creativa. Bogotá D. C.: Editorial Magisterio.

- Lundgren, U. P. (1992). Teoría del currículum y escolarización. Madrid: Morata.

- Magendzo, A. (1986). Currículum y cultura en América Latina. Texas: University of Texas.

- Mejía, L. García, L.(s. f.). El currículum como mediación pedagógica cultural.

- Mejía, R. (1996). Educación y escuela en el fin de siglo. Bogotá D. C.: Cinep.

- Mejía, R. (1997). La recuperación del sujeto. Bogotá D. C.: Cinep.

- Memorias. (1996). Primer Seminario Nacional de Currículo. El currículo en la Educación superior. Cali.

- Memorias. (1997). Seminario Nacional currículum y modernidad hacia el siglo XXI. Manizales.

- Muñoz Arias, J. Visiones de ciudad región imaginarios colectivos en el eje cafetero.

- Naval, C. (1995). Educar ciudadanos. La polémica liberal-comunitarista en educación. Pamplona: Eunsa.

- Stenhouse, L. (1991). Investigación y desarrollo del currículum. Madrid: Morata,

- Torres, J. (1991). El currículum oculto. Madrid: Morata. 



\section{ANEXOS}

Anexo 1.

Problemas que inciden en el desarrollo regional y local

\begin{tabular}{|c|c|}
\hline Problemas & $\begin{array}{c}\text { Fenómenos a traves de los cuales } \\
\text { se encuentra el problema }\end{array}$ \\
\hline $\begin{array}{l}\text { Desigualdad social, } \\
\text { violación de los } \\
\text { derechos humanos } \\
\text { y crisis ética ligada } \\
\text { a crisis de valores e } \\
\text { instrumentalización del } \\
\text { ser humano. }\end{array}$ & 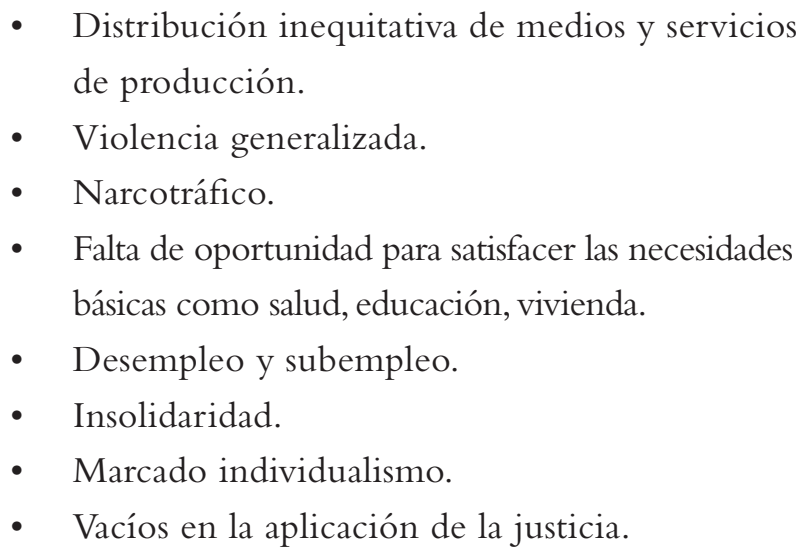 \\
\hline $\begin{array}{l}\text { Concentración del } \\
\text { poder económico, } \\
\text { político y social en } \\
\text { manos de unas pocas } \\
\text { familias. }\end{array}$ & $\begin{array}{l}\text { - Hay concentración de privilegios. } \\
\text { - Concentración de lo económico y lo político. } \\
\text { - Democracia recortada. } \\
\text { - Corrupción. } \\
\text { - Paternalismo. } \\
\text { - Dependencia política, económica, tecnológica } \\
\text { y cultural. }\end{array}$ \\
\hline $\begin{array}{l}\text { Retraso en el desarrollo } \\
\text { económico, tecnológico, } \\
\text { político, cultural, } \\
\text { educativo y científico. }\end{array}$ & $\begin{array}{ll}\text { - } & \text { Retraso científico y tecnológico. } \\
\text { - } & \text { Crecimiento inarmónico de las ciudades. } \\
\text { - } & \text { Pobreza. } \\
\text { - } & \text { Infraestructura económica y social inadecuada. } \\
\text { - } & \text { Actitud de pasividad por parte de las comunidades. } \\
\text { - } & \text { Distanciamiento entre el sector económico } \\
\text { - } & \text { Falta de un trabajo conjunto, intersectorial. }\end{array}$ \\
\hline
\end{tabular}




\begin{tabular}{|l|ll|}
\hline $\begin{array}{l}\text { Irracionalidad en el } \\
\text { manejo del medio }\end{array}$ & $\bullet$ & Manejo inadecuado del medio ambiente. \\
ambiente. & Visión a corto plazo de políticas ambientales. \\
\hline $\begin{array}{l}\text { Instituciones educativas } \\
\text { del Estado inadecuadas. }\end{array}$ & $\bullet$ & Bajos niveles de planificación educativa. \\
Fallas en el sistema & Bajos estándares de calidad y eficiencia. \\
educativo. & Baja cobertura educativa. \\
& - Falta de educación para la democracia. \\
& Baja calidad de la educación formal. \\
\hline
\end{tabular}


Anexo 2.

\section{Tendencias mundiales}

\begin{tabular}{|c|c|}
\hline Tendencias & Fenómenos en los cuales se halla la tendencia \\
\hline Internacionalización & $\begin{array}{l}\text { - Apertura económica, política ideológica. } \\
\text { - Aparición de nuevas agrupaciones políticas. } \\
\text { - Surgimiento de movimientos políticos } \\
\text { alternativos. }\end{array}$ \\
\hline $\begin{array}{l}\text { Avance y creciente } \\
\text { importancia de la } \\
\text { informática. }\end{array}$ & $\begin{array}{l}\text { - Aparición de redes informáticas de carácter } \\
\text { científico, cultural, tecnológico. }\end{array}$ \\
\hline $\begin{array}{l}\text { Recuperación paulatina } \\
\text { de la confianza y del } \\
\text { deseo de renovación y } \\
\text { cambio }\end{array}$ & $\begin{array}{l}\text { - Conciencia de integración y cooperación. } \\
\text { - } \quad \text { Búsqueda los países (G3, G7, C.E.E. etc.). } \\
\text { - Incentivo a la producción e innovación } \\
\text { tecnológica. }\end{array}$ \\
\hline $\begin{array}{l}\text { Surgimiento de un } \\
\text { nuevo humanístico }\end{array}$ & $\begin{array}{l}\text { - Focalización de subsidios a los más pobres. } \\
\text { - Intervención del gobierno para garantizar una } \\
\text { mejor asignación de recursos. } \\
\text { - Procesos de producción. }\end{array}$ \\
\hline Tendencias universitarias & $\begin{array}{l}\text { - Fomento de la investigación, auge de } \\
\text { posgrados, colaboración a las instituciones, } \\
\text { búsqueda de la excelencia. }\end{array}$ \\
\hline $\begin{array}{l}\text { Nuevo modelo de } \\
\text { desarrollo del país }\end{array}$ & $\begin{array}{l}\text { - Redefinición del rol del Estado, la sociedad y } \\
\text { la familia. } \\
\text { - Procesos de ordenamiento territorial. }\end{array}$ \\
\hline Cambios demográficos & - Disminución de las tasas de crecimiento. \\
\hline Autonomía regional & $\begin{array}{l}\text { - } \\
\text { - } \\
\text { - } \\
\text { Punicipalizaciontrán. } \\
\text { Partición. }\end{array}$ \\
\hline
\end{tabular}





\section{CURRÍCULO REGIONAL, DEPARTAMENTO DE CALDAS,}

COLOMBIA

El asunto curricular deviene humanidad. Por ello, el interés fundamental cursa en el interrogante de investigación que se expresa en caracterizar las interacciones del currículo en la región del departamento de Caldas, Colombia, con la aspiración de interpretar sus recorridos y orientar la hermenéutica hacia un currículo pertinente, contextualizado y problémico que ofrezca luces para el hallazgo de las condiciones posibles de la formación.

Luis Hernando Amador Pineda 